Portland State University

PDXScholar

Fall 11-6-2014

\title{
Latino Men Managing HIV: An Appraisal Analysis of Intersubjective Relations in the Discourse of Five Research Interviews
}

Will Caston

Portland State University

Follow this and additional works at: https://pdxscholar.library.pdx.edu/open_access_etds

Part of the Discourse and Text Linguistics Commons, and the Immune System Diseases Commons Let us know how access to this document benefits you.

Recommended Citation

Caston, Will, "Latino Men Managing HIV: An Appraisal Analysis of Intersubjective Relations in the Discourse of Five Research Interviews" (2014). Dissertations and Theses. Paper 2069.

https://doi.org/10.15760/etd.2068

This Thesis is brought to you for free and open access. It has been accepted for inclusion in Dissertations and Theses by an authorized administrator of PDXScholar. Please contact us if we can make this document more accessible: pdxscholar@pdx.edu. 
Latino Men Managing HIV: An Appraisal Analysis of Intersubjective Relations in the Discourse of Five Research Interviews

by

Will Caston

A thesis submitted in partial fulfillment of the requirements for the degree of

Master of Arts

in

Teaching English to Speakers of Other Languages

Thesis Committee:

Keith Walters, Chair

Susan Conrad

John Hellermann

Portland State University

2014 
(C) 2014 Will Caston 


\begin{abstract}
Latino men, particularly those who have sex with other men, have been disproportionately affected by HIV/AIDS. Scholars have sought for nearly two decades to understand how various social and cultural factors in the Latino community exacerbate HIV risk among these men. Although following the advent of life-sustaining medications in 1996, HIV is often regarded as a manageable chronic illness, as opposed to a death sentence, scant attention has been devoted to how HIV-positive Latino men experience managing the illness. Among studies that have focused on HIV-positive persons' illness management, few Latino men have participated.

Using the Appraisal framework from Hallidayan Systemic Functional Linguistics, with Bucholtz and Hall's theory of social identity $(2004,2005)$, this discourse analysis sought to explore intersubjective relations as reported by five HIV-positive Latino men, three native-born and two immigrants, in semi-structured interviews that attempted to avoid preconceived expectations about salient structures. While structures such as homophobia, machismo, and stigma emerged in each interview, the native-born men's discourse differed from that of the immigrants in that the former did not address financial concerns with regard to HIV medications, whereas the latter represented their agency as having been constrained by low income requirements for obtaining assistance in accessing expensive HIV medications. This finding tentatively suggests that the issue could be more salient for immigrants than native-born Latinos and warrants additional, more focused research on the effects of the structures of benefit programs on HIVpositive Latino immigrants.
\end{abstract}




\section{DEDICATION}

This thesis is dedicated in loving memory to my father, whose struggle with HIV/AIDS inspired this work, and to my mother and sister, whose lives were forever changed as a result of his illness. 


\section{ACKNOWLEDGEMENTS}

I wish to extend my sincere gratitude to my adviser, Keith Walters, for having encouraged me to embark on a challenging endeavor that often seemed insurmountable and for having offered his ongoing support, even while on sabbatical; to Susan Conrad, for teaching me about discourse analysis, encouraging students such as myself to pursue their own interests, giving me an opportunity to present preliminary data analyses in her Systemic Functional Linguistics class, and being flexible with her time; to John Hellermann for personally reaching out while I struggled and being accommodating with his time; to the five men I interviewed for courageously opening themselves to me, a complete stranger who will have benefitted more than they; to my co-workers, particularly Jill Castek, Kathy Harris, and Drew Pizzolatto, on the Literacy, Language, and Technology Research team for their support and allowing me an open schedule; to my mother for her financial and emotional support; to numerous colleagues from the MA TESOL program for their friendship and informal feedback; finally, to my partner, Laurel Wing, for her insightful feedback and motivating presence. Each of you has done more for me than you may realize, and I will forever be grateful. 


\section{Table of Contents}

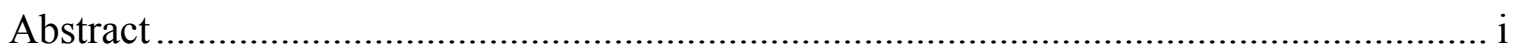

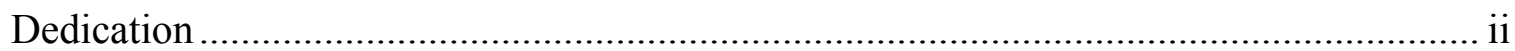

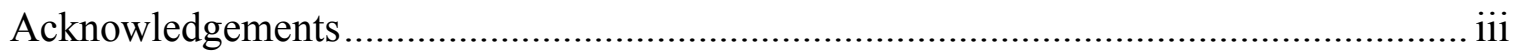

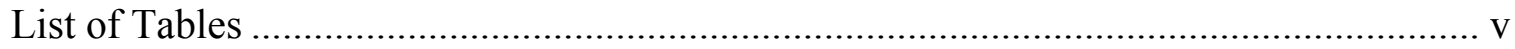

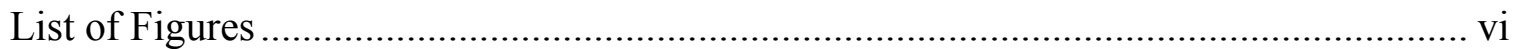

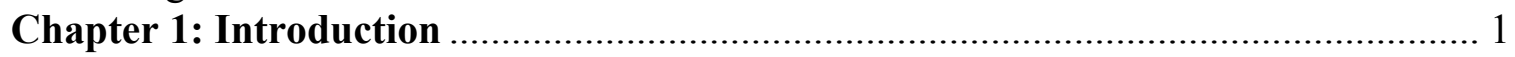

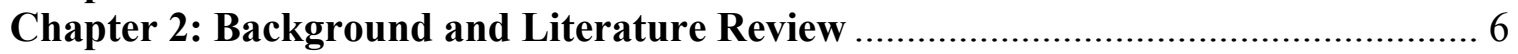

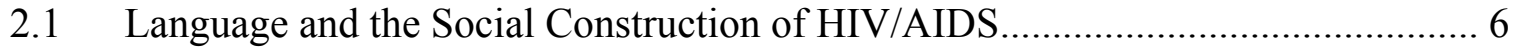

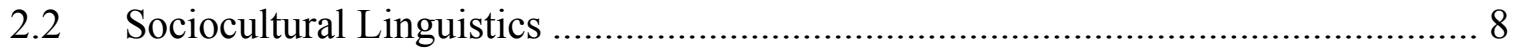

2.3 Sociocultural Linguistics and HIV/AIDS ...................................................... 9

2.4 Qualitative Studies on Negotiating HIV-positive Identity................................... 12

2.5 HIV/AIDS Risk Among Gay Latinos and Latino MSM ..................................... 17

2.6 Gay Versus Men Who Have Sex With Men (MSM) ......................................... 18

2.7 Sociocultural Factors Exacerbating HIV Risk Among Latino MSM ................... 20

2.8 Studies on Latino MSM That Include HIV-positive Men .................................... 23

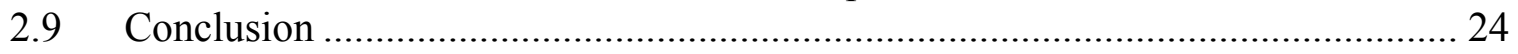

Chapter 3: Methodology and Theoretical Framework ......................................... 26

3.1 Summary of Analytical Process ........................................................................ 26

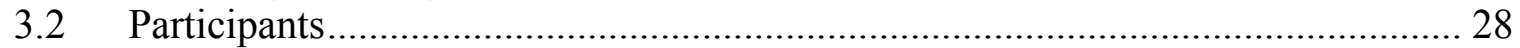

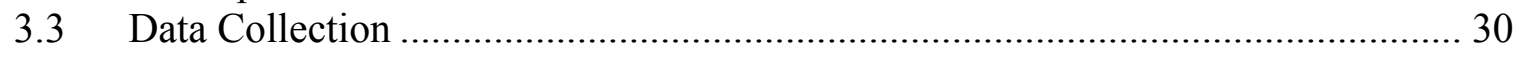

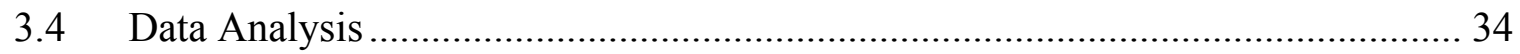

3.5 Theoretical Framework: The Tactics of Intersubjectivity ................................. 36

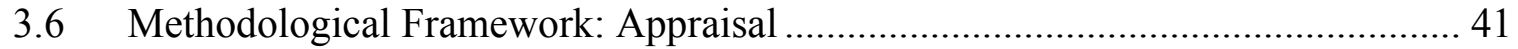

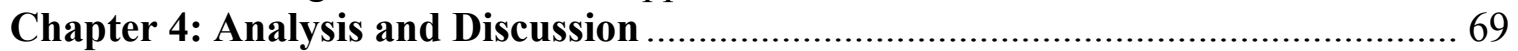

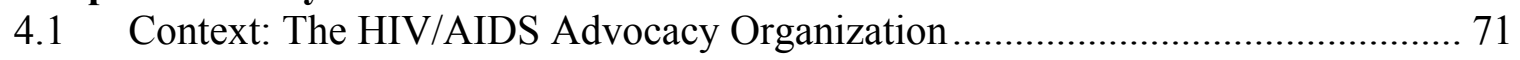

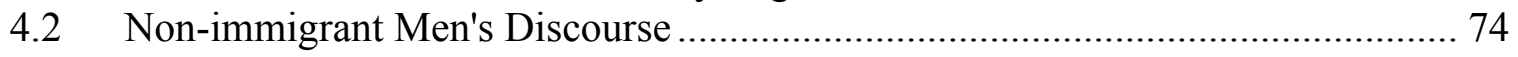

4.3 Immigrant Men's Discourse .......................................................................... 98

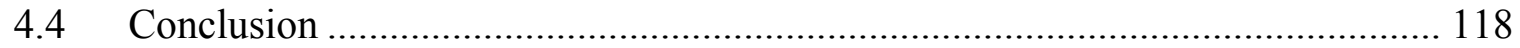

Chapter 5: Conclusion ......................................................................................... 119

5.1 Answering the Research Question ................................................................... 119

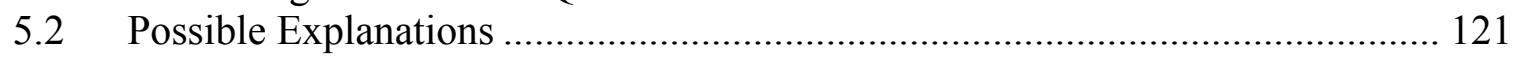

5.3 Positioning the Study Within Existing Research ............................................ 122

5.4 Recommendations for HIV/AIDS Organizations ....................................... 125

5.5 Limitations of the Study............................................................................. 126

5.6 Suggestions for Future Research .............................................................. 128

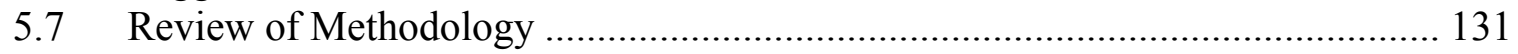

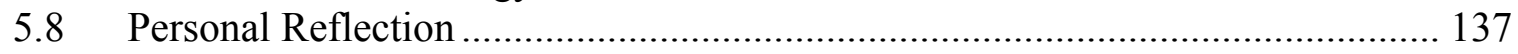

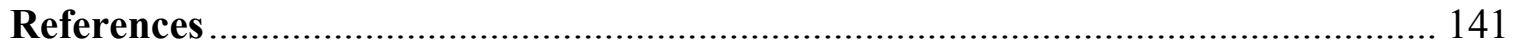

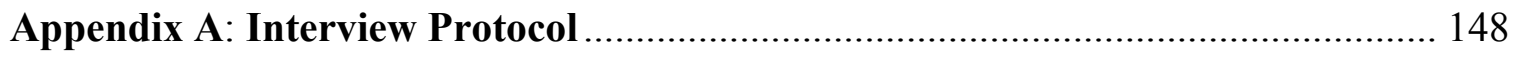

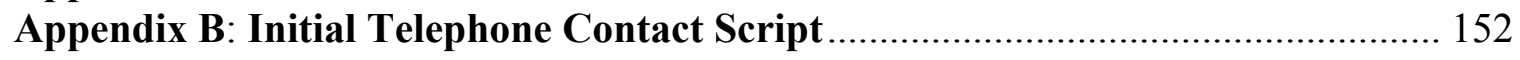

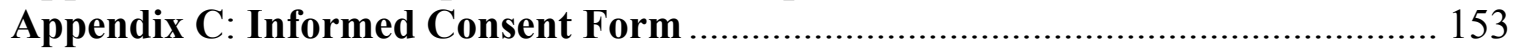




\section{List of Tables}

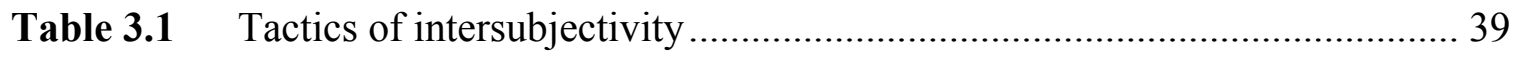

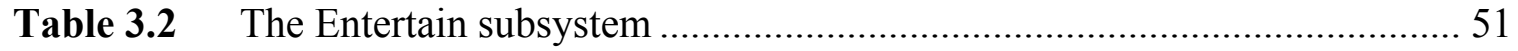

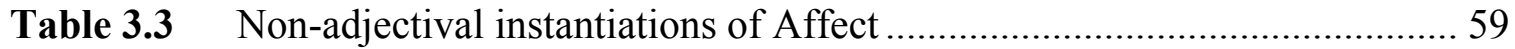

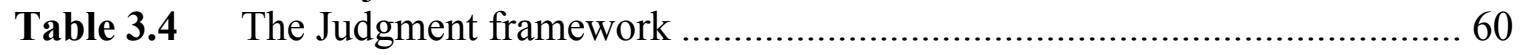

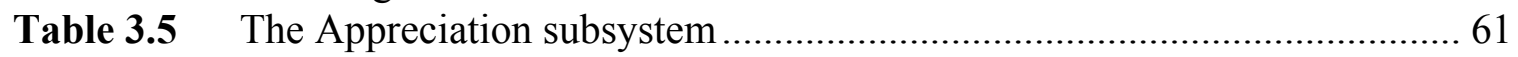




\section{List of Figures}

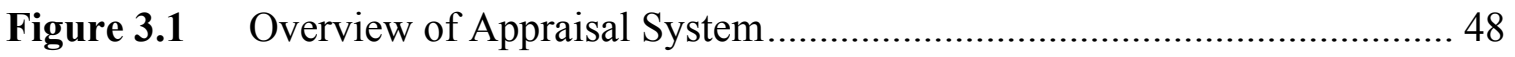

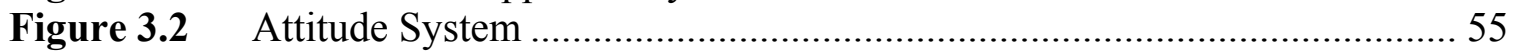

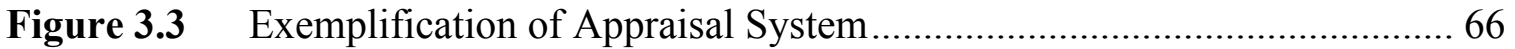

Figure 4.1 Intersubjective Alignment/Disalignment With Regard to HIV Management in Example (1)....................................................................... 79

Figure 4.2 Intersubjective Alignment/Disalignment With Regard to HIV Management in Example (2).............................................................. 84

Figure 4.3 Intersubjective Alignment/Disalignment With Regard to HIV Management in Example (3)

Figure 4.4 Intersubjective Alignment/Disalignment With Regard to HIV Management in Example (4)

Figure 4.5 Intersubjective Alignment/Disalignment With Regard to HIV Management in Example (10). 105

Figure 4.6 Intersubjective Alignment/Disalignment With Regard to HIV Management in Examples (13), (14), and (15) 


\section{Chapter 1: Introduction}

Friends and colleagues who hear that my thesis is an investigation of the social construction of HIV/AIDS often ask me what this illness has to do with TESOL or Applied Linguistics. Admittedly, studying social phenomena that are not directly related to language education may appear to be rather unorthodox in our field. My experience in the program has led to my developing a broad multidisciplinary perspective on the social sciences and a belief that investigations of any socially constructed phenomena stand to benefit from linguistic analysis. As Sandstrom $(1990,1994)$ has pointed out, HIV/AIDS is both a biological disease and a socially constructed illness. Because socially constructed realities hinge, in large part, on the use of language, Applied Linguistics is an appropriate position from which to explore the social constructions of HIV/AIDS.

It is important to make clear that I am not HIV-positive nor am I a member of any class of people who have been disproportionately affected by the HIV/AIDS pandemic. Many are more authorized to address the social construction of this illness than I. Still, HIV/AIDS is a social problem that has implications for us all, from a public health perspective down to the individual level, including its impact on loved ones. It is through my individual experience with my father, who passed away as a result of AIDS, that I approached the work I have done for this thesis. In this section, I will summarize my experience in order to contextualize my research as personally relevant.

My father died about a month prior to my entering graduate school. Although he had exhibited classic signs of AIDS, a recurring case of pneumonia and oral thrush, my family and I did not know for certain that he was even HIV positive until the last week of 
his life. When we learned that his sickness was AIDS-related, my father revealed to my sister that he had always identified, unbeknownst to us, as a gay man. At the time of his death, he had maintained a marriage to my mother for nearly forty years. Over the years, there had been signs that led my sister and me to suspect that my father might have been gay, and his revelation was neither shocking nor even surprising.

What was shocking, however, was the extent to which he went to maintain his cover around our family. Due to the symptoms of his illness, my sister and I had suspected that my father may have had AIDS; however, mitigating our reasonable suspicions was the fact that my father's doctor had reported to my mother that he had ordered an HIV test that had come back negative. In light of the doctor's report, the mysteriously persistent nature of my father's symptoms during the last year of his life was an awful source of frustration and confusion for our family. The week after my father passed away, the doctor told my mother that he had been mistaken about an HIV test ever having been done. My father may have requested that the doctor not reveal a positive result to my mother, or perhaps the initial test was not actually done. Regardless of the reason we did not learn about my father's HIV status until such a late stage, I suspect that my father himself was aware of his status and chose not to share his knowledge with us. Whether he was motivated by internalized homophobia, fear of stigma, or the anticipated rejection of his family will forever remain unknown. Nevertheless, certain socially constructed factors situated in a specific time and place framed the cultural backdrop within which my father made his individual choices. 
My father was born in Mississippi in 1941 to two Southern Baptist parents who were considered austere even within such an incredibly traditional and conservative context. Growing up in such a context, he was undoubtedly confronted with numerous homophobic social messages. Even though I will never know the details of the specific messages he encountered or how he interpreted them, I feel certain that homophobic discourses in his sociocultural and historical context led to his inability to fully come to terms with his gay identity and, ultimately, to his seroconversion and horrible demise. Had he been able to better negotiate his sexual identity, it is far more likely that he could have led a healthier life and actively sought support when he needed it.

Fortunately, I was able to spend approximately the last 36 hours of my father's life with him in hospice. This indescribably emotionally charged experience instilled in me a profound sense of compassionate solidarity with the many others who have been personally impacted by the pernicious illness of HIV/AIDS. Shortly before my father passed away, I promised him that I would take action to help the HIV/AIDS community. The thesis work that I have embarked on here is a step in fulfilling that promise.

Apparently, my father chose to ignore his health needs in order to maintain his cover around our family. This was an extreme response to his conflicted perspective on his sexual identity and his illness. Obviously, not all HIV-positive men who are confronted with marginalizing discourses and social structures take such extreme measures. Since my father's death, I have had many questions about how people who are HIV positive have negotiated life with this illness. 
This thesis is based on an exploratory study that I conducted. When I began this work, I was not already embedded in any contexts that offered access to any HIVpositive populations. I simply wanted to interview HIV-positive men to learn more about their experiences. Accessing this population was challenging, but I was eventually able to connect with five participants through a local HIV/AIDS advocacy organization. As I report in more detail in Chapter 3, an initial conversation with the director of this organization led me to narrow my focus to Latino men, who, as I will explain further in Chapter 2, have been disproportionately affected by HIV/AIDS due to various sociocultural factors.

This thesis seeks to explore the relationships between the individual Latino men's agency and social structures that they reported as salient in research interviews about their experiences in managing HIV illness. More specifically, the analysis relies on a theoretical framework that views social identity as a set of relations involving both agency and social structure (Bucholtz \& Hall, 2004; 2005). At a finer grained analytical level, this study, inspired by Morrish and Sauntson (2007), uses the Appraisal framework (Martin, 2000; Martin \& Rose, 2007; Martin \& White, 2005) situated in the Systemic Functional Linguistics paradigm to elucidate how such sets of relations emerge in the interview discourse.

The thesis is organized into this introduction and four subsequent chapters. In Chapter 2, I situate the study broadly in language-related research into the social construction of HIV/AIDS and more narrowly in Applied Linguistics-related HIV/AIDS research. Then, I briefly review literature that has examined the construction of HIV- 
positive identities. Finally, I review relevant literature on HIV/AIDS risk among gay Latino and Latino men who have sex with men (MSM) while addressing the problematic nature of that label. Throughout each of these sections, I identify gaps that the current study seeks to address. Chapter 3 outlines the methodology I have employed and includes a detailed description of the theoretical and methodological frameworks. I have chosen to discuss these frameworks in Chapter 3 rather than Chapter 2 because their descriptions are facilitated through exemplary analyses and thus logically flow better into Chapter 4 , where I present and discuss the discourse analysis of the interviews I performed. In Chapter 5, I conclude the thesis by offering possible explanations for my main finding, addressing limitations of the current study, suggesting directions for future research, and personally reflecting on this project. 


\section{Chapter 2: Background and Literature Review}

This thesis is situated at the intersection of three strands of literature: language and HIV/AIDS, HIV-positive identity construction, and sociocultural risk factors among gay and men who have sex with men (MSM) Latinos. In this chapter, I broadly describe the relationship between language and the historical sociocultural representations of HIV/AIDS. Then, I broadly position my study within what Bucholtz and Hall (2004, 2005) have described as sociocultural linguistics. Next, I briefly review the small corpus of Applied Linguistics research into the social construction of HIV/AIDS while identifying a gap in this literature. Following this, I briefly review studies of HIV-identity construction while identifying a gap in this literature. Finally, I draw on the literature of HIV/AIDS risk among gay and MSM Latinos to generalize what has been documented about members of my population while identifying a gap in this literature. At the end of each section, I offer a short description of how my exploratory study sought to address the gaps I identify.

\subsection{Language and the social construction of HIV/AIDS}

HIV/AIDS is both a biological disease and a socially constructed illness (Murray and Payne 1989; Sandstrom 1990, 1994; Treichler 1987). As a socially constructed

phenomenon, HIV/AIDS has always been contingent on language. Many humanities and social sciences scholars have critically examined the ways in which language has shaped the emergence and crystallization of problematic HIV/AIDS discourses at the societal level (see, for example, Murray and Payne, 1989; Preda, 2005; Sontag, 1989; Treichler, 1987). Such work is interdisciplinary and vast in scope; however, these examinations 
share a common approach in focusing on specific aspects of language, including lexical descriptors, rhetoric, and metaphor, to identify and critique societal level constructions of HIV/AIDS. These scholars have well documented ways in which biomedical discourses historically constructed HIV/AIDS as an illness of the homosexual, the Haitian, the drug addict, and the prostitute, thus shaping the public's association of HIV/AIDS with deviancy. Treichler explicitly admonished that if we ever hope to understand this "epidemic of meanings or signification" (p. 32), we must "intervene at the point where meaning is created: in language" (p. 31). In other words, there is no underlying truth about HIV/AIDS as a social entity; rather, there are multiple social constructions of the illness resonating throughout societies, and these constructions are largely manifest in language.

Leap and Colón (2010) succinctly described the results of the type of work I have described above as showing "how discussions of AIDS are always embedded within broader assumptions about marginality, risk, fear, and blame" (p. 60). In some respects, such work embodies traits of what Wells (2011) referred to as Foucauldian discourse analysis. This type of discourse analysis is concerned with how "stability and transition in thought may be uncovered through an historical method, with the analyst continuing to examine materials until he or she identifies where and how concepts originated, stabilized, and or changed over time" (p. 11). As incisive as such work has been in illuminating the production, crystallization, and reproduction of macro-social HIV/AIDS discourses, what is missing in such analyses is the role of individual agency. Leap and Colón (2010) articulated this limitation by noting that in language-focused HIV/AIDS 
research "the discursive power of language was confirmed on a broad scale, but the particulars of linguistic practice were still ignored" (p. 63).

How might broader social structures shape language use at more local levels? How can an analysis of language use in research interviews offer insight into the social construction of HIV/AIDS at broader levels? How might social structures facilitate or constrain individuals' agency in the management of HIV illness? Fundamentally, the current study intended to explore these basic questions in a specifically situated context of research interviews with five HIV-positive Latino men. In the following sections, I draw on Applied Linguistics and related literature as I hone these broader questions into the more focused question that guided my study.

\subsection{Sociocultural linguistics}

As an interdisciplinary field, Applied Linguistics has broad scope. The current study is situated within what Bucholtz and Hall $(2004,2005,2008)$ have deemed "sociocultural linguistics." This label describes "the broad interdisciplinary field concerned with the intersection of language, culture, and society" (2005, p. 586). Sociocultural linguistics includes sociolinguistics, linguistic anthropology, and discourse analysis, among other subdisciplines. The fusion of these subdisciplines under the label, Bucholtz and Hall emphasized, is not an attempt to erase disciplinary differences or create new divisions; rather, they proposed it as a strategy to "highlight an interdisciplinary coalition that is already thriving but not always recognized" (2008, p. 404). Most importantly, they identified "two of the primary avenues of exploration in contemporary sociocultural linguistic research" as "the concern with the linguistic 
construction of identity in social interaction and the relationship between individual speaker agency and larger social structures and processes" (2008, p. 404). Linguistics research into HIV/AIDS fits these theorists' description of sociocultural linguistics. I have chosen to use the label to facilitate cohesiveness throughout this review. In addition, I have drawn extensively on Bucholtz and Hall's theory of identity, which Chapter 3 explicates, for the current discourse analysis. Labeling the work I review in the following section as sociocultural linguistics is based on my own interpretation of Bucholtz and Hall $(2004,2005,2008)$ and does not reflect the authors' explicit positions.

\subsection{Sociocultural linguistics and HIV/AIDS}

Leap (1990) was perhaps the first sociocultural linguistic investigation into HIV/AIDS though his work anticipated the label by more than a decade. This early linguistic exploration of the social construction of HIV/AIDS sought to elucidate "how speakers use language to establish their sense of self, as actor and/or observer, within AIDS-related social domains" (p. 150). To accomplish this aim, Leap, as in his later work, analyzed verb choices (1990, 1995; Leap \& Colón 2010). Particular verbs, Leap correctly emphasized, had implications for the possibilities of thematic roles assigned to noun phrases. Thus, speakers' verb choices allowed or constrained options for assigning agency to themselves or other people described in their discourse. In addition, Leap analyzed pronoun use and found that choosing we or they had implications for representations of social proximity to at-risk communities and/or agency when describing participation in risky sexual situations. One can see in Leap (1990), then, the genesis of 
the broader sociocultural linguistic notion of identity as constructed in discourse as a site of tension between social structures and individual agency in the context of HIV/AIDS.

Despite Leap's (1990) early invitation for additional linguistic contributions to discussions of HIV/AIDS as a socially constructed phenomenon, the use of linguistic theories and methods in socially oriented HIV/AIDS research remains rare. Moreover, HIV/AIDS research from a linguistic perspective has not generally coalesced around any unifying issues or constructs. One exception is Higgins and Norton (2009), an unprecedented edited volume of sociocultural linguistic studies that have drawn from a diverse array of theoretical and analytical frameworks to investigate HIV/AIDS in various global contexts. The common thread that connected the various studies in this volume was the construction of local HIV/AIDS knowledge. This notion emphasized "the political nature and uses of local knowledge to contest prevailing views about HIV/AIDS" as well as "how local knowledges are produced by local subjects navigating societal and cultural strictures around AIDS" (p. 16). Again, we see the idea of the struggle between structure and agency. In the following paragraph, I will briefly describe some of the studies from this volume to exemplify how sociocultural linguistics has examined these sites of struggle between local subjects' knowledge construction and macro-social discourses.

Mutonyi and Kendrick (2009) used multi-modal discourse analysis to examine how "Ugandan youth use cartoon drawings to represent the social, cultural, psychological, and physiological context of their HIV/AIDS knowledge” (p. 57). Framing language in context as performance of identity, Clemente and Higgins (2009), 
examined a group of Mexican pre-service English teachers' code choice between English and Spanish in the "construction of imagined communities between themselves, their future English students, and the world of people with AIDS” (pp. 86-87). Jones (2009) incorporated Lave and Wenger's [1991] construct of "legitimate peripheral participation" in his mediated discourse analysis of interactions in a Hong Kong online gay chat forum to show that learning about HIV/AIDS involved "not just mastering a body of knowledge but also constructing an identity for oneself within one's peer group" (p. 190). From this sample of studies, it should be clear that sociocultural linguistics is capable of rigorously examining the "epidemic of signification" Treichler (1987) described, but from the micro or local perspective that Leap (2010) described.

Not only are the previous studies cohesively bound around the notion of locally constructed knowledge but each, as Savage (2009) described, tells the story of a specific community affected by HIV/AIDS. He avoided debating the value of narrative inquiry in the social sciences, opting instead:

[to] celebrate some of what listening to and telling stories offer us as people who work at or are intrigued by the intersection of education and applied linguistics and HIV and AIDS, what Pavlenko refers to as "attention to ways in which storytellers use language to interpret experiences and position themselves as particular kinds of people” (pp. 38-39).

However, Savage is the only HIV/AIDS story from the United States that is represented in Higgins and Norton (2009). Although I am not HIV positive or gay like Savage, I have personally suffered as a result of HIV/AIDS. By contributing evidence of how a 
small group of Latino men in our own community have gone about managing their HIV illness, I hope the current study can add unheard stories of marginalized voices from the U.S. to the small corpus of sociocultural linguistics research into HIV/AIDS.

The two sociocultural linguistics studies most germane to the current study are Körner (2009) and Morrish and Sauntson (2007). Körner utilized her expertise in systemic functional linguistics' Appraisal system to analyze how gay men in Sydney, Australia discursively aligned themselves with and/or contested the official public health message of "use a condom every time" in their descriptions of safe sex negotiations. Morrish and Sauntson also used the Appraisal system but in conjunction with the tactics of intersubjectivity, a theoretical framework for analyzing social identity formulated by Bucholtz and Hall (2004, 2005). Most importantly, each of these studies inspired the current study in terms of methodologies that allowed for robust discussions of relationships between individual agency and social structures. Because these studies' specific findings and conclusions are less relevant to the current study than are their methodologies, I draw on them in more detail in Chapter 3 while discussing my methods.

\subsection{Qualitative studies on negotiating an HIV-positive identity}

The current study seeks to examine the salient social structures that facilitate or constrain individual men's agency in the management of HIV illness. As I elaborate in Chapter 3, such relationships between structure and agency are equivalent to social identity according to the theoretical framework I use. Thus, briefly reviewing studies that have investigated the construction of HIV-positive identities is warranted. 
As far as I have been able to identify, studies on HIV-positive identities are grounded in sociological, often symbolic interaction, perspectives (see Baumgartner 2007; Baumgartner and David 2009; Lewis 1999; Sandstrom 1990, 1994). These qualitative studies have shown that taking on an HIV-positive identity is a highly negotiated social process. Many of these studies cited chronic illness literature that described being diagnosed with a chronic or terminal illness as precipitating a biographical disruption (Baumgartner and David 2009, p. 1731; Sandstrom, p. 82). Regardless of whether it was explicitly described this way, however, an HIV-diagnosis was found in all these studies to typically lead to a situation in which individuals found their previously held social positionings coming unmoored. At a broad level, these studies investigated how individuals negotiated social identities to regain a measure of social equilibrium as they became people living with HIV.

While two of these studies focused on a range of people, including women (Baumgartner, 2007; Baumgartner \& David, 2009), others focused specifically on gay men (Lewis, 1999; Sandstrom, 1990, 1994). Specific populations aside, each of these studies concluded that living with HIV presents a different complex of social challenges for gay men in large measure due to the double stigma attached to homosexuality and an HIV-positive status. As Sandstrom (1990) reported, for example, “The vast majority of our informants had already experienced some kind of stigma because of their gay identities. When they were diagnosed with AIDS, they usually encountered even stronger homophobic reactions and discreditation efforts" (p. 278). Similarly, Lewis (1999) compared the process of revealing HIV-positive status to "coming out as gay" in that 
“coming out as a PHA [person who has AIDS] typically involved a gradual revealing of self to others" (p. 106). Finally, Baumgartner and David (2009) suggested that "HIV/AIDS educators and counselors need to recognize that HIV impacts other identities, so assisting a person living with HIV might mean helping the person come to terms with a gay identity" (p. 1740). Of course, HIV may also impact other social identities, including an immigrant identity.

These sociological studies used different theories, constructs, and methods to examine and discuss the identity work that the participants undertook in what Sandstrom aptly described as "personalizing the illness" (1990, p. 274; 1994, p. 82). Although the frameworks differed, some generalizations can be drawn from these studies. First, identity was viewed as socially constructed and based on roles that a person took on in society (Baumgartner \& David 2009, p. 1730; Lewis 1999, pp. 94-96; Sandstrom 1990, 1994, p. 46). Second, many of these studies proposed certain trajectories or paths of progression in negotiating an HIV-positive identity. While there was some disagreement as to whether a person who suspects he is HIV-positive begins negotiating an HIVpositive identity upon this suspicion, the basic path of HIV identity negotiation in this literature involved getting tested for HIV, receiving a positive result, reacting to the diagnosis, and then managing the illness. Rather than seeking to identify a progression of stages as a person constructs an HIV-positive identity as these studies have done, the current study will focus on the construction of an HIV manager identity. Moreover, the theoretical and analytical frameworks I will describe in Chapter 3 facilitate illuminating 
such an identity by way of analyzing relationships between structure and agency as represented in discourse, which the studies I have reviewed here have not done explicitly.

The most striking and relevant limitation of these studies is the scant representation of minority voices, particularly those of Latino men. A recent New York Times article reported that Black and Hispanic men account for 25 percent of new HIV infections (McNeil, Jr., 2013). Nonetheless, of the studies I have reviewed in this sect, only Baumgartner and David (2009) explicitly mentioned including any Latino men, and that study included only a single Latino man.

Crucially, the interviews for these sociological studies, except Baumgartner and David (2009), took place prior to the advent of life-sustaining HIV medications in 1996. With the development of these medications, HIV changed from being a necessarily terminal to a manageable chronic illness (Teague, 2007). Popular representations as found in Moisse (2013) and Young (2014) often still discuss the historical shift from HIV being a death sentence to a manageable chronic illness.

Unfortunately, HIV manageability has not been very simple for many people. A relatively recent news article reported that "in many states, there is a sense of reverting to the 1980's and early 1990's, before the development of protease inhibitors reversed the rise in AIDS deaths" due to dwindling resources to support the government's AIDS Drug Assistance Program (ADAP) (Sack, 2010). Sack reported that these medications cost patients in the program "an average of $\$ 12,000$ a year" and that one Florida man, who "was four days late to re-enroll," which is required every six months, had paid $\$ 4500$ a 
month for two HIV medications and three other medications after being placed on an ADAP waiting list.

Problems in managing HIV illness are, unsurprisingly, more pervasive among the poor and particularly men of color than they are for the more affluent. In their metaanalysis of qualitative studies on HIV risk among minority MSM, including Blacks and Latinos, Dillon and Basu (2014) found that a salient theme reported by Black MSM was an unrealistic perception in their communities that HIV is now an easily manageable chronic illness. Contributing to such a misperception, as reported by some Black MSM, were powerful representations in the media, such as Magic Johnson's ability to effectively manage the illness (Han, Lauby, Bond, LaPollo, \& Rutledge, 2010). These researchers concluded that a focus on the lived experiences of HIV-positive Black MSM was necessary to "design effective health and social services options for members of this group" (p. 389). Dillon and Basu's meta-analysis did not include any studies of HIVpositive Latino MSM. Because Latino MSM, like Black MSM, have suffered disproportionately from HIV/AIDS, examining the experiences of HIV-positive Latino men is likewise necessary to fill this gap.

Although the sociological studies in this section identified and documented complex processes of identity negotiation among HIV-positive persons, most were conducted after the advent of life-sustaining HIV medications in 1996 and none sought to elucidate the relationships between how medication expense might factor into processes of managing the illness. In addition, none of these studies focused on HIV-positive Latino men. The current study seeks to fill this gap by focusing on Latino men and 
employing a method of discourse analysis and theoretical framework for analyzing the construction of social identity that facilitates the elucidation of relationships between social structures, such as HIV medication assistance programs, and individual agency in managing HIV illness.

\subsection{HIV/AIDS risk among gay and MSM Latinos}

The most comprehensive and cohesive body of knowledge about the social construction of HIV/AIDS in the Latino community, including among men who have sex with men (MSM), is documented in theory papers, literature reviews, and reports on quantitative and, to a lesser extent, qualitative studies that have aimed to illuminate how social and cultural factors exacerbate the risk for HIV infection as well as to develop interventions that reduce such risk. Because the term Latino includes a widely diverse group of people, theorists and researchers in this domain have tended to focus on salient risk factors among specific Latino subpopulations, including women (Ulibarri, Raj, \& Amaro, 2012; Rios Ellis, 2012; Vega \& Cherfas, 2012), heterosexual men (Rhodes, 2012), male sex workers (Colón, Muñoz-Loboy, \& Hernández, 2012), migrant workers (Kissinger \& Shedlin, 2012), male prisoners (Comfort, Albizu-García, Rodriguez, \& Molina, 2012), transgender women (Galvan \& Keatley, 2012), adolescents (Villarruel, Guilamo-Ramos, \& Bauermeister, 2012), Puerto Rican IV drug users (Saxe Zerden, Marilis López, \& Lundgren 2012), gay men (Díaz, 1998); and men who have sex with men (MSM) (Zea, Reisen, Bianchi, \& Poppen, 2012). Surprisingly, few studies within this literature have focused on HIV-positive Latino men's experiences in managing the illness. In this section, I briefly review relevant studies from this literature in order to 
describe the social and cultural factors related to HIV/AIDS that have been generally documented among Latino MSM.

\subsection{Gay versus men who have sex with men (MSM)}

Before reviewing the HIV/AIDS risk literature among Latino MSM, it is first necessary to address the problematic label MSM. As I will discuss in some detail below, sociocultural factors such as homophobia, hegemonic masculinity, family loyalty, and sexual silence have been found to be generally prevalent in Latino communities. Thus, Latino men often face great challenges in openly identifying as homosexual. Some Latino men identify as bisexual as part of "a transitional identification that facilitates the development of a gay identity," while for others bisexuality may signify an authentic attraction to both men and women (Díaz, Sánchez, \& Schroeder 2012, p. 124). Other Latino men may "opt for bisexual life choices — such as getting married to a woman at the same time that a male lover is maintained at the margins of family life" in order to smoothly negotiate cultural expectations (p. 124). Additionally, there are Latino men whose sexual orientation and identity is heterosexual who have engaged in bisexual behavior out of temporary necessity in the contexts of sex work or incarceration (p. 124). Of course, Latino men may also openly identify as homosexual. As Díaz, Sánchez, and Schroeder (2012) stressed, such identifications are important because homosexual identity and disclosure may impact Latino gay men's integration to the mainstream gay culture in the United States - a culture that often demands uncompromised 'outness' and public openness about homosexuality—as well as 
their sensitivity to messages about HIV/AIDS, including access to HIV treatment and prevention services. (p. 124)

As a strategy of capturing behavior rather than identity, however, the Centers for Disease Control has come to use the label men who have sex with men (MSM). As Díaz (1998) wryly explained, "In the name of cultural sensitivity and 'political correctness"” the clinical literature has used the term men who have sex with men (MSM) "when describing the population of men who engage in same-sex behavior, especially if these men are from ethnic and racial minorities" (p. 5). Díaz concluded that the "label MSM itself witnesses without challenge the cultural forces that promote public silence and personal shame about same-sex desire and behavior" (p. 7).

As a Latino who has embraced his gay identity, Díaz (1998) found that "addressing self-identified gay Latinos as MSM is deeply insensitive, insulting, and ultimately conspires with the homophobic silence that creates so much disruption, suffering, and risky behavior in our lives" (p. 7). Díaz, Sánchez, and Schroeder (2012) also addressed similar concerns. To address these concerns, these researchers chose to "use the term 'Latino gay men' to broadly define the population of Latino men who have sex with men (MSM), but more precisely those men whose same-sex sexual activity expresses an underlying homosexual or homoerotic sexual orientation" (p. 122). In other words, they chose to study those men who primarily have an erotic orientation at some level toward other men, whether they identify as homosexual or bisexual. In so doing, they excluded MSM who identify as heterosexual and male-to-female transgender individuals because they believed these latter two groups face sufficiently distinct 
challenges to warrant separate studies (Díaz, Sánchez, \& Schroeder 2012, p. 122). While Díaz (1998) used the term Latino gay men following his initial criticism of the term MSM, Díaz, Sánchez, and Schroeder (2012) continued using MSM to refer to the population described in this paragraph. Clearly, this is a problematic term.

Addressing the problematic nature of this term is critical in my study because I interviewed four men who identified as gay, but one man, who reported having had sex with other men, identified as heterosexual. Even though I will use the terms gay and $M S M$ in accord with the respective work I cite, the literature I review is grounded in the experiences of gay and bisexual Latino men and will likely not accurately reflect the experiences of my entire study population. This fact resulted from my reliance on a convenience sample, which prevented my targeted selection of specific subpopulations. As a heterosexual White man who is representing the voices of these men, I want to make clear that I in no way have intentionally sought to offend those Latino men who have had the courage to openly identify as gay within a culture that too often suppresses the open expression of such an identity.

\subsection{Sociocultural factors exacerbating HIV risk among Latino MSM}

In his groundbreaking work, Díaz (1998) drew from in-depth qualitative interviews and quantitative measures to develop a model of HIV risk for gay Latino men. At the heart of his model were six "cultural scripts" (p. 61). These scripts included the sociocultural factors machismo, homophobia, family loyalty, sexual silence, racism, and poverty. Díaz referred to these factors as scripts because he found them to be so embedded in Latino culture that gay Latino men have come to internalize them. This 
internalization, he argued, created underlying scripts that his participants unconsciously drew from when making decisions in risky sexual contexts. Conflicts arising from these scripts, Díaz postulated, led to volitional breakdowns for these men in such contexts despite the fact that they often possessed accurate knowledge of HIV risk. In other words, Díaz found that gay Latino men were often unable to actually enact their knowledge of HIV risk as a result of these cultural scripts.

Discussing the psychological details Díaz presented is unwarranted here, but the sociocultural factors he identified as having contributed to exacerbated risk remain ubiquitous across more recent research on HIV/AIDS risk among Latino gay men (see, for example, Organista 2012). In my more socially oriented investigation, I expected and found that some of these factors appeared as structural issues around which my participants had had to negotiate. Thus, in the following paragraphs, I will draw on Díaz (1998) to discuss these sociocultural factors in turn.

According to Díaz, machismo and homophobia are directly related to each other in Latino culture (p. 63). Machismo is the prescribed construction of masculine gender as defined by such traits as “courage, fearlessness, protection, and strength" (p. 63). However, this masculinity is not biologically endowed, it must be proven (p. 64). Moreover, Díaz explained that the conflation of sexual orientation with gender identity in Latino culture gave rise to the perception that homosexuality in men is a "failure to achieve the culturally given and highly prized masculine ideal and, therefore, is something to scorn and be ashamed of' (p. 64). Writing as a Latino gay man himself, 
Díaz attested that there are a host of insults in the Spanish language based on this perception of homosexuals as failed men.

Díaz also discusses family loyalty and sexual silence in tandem. He stressed that for Latinos:

family relations and the actual close involvement of families in the lives and affairs of the individual members is not considered a temporary situation of youth, but rather a life-long commitment that connects individuals, even after marriage, to a relatively large and supportive social network of caring and concerned human beings. (pp. 92-93)

Indeed, Díaz found many examples of the men in his study proudly distinguishing themselves from Anglos based on this cultural trait of family loyalty (p. 93). Given the homophobia described above, then, it follows that a homosexual orientation engenders tension with respect to these important familial social relationships. In fact, Díaz tentatively concluded "that the most important expression and manifestation of familism values among homosexuals is precisely keeping silent about their homosexuality" (p. 95).

Finally, in addition to homophobia, poverty and racism round out what Díaz described as the "triple oppression" that Latino gay men face. He indicated that poverty for Latinos increased six percentage points from 1979 to 1992, a bigger increase than found for Blacks and non-Latino Whites. In addition, Díaz criticized California's notorious Proposition 187, which aimed "to withhold and deny health, education, and social services to Mexican undocumented immigrants and their families” (p. 116). 


\subsection{Studies on Latino MSM that include HIV-positive men}

Thus far, my review has addressed the generally salient social and cultural factors that have contributed to heightened risk for HIV among gay and MSM Latinos. Most studies that have focused on social and cultural aspects of HIV/AIDS illness have not focused on HIV-positive Latino men. Several studies, however, examined patterns of HIV-positive identity disclosure and found that HIV-positive Latino men tend to strategically disclose (Zea, Reisen, Poppen, Bianchi, \& Echeverry, 2005; Zea, Reisen, Poppen, Echeverry, \& Bianchi, 2004; Zea, Reisen, Poppen, \& Díaz, 2003); however, few, if any, studies have sought to explore other aspects of illness management among HIVpositive Latino men.

Although Díaz (1998) called for a more structural, cultural approach to HIV/AIDS health interventions decades ago, Organista (2012) has more recently pushed for a similar approach. From a communication perspective, the meta-analysis of Dillon and Basu (2014) noted that findings made in the literature on HIV/AIDS among Latino MSM were "often interpreted in isolation without explicating productive links to previous research," which, they argued, resulted in a failure "to meet its full potential for knowledge development and theory building" (p. 183). In constructing this review, I, too, found it difficult to synthesize findings on the social construction of HIV/AIDS among Latino MSM. Dillon and Basu emphasized the need for more qualitative approaches that seek to elucidate connections between larger structures that constrain the agency of MSM in ways that heighten HIV risk and impede prevention. They specifically recommended Giddens's theory of structuration (1984), which "describes how micro- and macro-level 
aspects of social life mutually influence each other through the social conduct of everyday interaction" (p. 188). Although they do not specifically address minority HIVpositive MSM and their efforts to manage the illness, it is reasonable to conclude that there is also a need for such work among this specific group. The framework I used in my analysis assisted an elucidation of the kinds of relationships that Dillon and Basu (2014) deemed important.

In this section, I have addressed the problematic nature of the term men who have sex with men (MSM), drawn on Díaz's benchmark study (1998) to describe the general sociocultural factors that remain salient in exacerbating HIV risk among Latino MSM, identified the gap of a dearth of HIV-positive voices in the literature on HIV/AIDS among Latino men, and used Dillon and Basu's meta-analysis (2014) to make a case for more qualitative studies that seek to elucidate relationships between structure and agency in the context of HIV/AIDS among Latino MSM. The current study sought to position itself among studies in this literature by drawing on the interview discourse of five HIVpositive Latino men and analyzing the social identities of HIV managers that the men constructed in order to examine relationships between social structures and individual agency.

\subsection{Conclusion}

In the first section, I defined and situated my study within the nascent domain of sociocultural linguistics. Then, I briefly examined the small corpus of sociocultural linguistics research into HIV/AIDS, focusing on how studies therein examined particular linguistic and semiotic social practices in the construction of local forms of HIV 
knowledge. I identified the lack of voices from the United States as a gap in this work. I likewise mentioned two relevant sociocultural linguistics studies that inspired my choice of theoretical and analytical frameworks. In the second section, I reviewed sociological studies that examined the experiences of gay men and others as they took on HIV/AIDS identities. The main limitations I identified for this literature were the lack of Latino voices and the fact that none addressed issues of medical expense in the construction of HIV-positive identities after the advent of life-sustaining medications in 1996. In the last section, I drew from the HIV/AIDS risk prevention among Latino gay men to create a broad description of the context for this population. The main limitation I identified in this realm was a lack of qualitative studies that examine the relationship between structure and agency for HIV-positive gay Latino men and MSM.

In the following chapter, I will describe my methodology and explain in detail as well as exemplify how I used the theoretical and methodological frameworks for discourse analysis that Körner (2009) and Morrish and Sauntson (2007) inspired. 


\section{Chapter 3: Methodology and Theoretical Framework}

This qualitative investigation followed an exploratory case study design that sought to capture rich descriptions of life with HIV from five HIV-positive Latino men in the context of a local HIV/AIDS advocacy organization located in a major urban area in the Northwest. Hood (2009) summarized a case as "a bounded system comprised of an individual, institution, or entity and the site and context in which social action takes place, the boundaries of which may not be clear and are determined by the scope of the researcher's interests" (p. 69). Initially, the broad purpose of this study was to explore the relationships between individual agency and social structures as reported by HIV-positive men in the context of research interviews.

In this chapter, I summarize my analytical process, describe how the case boundaries developed through the process of participant recruitment, report on how data were collected, and explain the method of data analysis, including a fairly detailed explanation and exemplification of the two theoretical frameworks that facilitated my analysis. I have chosen to describe these frameworks here rather than in Chapter 2 because I have used primary data to exemplify their description; such a technique resulted in sections that move more logically into Chapter 4, where I report on my analysis.

\subsection{Summary of analytical process}

In this section, I summarize the steps I took throughout the analytical phase of my study. The sections that follow report on these steps in more detail. 
My general analytical process was iterative, taking both a top-down and bottomup approach in its earliest stage. First, after having transcribed each of the five interviews, I closely read each of the transcripts multiple times. Second, I performed thematic analyses on the interview data. The themes I identified included family, homophobia, disclosure of HIV status, fear of death, machismo, stigma, drug and alcohol use, condom use, condom availability, government and media representations of HIV/AIDS, activism, use of HIV medications, financial assistance with accessing HIV medications, and financial independence. During the process of identifying these themes, I observed that the use of and financial assistance with HIV medications were the most commonly prevalent themes across all the interviews. Moreover, during the interview with "José," I had observed that paralinguistic behavior such as sarcastic intonation and increased volume often accompanied his frequent references to financial assistance with HIV medications and financial independence. During the interview with Rofino, the other immigrant man, I had also noticed that he frequently referred to the same themes. Focusing on discourse excerpts that contained these themes, I conducted Appraisal analyses of a limited number of excerpts. Importantly, the Appraisal analyses identified that the immigrant men's discourse enacted highly negative opinions about the practice of gaining HIV medication assistance as having impinged on their sense of financial independence. In contrast, the non-immigrant men's discourse made no references to medical expense nor enacted any negative opinions about gaining access to HIV medications. In fact, when the non-immigrant men referred to the access and use of HIV medications, their opinions tended to be positive. That such a bifurcation between the 
immigrant and non-immigrant men's opinions emerged in my limited Appraisal analyses led me to do global searches of each transcribed interview for the lexical items drugs, medications, meds, health care, expense, self reliance, and independence. Following this, I extracted discourse excerpts that showed these terms and performed detailed Appraisal analyses of them. Using Bucholtz and Hall's (2004, 2005, 2008) tactics of intersubjectivity, I made the argument that the distinct, albeit partial and situated only in my interviews, social identities of effective HIV manager and challenged HIV manager, emerged in the discourse data, respectively, for the non-immigrant and immigrant men. Space did not allow for reporting on each of these detailed Appraisal analyses; therefore, I reported the excerpts that I determined to most exemplify my main finding.

\subsection{Participants}

As mentioned above, the boundaries of this case study were initially fairly nebulous. Participant recruitment began with attempts to access HIV-positive men, with no further demographic criteria specified. Accessing HIV-positive men proved challenging, and during the nascent phases of the study, I made several unsuccessful attempts to access participants through friends as well as via emailing and calling local HIV/AIDS organizations. Eventually, the director of one local HIV/AIDS organization graciously agreed to help gain access to men for the interviews.

After several email and phone correspondences, the director and I met at her office. At our meeting, I described the general purpose of my study and asked how the study might best benefit her organization. The director told me that she would like to know more about the Latino men her organization serves and requested that I study this 
population. Based on my background with the Spanish language, experience working as a Spanish GED and ESL teacher with Latinos, time spent living in the Spanish-speaking world, and desire for my investigation to be useful to the organization, I agreed to the director's request.

The director and I collaboratively established several criteria for participant recruitment. Participants had to self-identify as Latino and must have been at least eighteen years old. In addition, participants had to have known about their HIV-positive status for at least one year. We established this criterion in hopes of minimizing psychological or emotional turmoil for the men during the interviews. We also thought this criterion would be a good strategy for gathering richer data because participants would have had more experience managing HIV than men who had more recently learned about their HIV status. Finally, the men had to report being comfortable participating in an English language interview. Although I speak Spanish fairly well, I had thought accurate construal of subtle and pragmatic aspects of language would be important in my study, and I was not sufficiently confident that I would understand Spanish well enough in that regard. In addition, translating lengthy interviews would have likely been beyond the scope of my study.

After having established these criteria, the director and I met with case managers from her organization. These case managers kindly devoted time to reviewing my proposed interview protocol (Appendix A) and offering feedback. They thought that my questions would yield useful data and suggested I be sure to probe for experiences with the healthcare system. To help protect confidentiality and minimize coercion, these case 
managers graciously recruited five men to participate in the study. Facilitating the recruitment was a telephone script (Appendix B) that I drafted. As set forth in the script, each interview was to last for about one hour, but an apparent miscommunication led to two interviews being scheduled for two hours. In an attempt to maintain consistency, I asked the other participants during the interviews if they would not mind talking with me for longer than one hour. In the end, three interviews lasted two hours, one was an hour and a half, and one was just over an hour.

The participants were five HIV-positive Latino men. Four of the men identified as gay. One man identified as heterosexual but reported having had sex with men for money during times of economic duress. Three of the men had been born in the U.S., and two of the men had immigrated to the U.S. in the nineties. The men's ages ranged from late twenties to late forties or early fifties. Each of the men was of Mexican origin. Chapter 4 provides additional relevant participant characteristics as needed.

\subsection{Data collection}

The research interview, according to Richards (2009), "offers different ways of exploring people's experience and views" (p. 183). The view that the research interview is a site, not an experimental laboratory, in which social actors, participants and interviewer alike, co-construct the ensuing talk informed this study. Moreover, the theoretical perspective, which I will detail below, taken here understands social identity as discursively emergent relations between individual actors and social structures. Given the contentious history of the social construction of HIV illness, such orientations allowed for the reasonable assumption that data from interviews would generate discursive 
representations of social identities, which would concurrently offer insight into social structures salient to the men's experiences as agents in the process of managing HIV illness. The fundamental question that guided this study was: What social structures facilitate or constrain the individual agency of the men as reported in their talk about their experiences in managing HIV illness? Appropriately, the research interview facilitated the collection of data with the purpose of elucidating this guiding question.

The semi-structured interview, explained Richards (2009), offers structure but also allows "the interview to develop in unexpected directions where these open up important new areas" (p. 186). I am an HIV-negative heterosexual middle-class White man, which does not offer me an insider's view of these men's experiences. Moreover, I am a graduate student and researcher. Collectively, my positions likely portrayed in the interviews the social identity of a relatively powerful person and one knowledgeable in some regards. Certainly, I entered the interviews having some preconceived notions based on the literature review constructed for this thesis. At the same time, based on my own relatively distinct identity and limited experience with HIV-positive persons, I wanted to provide a context in which the men could express their experience and views about HIV on their own terms without expectations that the researcher was seeking particular answers. In short, I chose the semi-structured interview format to allow unanticipated directions to unfold as much as possible.

An interview protocol (Appendix A) adapted from Sandstrom (1994) and approved by the men's case managers facilitated each interview. This protocol served as an interview guide, but I encouraged the men to talk about any topics that they thought 
were important and relevant in their social experiences as HIV-positive persons. As much as possible, I followed the participants' leads during the interviews and asked clarifying questions accordingly. At the end of their interviews, two of the men commented that they felt like they had not been interviewed but had had a conversation, which Richards (2009) identified as a sign of a successful semi-structured interview (p. 186).

The interviews took place in a private office at the HIV/AIDS organization. The director and I had previously chosen this setting because it was familiar to each participant and, we thought, would create a sense of comfort for the men. There were also trained counselors available in case any of the men were to have psychological or emotional difficulties during the interviews. Fortunately, such services proved unnecessary.

Ensuring participant protection in any research is of the utmost importance. The Institutional Review Boards of both Portland State and the medical research university affiliated with the HIV/AIDS organization approved my study. I outline specific steps I took to protect participants in this paragraph. I strongly encouraged each man to choose a pseudonym at the outset of each interview. Three took this option, but two adamantly insisted that their actual first names appear in the report. In light of these men's wishes, it would have been unethical to have changed their names. Other than these two participants' first names, I removed or changed all proper nouns that might have facilitated easier identification of participants. Because I could not promise protection from law enforcement authorities, I explicitly discouraged the two immigrant participants from talking about their documentation status. I kept the interview recordings locked in a 
safe place at Portland State. Upon final approval of this thesis, I will permanently delete these recordings. I ensured that the men understood that they could withdraw their participation at any time for any reason during the interview, but none took this option. Each man willingly agreed to participate by signing the informed consent form (Appendix C) approved by each Institutional Review Board.

Applied Linguistics researchers often emphasize giving back to the communities they enter to perform their work. The men I interviewed graciously volunteered their time and made themselves vulnerable in an exploratory project with a fledgling researcher. As such, I will have likely benefitted from this research more than the participants will have. As a modest token of appreciation, I offered each man ten dollars for having donated their valuable time to my project. Two men initially declined compensation, but I suggested they donate it to a local HIV/AIDS organization. Of these two, the first man agreed to my suggestion, but the second man refused this offer and told me that I should donate the money if I so chose.

To build rapport with the men, I told each of them at the outset of the interview my own HIV/AIDS story. By doing this, I wanted to let them know that I was not "basically some sort of verbal voyeur" (Walters, personal correspondence, 7/12/12) and that I had a personally sincere interest in learning about their experiences. One IRB, however, identified an ethical dilemma related to this strategy. The Board expressed concern that my story may be "conveyed in such a way that would be overly influential in a participant's decision to join the study" (Lager-Mesulam, personal correspondence, 3/5/13). To address this concern, I made sure to not tell my story until the men had 
agreed to participate, at which time I reiterated the fact that they could withdraw their participation at any time. I hoped this strategy would set an empathetic tone of solidarity, facilitate participants' opening to the vulnerability inherent in sharing the sensitive information I sought, and, very importantly, secure the participants' rights and overall ethical integrity of the study.

All five interviews took place over the course of one week. With the permission of each man, I recorded all of the interviews. I transcribed all of the interviews so that I could perform a discourse analysis based on the interview texts. I completed transcribing all of the interviews by the end of the week following the final interview. The recorded data yielded approximately one hundred and sixty pages of transcribed data. After completing each interview, I made notes on the context and reflected on my experience. My notes and reflections informed the analysis and discussion in Chapter 4.

Elucidating objective truth was never the intention of this study; rather, the study sought to elucidate these five men's subjective experiences as represented in the interactive discourse of one specific setting and to draw insightful inferences about Latino culture's potential influence on these individuals' experiences. As Leap and Colón (2010) argued, retrospective narratives may not reflect objective reality but can indeed signal ways in which "the respondents now make sense out of the AIDS-related experiences they are revisiting through their storytelling” (p. 66).

\subsection{Data analysis}

Because the interviews yielded approximately one hundred sixty pages of data, it was necessary to reduce the number of discourse excerpts for the more fine-grained 
Appraisal analyses. Discussions in Corbin and Strauss (2008) informed my method of close observation of participants during the interviews, careful reflective note taking following the interviews, and attentive reading and rereading of interview data. The fact that I transcribed the interviews shortly after having completed them helped in this regard. My adviser and I agreed that, out of respect for the men, I should include each of their voices in my report.

Throughout the initial broad analytical phase, it became clear that the theme of HIV medications and related theme of the health care system were central to this case. Furthermore, it became apparent that there was a consistent bifurcation between the reported experiences of the non-immigrant participants and the immigrant participants in relation to these themes. Early in this process, I also performed practice Appraisal analyses based on discourse excerpts in which these themes occurred. These Appraisal analyses proved useful in elucidating a general distinction between social identities that I describe as effective HIV manager and challenged HIV manager for the non-immigrant and immigrant men, respectively.

Based on the process described above, I decided to identify all discourse excerpts from each interview in which the theme of HIV medications and the healthcare system had emerged. Then, I performed Appraisal analyses on these selected excerpts. The Appraisal analyses informed further discussion through the lens of Bucholtz and Hall's tactics of intersubjectivity, a theoretical framework on the discursive construction of social identity. 
In the following sections, I describe Bucholtz and Hall's theory of identity and the Appraisal framework in some detail. Then, I use primary data to exemplify how juxtaposing these two perspectives facilitates the discussion and analysis in Chapter 4. By the end of the chapter, I hope to have made the process of discourse analysis clear for understanding the following chapter.

\subsection{Theoretical framework: The tactics of intersubjectivity}

Bucholtz and Hall (20050 observed that the sociocultural linguistics literature often writes about social identity without situating the concept in any specific theory. In this research, they argued, the overall theoretical approach "to identity remains at best a secondary concern, not a focused goal of the field" (p. 585). To address this limitation, the theorists drew on a range of social science disciplines to develop a theoretical perspective on identity for sociocultural linguistic researchers. By defining identity simply as "the social positioning of self and other" (p. 586), the theory is flexible and open to myriad analytical approaches. At the same time, the theory offers an analytical advantage in the form of five specifically articulated principles. In the following paragraphs, I describe the three principles from the theory that are relevant to this study.

The principle of emergence articulates a fundamental aspect of Bucholtz and Hall's theory: "Identity is best viewed as the emergent product rather than the pre-existing source of linguistic and other semiotic practices and therefore as fundamentally a social and cultural phenomenon" (2005, p. 588). Acknowledging that a "sense of self is certainly an important element of identity," the theorists maintain that "the only way that such self-conceptions enter the social world is via some form of discourse" (p. 587). 
Thus, the theory orients around the notion of identity not as "a psychological mechanism of self-classification that is reflected in people's social behavior but rather as something that is constituted through social action, and especially through language" (p. 588). In sum, the theory understands identities as social positionings that only emerge in discourse as language is used.

The second fundamental principle is the principle of partialness. This principle is important in the current study for its emphasis of the idea that all accounts of social identity are necessarily partial as well as for its conceptualization of agency as bound to other individuals as well as larger social structures in specific social sites. Bucholtz and Hall (2005) have articulated this principle as:

Any given construction of identity may be in part deliberate and intentional, in part habitual and hence often less than fully conscious, in part an outcome of interactional negotiation and contestation, in part an outcome of others' perceptions and representations, and in part an effect of larger ideological processes and material structures that may become relevant to interaction. It is therefore constantly shifting both as interaction unfolds and across discourse contexts. (p. 606)

Further elaborating this principle is unnecessary as the ideas regarding agency should come into more concrete view throughout the remainder of this chapter. Crucially, however, I want to emphasize that my analysis illustrates but partial representations, which have been reentextualized through my own interpretive lens, of the men's social identities as HIV managers. As "José," one of the interviewees, told me, "an hour or two 
hours is not gonna express my whole life, and especially when, you know, something this big."

The most specifically relevant principle in Bucholtz and Hall's theory is the relationality principle, also known as the tactics of intersubjectivity. Relationality emphasizes the "point that identities are never autonomous or independent but always acquire social meaning in relation to other available identity positions and other social actors" (2005, p. 598). Although the principle comprises three distinct relational aspects, the theorists have stressed that the relations or tactics are not "mutually exclusive" and that "since these are relational processes two or more typically work in conjunction with one another" (p. 599). In the discourse data of the current study, two tactics emerged as particularly salient: adequation/distinction and authorization/illegitimation. The two paragraphs below describe each of these in turn and draw on the primary data to offer simple exemplifications.

The tactic of adequation/distinction involves, respectively, the relations of similarity and difference, which are "the most widely discussed in social-scientific research on identity" (Buholtz and Hall, 2005, p. 599). Adequation is a process through which "differences irrelevant or damaging to ongoing efforts to adequate two people or groups will be downplayed, and similarities viewed as salient to and supportive of the immediate project of identity work will be foregrounded" (Bucholtz \& Hall, 2004, p. 599). Conversely, distinction "focuses on the identity relation of differentiation" (p. 600).

The tactic of authorization/illegitimation involves the "structural and institutional aspects of identity formation" (p. 603). Authorization "involves the affirmation or 
imposition of an identity through structures of institutionalized power and ideology," whereas illegitimation "addresses the ways in which identities are dismissed, censored, or simply ignored by these same structures" (p. 603). Importantly, Bucholtz and Hall have stressed that such social structures and ideologies are not necessarily "all-encompassing" and "interactional dynamics may shore up ideological structures even in the absence of a locatable powerful authority" (p. 604).

Table 3.1 illustrates simple instantiations of the tactics of intersubjectivity that I have drawn from my data.

Table 3.1 Tactics of intersubjectivity

Adequation Distinction

I'm just a regular guy like everybody else, ... like I'm not an anarchist. the billions and billions of people with a $401 \mathrm{k}$ with an IRA. I'm just a regular person.

\begin{tabular}{|c|c|}
\hline Authorization & Illegitimation \\
\hline $\begin{array}{l}\text { The doctors they always say "Oh yeah, you have } \\
\text { these drugs" and "yeah you can," you know, "live } \\
\text { forever." }\end{array}$ & $\begin{array}{l}\text { I don't think it's working } \\
\text { this message of like demonizing, um, HIV in that } \\
\text { way, especially with like the current drugs. }\end{array}$ \\
\hline
\end{tabular}

The example of adequation illustrates an immigrant man, "José," emphasizing his similarities through the copula and preposition like to the average person. Conversely, the example of distinction, also from José's interview, highlights the difference he sees between himself and an anarchist through the use of negation. In the authorization example, José's discourse has drawn on the powerful voices of medical doctors, heteroglossically reflecting the authorization of an ideology that HIV is a manageable chronic illness. In contrast, the example of illegitimation displays a discourse excerpt in which a non-immigrant man, "Mark," has described media and government efforts to 
educate the public about HIV as demonizing. Such a representation, alongside the representation of modern HIV medications, functions to portray the powerful social structures of government and media as dismissive of the ideology that HIV is a manageable chronic illness.

Although I have described the two pairs of tactics above distinctly, Bucholtz and Hall have stressed that these aspects of social identity are not mutually exclusive. Note in the adequation example shown in Table 3.1 that José's discourse not only functions to emphasize the similarities between his position and that of average persons but also represents a middle-class ideology that the norm is having saved money for retirement. As Bucholtz and Hall (2005) stressed, "it is not a matter of choosing one of these aspects of identity over others, but of considering how some or all of them may potentially work with and against one another in discourse" (p. 607). José's example, then, shows how his language has worked to draw similarities between himself and others, which only works in relation to the represented middle-class ideology.

The analytical process I have described above reflects the relational character, including structure and agency, of identity as constructed in Bucholtz and Hall's theory. My analysis in Chapter 4 frequently examines the discourse in a similar way as I have described here, particularly with respect to the ideology of HIV being a manageable chronic illness.

At the outset, I pointed out that Bucholtz and Hall (2005) designed this framework to be compatible with multiple analytic approaches. One approach they mentioned is an analysis of "evaluative, affective, and epistemic orientations in 
discourse" (p. 595). Thus, the Appraisal analytical framework I describe in the next section fits well with this theory.

\subsection{Methodological framework: Appraisal}

I used the Appraisal system developed within the Systemic Functional Linguistics (SFL) paradigm as the analytical framework for my discourse analysis. In this section, I provide an overview of Systemic Functional Linguistics (SFL), offer a short historical account of the development of the Appraisal system followed by a detailed description of the system while exemplifying relevant linguistic functions with primary data.

\subsubsection{Overview of Systemic Functional Linguistics (SFL)}

Systemic Functional Linguistics (SFL) "is a functionally based theory, developed during the past 45 years, which examines the functions that language has evolved to serve in society" (Young \& Harrison, 2004, p. 1). The principal architect of this theory is Michael Halliday. According to Halliday (1985), SFL is functional in orientation, for one, because "it is designed to account for how the language is used" (p. xiii). That the theory concerns itself with language in actual use crucially distinguishes SFL from Chomskyan linguistic perspectives, which are likely more familiar to an American audience. Halliday (1985) has critiqued Chomsky's presentation of language as a formal logical system because "the language has to be so idealized that it bears little relation to what people actually write — and still less to what they actually say" (p. xxviii). In this section, I present a cursory overview of SFL and distinguish the theory from formal linguistic approaches. 
Most American linguistics students and scholars probably associate the terms grammar, syntax, and structuralist with Chomsky's formal grammar. While such terms may typically belong to the lexicon of formal linguistics, the functionally based SFL does not disregard such structural relationships in language.

To discuss the main difference between formal and functional linguistics, it is first necessary to briefly discuss two perhaps unfamiliar terms: paradigmatic relations and syntagmatic relations. Paradigmatic relations, which Halliday and his followers have deemed systems, are "sets of options which are available to the speaker or writer covering the meanings that can be and are typically expressed in particular contexts, and the linguistic means of expressing them" (Martin 2000, p. 142). Paradigmatic systems are conceptualized along a vertical axis and include options of linguistic resources related to each other in terms of either/or (Bache, 2010, p. 2563). Bache offered the following simple description and exemplifications of two paradigmatic relations:

the choice between definiteness (realized by e.g. the definite article) and indefiniteness (realized by e.g. the indefinite article) in a sentence like I gave her _ book (either a book or the book) is an example of a paradigmatic relation, and so is the choice between present and past in a sentence like He likes/liked her a lot (either likes or liked). (p. 2563)

Syntagmatic relations, on the other hand, are

'horizontal' or 'linear' and can be defined as 'both-and' relations resulting in chains or sequences. Thus the relationship between article and head noun in the 
direct object noun phrase in I gave her the book is a syntagmatic relation (both the and book). (Bache, p. 2563)

Halliday (1985) has argued that the main distinction between formal and functional grammars is that the former are "syntagmatic in orientation" and have "their roots in logic and philosophy" whereas the latter are "primarily paradigmatic" and have "their roots in rhetoric and ethnography" (p. xxviii). He further explicates that the former "interpret a language as a list of structures" and "take grammar (which they call 'syntax') as the foundation of language" (p. xxviii) whereas the latter "interpret a language as a network of relations, with structures coming in as the realization of these relationships" and "take semantics as the foundation" (p. xxviii).

Now, describing grammar in SFL as fundamentally semantic might lead some to misconstrue the theory as unconcerned with linguistic structures, but this is not the case. In fact, SFL has elaborately described structural relationships in language. Martin and White (2005) have opined that Halliday's main contribution to the work of his predecessor, Firth, "was to treat units of structure as a whole as points of departure for systems, and deriving their structure from choices made with respect to the unit as a whole" (p. 13). In other words, structural elements such as clauses in Hallidayan SFL can be options within paradigmatic systems, whereas Firth theorized only "elements of structure in syntagmatic chains" (p. 13) choices available within paradigmatic systems. Furthermore, options chosen in one paradigmatic system have implications for the possible choices in other syntagmatically related systems. As Bache explained, 
the choice of indefiniteness realized by the indefinite article a/an in English implies the choice also of the singular in the number system, whereas the choice of definiteness realized by the definite article the is compatible with both the singular and the plural. (p. 2564)

Thinking in terms of the myriad other potential implications paradigmatic choices have on potential syntagmatic relations, it becomes clear that SFL takes quite a sophisticated view of structure.

It should be clear that the fundamental difference between formal and functional grammars with regard to linguistic structure is not that the former are structural whereas the latter are not; rather, as Halliday (1985) has emphasized, the difference lies in the direction of the analysis. Where formal grammars seek to catalog lists of possible structures available in a language "to which meanings are then attached" (p. xiv), functional grammars view language from a reverse direction "as a system of meanings, accompanied by forms through which the meanings can be realized" (p. xiv). Such a view aligns with Morley's (1985, p. 42) suggestion that the paradigmatic systems are the most fundamental abstract components of grammar in SFL.

The main point of this discussion has been to distinguish SFL from the likely more familiar formal linguistic approach of Chomsky. SFL theorizes language as having evolved, based on functional needs, to become a conventionalized semiotic system that people use to get things done. As Halliday (1985) summarized the distinction, SFL "puts 
the forms of a language in a different perspective: as means to an end, rather than as an end in themselves" (p. xiv).

One of the ends that SFL has accomplished is a theory of meaning in language at three different levels, technically known as metafunctions: the ideational, the interpersonal, and the textual. The ideational functions to "represent experience" (Martin \& Rose, 2007, p. 7). Meaning at this level may be thought of as the "content of a discourse" (p. 17). The interpersonal functions to act upon others in the environment, including establishing and maintaining social relations, influencing others' behavior, and conveying attitudes, emotions, and opinions (Halliday, 1985, p. xiii; Morley, 1985, p. 44). Finally, the textual functions to provide "coherence and cohesion to a passage" (Morley 1985, p. 46). These meanings manifest simultaneously in language; however, for my research purposes, the interpersonal meanings that participants conveyed were most relevant.

It follows that SFL takes a social as opposed to an individual psychological orientation to language (Halliday, 1985, p. xxx). Such a social orientation makes it an appropriate theory for exploring meaning in the reported experiences of men who are managing HIV illness.

A final basic note regarding SFL is that paradigmatic systems can consist of subsystems that are not necessarily logically connected by an either/or relationship. It is at the level of choosing an actual linguistic resource in writing or conversation from a system that such a logical connection applies. Thus, as I describe further in the next 
section, it is possible and indeed the case with Appraisal that systems can comprise simultaneously occurring subsystems of meaning potential.

My discussion of SFL has been necessarily brief and simplified, particularly with respect to the relationships between the paradigmatic systems and syntagmatic structures. Further discussion of these relationships is unwarranted because as I describe in the next section, the Appraisal system primarily consists of lexical options, even though SFL does not sharply distinguish lexis from grammar and prefers the term lexicogrammar (Martin \& White, 2005, pp. 8-9). I hope that I have provided the reader with adequate descriptions of technical terms to avoid later confusion as well as sufficient background information to understand implications that may arise as I discuss Appraisal, one of the paradigmatic systems for organizing linguistic resources within the interpersonal metafunction, in the next section.

\subsubsection{Brief history of Appraisal}

The Appraisal system emerged from Martin and his colleagues' work on an extensive research project investigating writing at work and in secondary school (See Martin \& White, 2005, pp. xi-xii). On this project and in subsequent work, these researchers faced the need to expand the scope of SFL for analyzing interpersonal meaning in discourse. Traditionally, SFL had discussed interpersonal meaning primarily in terms of the Mood and Modality grammatical systems (Martin 2000; White 2005). Appraisal theorists, however, found that analyses based on these grammatical systems tended to limit the interpersonal metafunction to exchanges of goods and services, thus neglecting lexical resources conveying "how the interlocutors are feeling, the judgements 
they make, and the value they place on the various phenomena of their experience" (Martin 2000, p. 144). In recent decades, a thread of linguistics research sometimes described as "evaluation" has increasingly sought to understand and map how such functions manifest in language. (See Hunston \& Thompson, 2000.) Developments in Appraisal have coalesced around the needs to enrich the SFL theoretical paradigm by providing systematic ways of accounting for evaluation as a semantic domain within the interpersonal metafunction. This description only very briefly and broadly sketches a decades-long history of theoretical development in Appraisal. (See Martin and White, 2005 , for the most comprehensively detailed account.)

\subsubsection{Basic description of Appraisal}

According to Martin and Rose (2007), Appraisal is fundamentally concerned with semantic "evaluation - the kinds of attitudes that are negotiated in a text, the strength of the feelings involved and the ways in which values are sourced and readers aligned" (p. 25). This description of evaluation corresponds respectively to the basic subsystems of Appraisal: 1) Attitude, 2) Graduation, and 3) Engagement as shown in Figure 3.1. These subsystems represent semantic domains of meaning potential that might be realized through particular instances of language use. Appraisal theorists have found that language users often realize each of these semantic domains simultaneously when they are making evaluations in discourse. By convention, the pointed bracket in the figure represents such simultaneity. In the following subsections, I will describe and exemplify each of these Appraisal subsystems using primary data. Because the Engagement subsystem is the most 
relevant semantic domain in my study I have emphasized its description and exemplification.

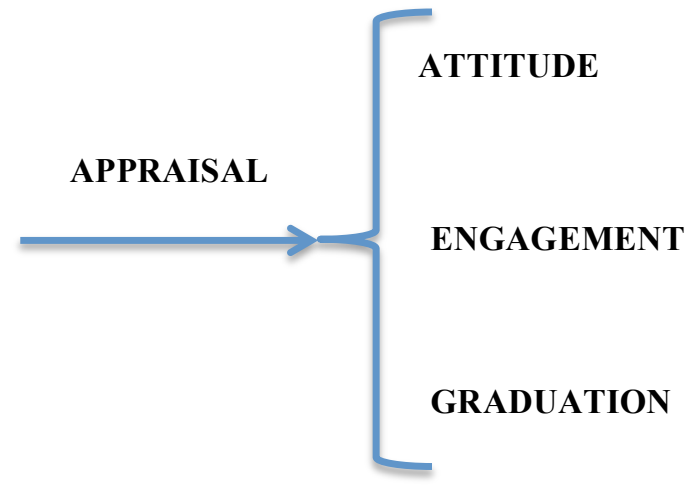

Figure 3.1 Overview of Appraisal system, adapted from Martin and Rose, 2007, p. 28

\subsubsection{Engagement}

A main concern of Appraisal theorists is how "speakers/writers adopt a stance towards to [sic] the value positions being referenced by the text" (Martin and White, 2005, p. 92). The framework organizes the linguistic resources that perform this basic

function under the subsystem labeled Engagement, a label that conveys its fundamentally dialogic perspective. As noted above, Bucholtz and Hall (2004) identified "the display of evaluative, affective, and epistemic orientations" as one entry point into the analysis of social identity in discourse (p. 595). In my study, I have used the Appraisal framework fairly holistically, but the subsystem of Engagement proved to offer the most specifically productive analytical perspective for elucidating intersubjectivity as set forth in Bucholtz and Hall's theory of identity. Thus, I describe the Engagement subsystem in some detail below. 


\subsubsection{Dialogism and the heteroglossic backdrop}

To make my data analysis process clear, I first need to briefly unpack and distinguish the concepts of dialogism and the heteroglossic backdrop as constructed in the Appraisal framework.

Drawing on Bakhtin's notions of dialogism and heteroglossia, Martin and White (2005) have described all speech and writing as dialogic, meaning "that to speak or write is always to reveal the influence of, refer to, or to [sic] take up in some way, what has been said/written before, and simultaneously to anticipate the responses of actual, potential or imagined readers/listeners" (p. 92). In other words, to speak or write is to construct for one's self a subjective position in relation to other subjective positions. Such a view aligns well with Bucholtz and Hall's theory of identity in that this type of positioning only emerges through language use and is relational.

The term heteroglossic backdrop is used by Appraisal theorists to refer to the prior utterances or subjective voicings in relation to which a speaker's own utterances position his or her own subjectivity in discourse. As cited in Martin and White (2005), Bakhtin theorized all utterances as manifest "against a backdrop of other concrete utterances on the same theme, a background made up of contradictory opinions, points of view and value judgements ... pregnant with responses and objections" (p. 93). This Bakhtin quote may be slightly misleading, however, because it could suggest that the discursive interaction between a speaker/writer and the heteroglossic backdrop is necessarily of a dissonant character. Of course, speakers and writers can also use 
language that constructs positions that harmonize with the values and opinions expressed through others' utterances.

Dialogism is the term that Appraisal theorists, following researchers influenced by Bakhtin, use to describe a speaker or writer's interaction with the heteroglossic backdrop. Summarizing Martin and White (2005), Körner (2009) explains the related concepts of dialogism and the heteroglossic backdrop thusly: "A dialogistic perspective attends to the relationship between a speaker's utterances and the utterances of other speaker's on the same issue" (p. 105). In sum, dialogism refers to language users' engagement with the values and opinions heteroglossically manifest in their discourse.

Crucially, from the dialogistic perspective taken up by Appraisal theorists, Engagement resources are typically seen as either aligning or disaligning a speaker or writer's position in relation to the heteroglossic backdrop. The notion of alignment/disalignment "refers to agreement/disagreement with respect to attitudes, beliefs, and assumptions about the world as it is or ought to be" (Körner, 2009, p. 107). Importantly, heteroglossic values might be represented as those of other individuals or institutions such as the health care system or the pharmaceutical industry. Thus, an Engagement analysis can facilitate the identification of the discursive construction of the tactics of intersubjectivity, which allows for a discussion of individual agency and its relationship to certain social structures, as set forth in Bucholtz and Hall (2004, 2005).

A detailed description of the Engagement subsystem is necessary to facilitate my analysis and discussion in Chapter 4. This subsystem organizes linguistic resources under 
"two broad categories according to whether they are 'dialogically expansive' or 'dialogically contractive' in their intersubjective functionality" (Martin and White, 2005, p. 102). In the following paragraphs, I describe and exemplify each of these categories in turn.

Dialogically expansive resources are those that open the textual space to allow for alternative voicings (Martin and White, 2005, p. 104). Under the category of Dialogic Expansion are the two main subcategories of Entertain and Attribute.

The Entertain category includes those resources that function to convey the sense that the speaker's position "is but one of a number of possible positions, and thereby, to greater or lesser degrees, makes dialogic space for those possibilities" (Martin and White, 2005, p. 104). Other, perhaps more familiar, renderings of this semantic region include epistemic modality, evidentiality, and probability (Martin and White, 2005). Table 3.2 shows examples from my data that are typical instantiations of the Entertain subsystem.

Table 3.2 The Entertain subsystem

\begin{tabular}{ll}
\hline Resource Type & Example \\
\hline Adjunct & How would you describe yourself? Hopefully, positive. \\
Circumstance & $\begin{array}{l}\text { To me, the hard part would be telling a partner, "Hey, before we get } \\
\text { involved in this." }\end{array}$ \\
Mental Verb & I think I'm a capitalist. \\
Rhetorical Question & $\begin{array}{l}\text { What if it's better to collect food and stamps and everything else and ... } \\
\text { you get a bigger paycheck than actually going to work for McDonald's? }\end{array}$ \\
\hline
\end{tabular}

The Attribute category includes those resources that open the textual space by explicitly assigning propositions to other voices. In my analysis, reporting verbs are the only relevant instantiations of this subsystem. Examples include he explained to me about 
being undetectable and sometimes a publicity has the mistake to say oh we find a cure for HIV or things like that.

In contrast to dialogically expansive resources, dialogically contrastive resources close or restrict the textual space from alternative voicings (Martin and White, 2005, p. 117). Dialogic Contraction comprises the two main subcategories of Disclaim and Proclaim.

The Disclaim subsystem includes resources that reject alternative voicings by way of negation as well as resources that challenge expected subjective positions; each of these kinds of resources is categorized, respectively, as Deny and Counter (Körner, 2009, p. 108). Consider the following excerpt from my data as an example of the Deny function: It doesn't have to be the end of it, either. Here, the underlined resource works to reject the notion that HIV is necessarily fatal. Now, consider another excerpt as an example of the Counter function: I get helped with medicine . . but then, you know, you still gotta jump through hoops. Each of the underlined resources in this excerpt functions to contract the dialogic space by challenging heteroglossic expectations that assistance in obtaining HIV medications is sufficient for this speaker's effective management of the illness. In my data, the most typical types of resources that function under the Disclaim category are various forms of negation and contrastive conjunctions.

The Proclaim category includes resources that "act to limit the scope of dialogistic alternatives" in discourse (Martin and White, 2005, p. 121). This function is less relevant 
in my data, but several instances did emerge. The relevant categories of Proclaim include Concur and Pronounce.

The Concur category covers resources that "overtly announce the addresser as agreeing with, or having the same knowledge as, some projected dialogic partner" (Martin and White, 2005, p. 122). An example of the Concur function is obviously, I get helped with medicine. Here, the dialogistic alternative that the speaker is capable of independently paying for HIV medications is represented as "at odds with what is purportedly generally agreed upon or known" (p. 124). In other words, having to rely on assistance in obtaining HIV medications is represented as taken for granted.

The Pronounce category covers resources that emphasize "the authorial presence so as to assert or insist upon the value or warrantability of the proposition" (p. 128). An example of the Pronounce function is it will be impossible to think that having a deadly disease will not affect you. Such resources "imply the presence of some resistance, some contrary pressure of doubt or challenge against which the authorial voice asserts itself" (p. 128). Here, that pressure is the voicing that living with HIV might not have an impact on a person.

The final relevant aspect of the Engagement subsystem that requires description is that of the monoglossic utterance. Although the Appraisal framework takes the view that all language use is dialogic, the system does allow for analyzing utterances that "for the brief textual moment" do not engage with prior utterances. Drawing on White, Körner (2009) has explained that the monoglossic utterance is "understood to represent social 
subject positions that are unproblematic and uncontested in a communicative context" (p. 127). One example from the primary data is there's so much advancement medically. Note that the construction is a contracted form of existential there is, which differs from there can be or it is possible to access. This has the effect, at least temporarily, of presenting the proposition as taken for granted in this context.

Appraisal theorists have elaborated a broad and vast typology of resources under various subcategories under the headings of Dialogic Expansion and Contraction; however, as would be expected in a framework developed within the SFL paradigm, such typologies should not dictate the analysis. As Körner (2009) emphasized, Engagement resources "are oriented towards meaning in context and rhetorical effects rather than towards grammatical form" (p. 108). Thus, the typical instantiations that I have drawn from primary data to exemplify Dialogic Expansion and Contraction in the preceding paragraphs are by no means exclusive or complete. As will be seen in Chapter 4 , I have devoted considerable space to explaining, based on co-text, how various specific resources align and disalign the men's utterances in relation to heteroglossic backdrops and how these relations of (dis)alignment embody the tactics of intersubjectivity (Bucholtz and Hall, 2004) as the interview discourse unfolded. 


\subsubsection{Attitude}

Attitude is the label of the Appraisal subsystem that organizes those linguistic resources used to tell "our listeners or readers how we feel about things and people" (Martin \& Rose 2007, p. 26). Appraisal theorists have developed an intricate typology for organizing resources that embody various kinds of attitudinal evaluation (See, for example, Martin 2000 and Martin and White 2005). Morrish and Sauntson (2007) drew extensively on the Attitude framework to elucidate the tactics of intersubjectivity in the discourse of coming out narratives written by gay and lesbian youth. While I do use the Attitude subsystem, I draw more on the Engagement framework. Thus, the description of Attitude below is appropriately brief and relatively cursory.

As shown in Figure 3.2, Attitude comprises three subsystems for organizing the types of attitudinal evaluations speakers/writers make. Affect organizes evaluations made about people's feelings. Judgment organizes evaluations of people's behavior. Finally, Appreciation organizes evaluations of things, both material and abstract. The pointed bracket indicates that these three semantic regions may occur simultaneously during language use.

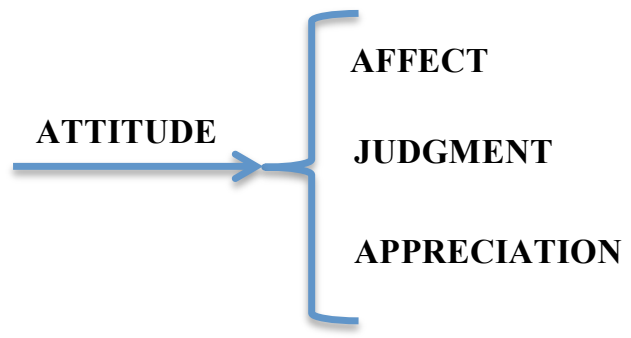

Figure 3.2 Attitude system, adapted from Martin and Rose, 2007, p. 28 
It is crucial to understand, before I briefly describe the finer categories of the Attitude subsystem, three fundamental relevant aspects of the kinds of resources that enact these kinds of evaluation. First, at their most basic level, these resources convey either positive or negative evaluation (Martin 2000; Martin and Rose 2007; Martin and White 2005). Second, there is a connection between attitudinal evaluation and the notions of alignment and disalignment that I have described in the Engagement section of this chapter. Martin and White (2005) have noted that when speakers/writers announce their own attitudinal positions they not only self-expressively 'speak their own mind', but simultaneously invite others to endorse and to share with them the feelings, tastes or normative assessments they are announcing. Thus declarations of attitude are dialogically directed towards aligning the addressee into a community of shared value and belief. (p. 95) Third, the boundaries between the types of attitudinal assessments are often difficult to distinguish. Appraisal theorists often attribute such difficulty to their perspective that emotion is the ultimate genetic source of all evaluation with normative and aesthetic evaluation being institutionalized constructions of feelings (Martin 2000, p. 147; Martin and White 2005, p. 42).

All of the elements in the preceding paragraph are important because in my analysis, I often double or triple coded types of Attitude due to the difficulty in precisely determining the type of attitudinal evaluation; however, I found that simply identifying whether the evaluation was positive or negative alongside the Engagement and 
Graduation analyses to be sufficient for my purpose of discussing how certain social identities emerged in the discourse based on the theoretical framework of identity (Bucholtz and Hall, 2004). At the same time, identifying types of evaluation in terms of basic attitudinal subsystems often did facilitate my discussion in Chapter 4 . In the paragraphs below, I briefly describe and exemplify each main Attitudinal subsystem.

\subsubsection{Affect}

Affect is the Attitudinal subsystem that abstractly represents the language choices that function to evaluate feelings, other people's or one's own (Martin \& Rose, p. 29). Like all linguistic resources that instantiate Attitude, the language choices that realize Affect make evaluations in terms of positive/negative polarity (Martin 2000, p. 149; Martin and Rose, 2007, p. 29).

As exemplifications of Affect, consider the two examples below. The first shows "Mark," a non-immigrant man, answering my question about what, if anything, he had learned about himself and people in his social network since learning about his HIV status. The second shows "José," an immigrant man, telling me about the application process that he goes through every six months to obtain assistance for highly expensive medication.

In addition to exemplifying the Affect function, these examples introduce the coding scheme I use in Chapter 4. This scheme is based on Appraisal conventions (See Martin, 2000.). Basically, I have underlined the linguistic resources that instantiate the semantic subsystem, and I have added subsequent brackets that identify the particular subsystem as well as whether the evaluation is positive or negative. 
(1) because I'm happier [+AFFECT] I might be having better relationships with people.

(2) It's stressful [-AFFECT], because, well, when are you gonna lose it? When are you not gonna jump through the right hoop and then you gone?

I have coded the adjective happier as an instance of positive Affect in Mark's discourse and the adjective stressful as an example of negative Affect in José's discourse. In sum, the resources organized under the category of Affect convey either positive or negative feelings in discourse.

It is worth noting that Appraisal theory recognizes that numerous linguistic resources besides adjectives can directly instantiate Affect (Martin and White, 2005, pp. 45-46). While exploring these instantiations in depth is unwarranted here, I did encounter in my investigation instantiations of Affect in the form of processes, adverbials, and nominalizations. Table 3.3 exemplifies such non-adjectival instantiations of Affect that I found in my interviews. 
Table 3.3 Non-adjectival instantiations of Affect

Process

I remember thinking I'm not gonna

cry [-AFFECT].

You can still enjoy [+AFFECT] your life.

\section{Adverbial}

I try to look positively [+AFFECT] to everything as much as possible.

Fortunately [+AFFECT], I lived enough to get that.

\section{Nominalization}

What about the depression [-AFFECT]?

And so, that's my biggest problem or concern [-AFFECT].

\author{
Speaker and brief context \\ Mark on receiving news about his HIV status \\ Oscar giving advice to an HIV-positive neighbor
}

Oscar describing his general disposition

Charlie describing his survival with HIV until the advent of life-sustaining HIV meds in 1996

José posing a rhetorical question conveying one of his problems.

Rofino expressing his worry about low income requirements to obtain HIV medication

The main purpose of Table 3.3 is to make clear that numerous linguistic forms can function to instantiate Affect. Categorizing the particular forms that function to convey emotion in language is not very relevant to my main purpose of elucidating the social construction of HIV illness as reported by the men I interviewed. I have added the table simply to illustrate different possible instantiations of Affect. As I will show in Chapter 4, identifying such instances of positive and negative Affect within the overall Appraisal framework has proven useful in illustrating the different intersubjective positions that immigrant and non-immigrant men constructed in relation to the health care system. 


\subsubsection{Judgment}

Judgment is the Attitudinal subsystem that abstractly represents the language choices that function to evaluate people's behavior based on social norms (Martin, 2000, p. 155). JUDGMENT evaluations, like those of Affect, function basically along positive/negative polarity (p. 155). At a finer level of abstraction, the Judgment subsystem includes Social Esteem and Social Sanction. Language choices that evaluate "normality (how unusual someone is), capacity (how capable they are), and tenacity (how resolute they are)" realize Social Esteem, and language choices that evaluate "veracity (how truthful someone is) and propriety (how ethical someone is)" realize Social Sanction (p. 156). Although I do not code for such finer Judgment categories, this more detailed description should serve as a guide for understanding my rationale behind having coded certain resources as Judgment values in Chapter 4.

Table 3.4 illustrates instantiations of the Judgment semantic domain. While most of the resources shown in the table have come from primary data, some are hypothetical for purposes of illustration.

Table 3.4 Judgment framework adapted from Martin (2000, p.156)

\begin{tabular}{lll}
\hline Social Esteem & Positive [admire] & Negative [criticize] \\
\hline $\begin{array}{l}\text { normality } \\
\text { How special? }\end{array}$ & normal, undetectable, healthy & $\begin{array}{l}\text { infected, down spiral, } \\
\text { contagious, poor }\end{array}$ \\
$\begin{array}{l}\text { How capable? } \\
\text { tenacity } \\
\text { How dependable? }\end{array}$ & self-reliant, independent & welfare mom, sick, idiot \\
& courageous, confidence & procrastinate \\
\hline $\begin{array}{l}\text { Social Sanction } \\
\text { How truthful? }\end{array}$ & Positive [praise] & Negative [condemn] \\
Propriety & real, honest & fake, dishonest \\
& patient, sympathy & criminalizing, homophobic, \\
\end{tabular}




\subsubsection{Appreciation}

The final Attitudinal subsystem is labeled as Appreciation. The Appreciation category abstractly represents the language choices that function to evaluate things. Like Affect and Judgment, Appreciation evaluations are generally either positive or negative (Martin \& Rose 2007, p. 37). As Martin (2000) pointed out, such evaluations are typically "realized through attitudinal adjectives modifying objects of value in one or another institutional realm" (p. 147). Linguistic resources that function to evaluate any entities, whether physical or abstract, instantiate Appreciation, and Martin and Rose (2007) have specifically identified entities such as quality of life and relationships as evaluated in the Appreciation domain. By way of exemplifying Appreciation, consider the primary data shown in Table 3.5.

Note that, rather than directly evaluating behavior or conveying emotion, these resources evaluate entities such as the state of medical technology, the act of taking medications, obtaining medications (decontextualized), a scenario, and obtaining medications again.

Table 3.5 The Appreciation subsystem

\begin{tabular}{|c|c|}
\hline Positive & Negative \\
\hline There's so much advancement medically & They do have adverse side effects. \\
\hline $\begin{array}{l}\text { It's made that simple }(\text { it }=\text { accessing health } \\
\text { care) }\end{array}$ & It's a weird disease. \\
\hline $\begin{array}{l}\text { In certain states where it's a lot easier to } \\
\text { get on HIV drugs }\end{array}$ & $\begin{array}{l}\text { The more difficult part would be telling } \\
\text { a partner, Hey, before we get involved } \\
\text { in this ... }\end{array}$ \\
\hline That's probably the best scenario. & What about the worst scenario? \\
\hline
\end{tabular}




\subsubsection{Direct and Implied Evaluation}

Thus far, the exemplifications of Attitude that I have presented have been inscribed or direct evaluations (Martin \& White 2005, p. 61; Martin \& Rose, p. 33). These descriptors simply mean that the type of evaluation is fairly explicit. As I have noted above, Appraisal theorists state that there may not be clear boundaries between the types of attitudinal evaluation (Martin and Rose, 2007, pp. 39-42). To reiterate, Martin (2000) has argued that Affect is the basic attitudinal subsystem and has been institutionalized in "two major realms of uncommon sense discourse" as Judgment and Appreciation (p. 147). Below, I briefly discuss practical implications of such porous evaluative boundaries.

Appraisal theorists stress the importance of analyzing the surrounding discourse in determining particular instances of evaluation. These theorists have metaphorically described evaluation as resonating "prosodically" throughout discourse (Martin and White, 2005; Martin and Rose, 2007). Here, the theorists are not referring to phonology but are rather describing a perspective on evaluation in which instances of language that may appear to instantiate a certain Attitude subsystem or be exclusively ideational can take on an evaluative character from the surrounding discourse. Such instantiations of evaluation are referred to as evoked evaluation as well as tokens. These are not tokens in the more familiar sense; rather token is a synonym for an instance of implied evaluation. Consider the excerpt below as an exemplification of a token, denoted with a $t$.

(3) C: So how long was this? Was it before the uh the medications came out? W: No, this just happened about three years ago.

C: Oh my goodnesS [-AFFECT/t:-JUDGMENT]. 
In this example, "Charlie" had asked me how long it had been since my father passed away. The underlined evaluation, an interjection, is coded with a direct evaluation of negative Affect. Taking the surrounding discourse into consideration, however, this evaluation also evokes the sense that it is not normal for someone to die as my father had because we live in an era in which life-sustaining HIV medications are available.

This example is a fairly simple illustration of how different types of evaluation can manifest in certain sections of discourse as a result of the surrounding text. As I have already mentioned, even language that is superficially exclusively ideational can take on an evaluative character in this way. Where this type of evaluation occurs in the analysis I present in Chapter 4, I have identified it using the conventional code and added discussions explaining such tokens' significance to my argument. It should be noted that the notion of implied evaluation is a potential analytical limitation of Appraisal, a concern I address further in Chapter 5.

\subsubsection{Graduation}

Graduation is the final basic subsystem within the Appraisal framework. This subsystem organizes resources that adjust either the intensity or prototypicality of Attitudinal evaluation (Martin and White, 2005, p. 135). In other words, an analysis from a Graduation systemic perspective examines the relative strength of evaluation. The categories of Force and Focus organize those resources that adjust evaluative amplitude and typicality, respectively (p. 137). My analysis does not draw extensively on the Graduation subsystem, but a brief exemplification is warranted. 
First, I will exemplify the category of Force. Recall from the description of Appreciation above, the following example: there's so much [UPSCALE] medical advancement [+APPRECIATION]. Here, so much conveys a high degree of positive evaluation with regard to the state of medical technology. There is not simply medical advancement or some medical advancement; there is so much of it. Throughout my analysis, I have used the categories upscale and downscale based on Körner (2009) to identify relevant instantiations of the Force function. I should also note that lexical items such as terrible as opposed to simply bad, repetition, and swearing can also embody the Force function (Martin and Rose, 2007, pp. 42-46).

Next, I will exemplify the category of Focus, which adjusts the prototypicality of an evaluation. Consider the following example in which one of the men I interviewed had been describing his reaction to learning about his HIV-positive status.

(4) It was kind of [SOFTEN] like a shock [-AFFECT]

This was not a real shock but only kind of one. Thus, this resource has the effect of softening the negative evaluation. Throughout my analysis, I have used the category soften to identify relevant instantiations of the Focus function.

\subsubsection{Conclusion of data analysis method}

The descriptions and exemplifications of the Appraisal analytical framework I have offered may give the impression that this kind of analysis simply involves identifying certain types of evaluation, grading, and stance taking in discourse as distinct semantic domains; however, each of the Appraisal subsystems functions together in 
discourse to represent different kinds of social identities (Martin and White, 2005; Martin and Rose, 2007; Körner, 2009). As Körner and Martin and Rose have emphasized, the evaluative meanings with which Appraisal is concerned unfold or resonate throughout discourse and are more than the sum of their parts. On the following two pages, Figure 3.3 visually illustrates how the Appraisal subsystems function together in discourse using data from Oscar's interview. 


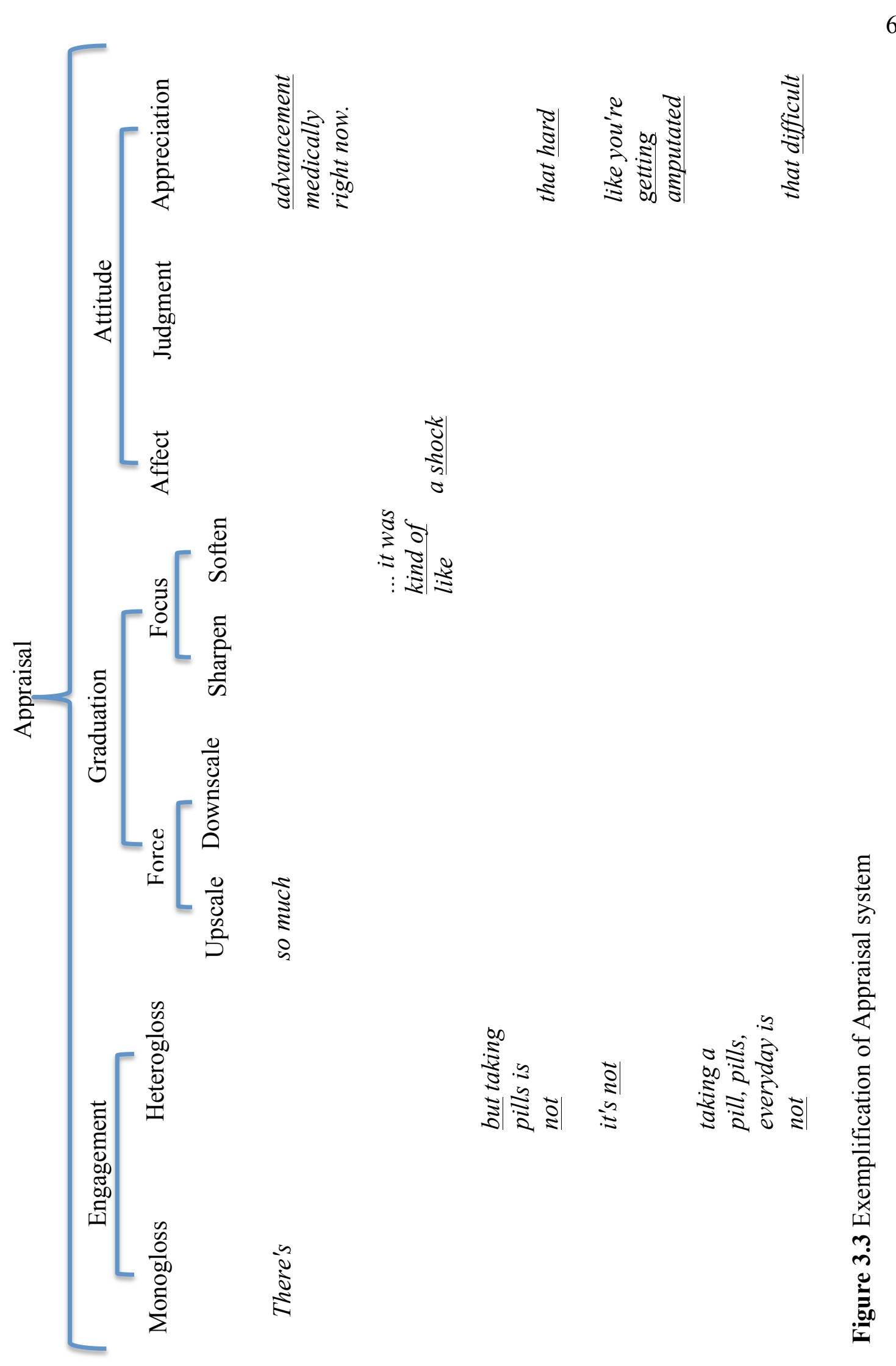




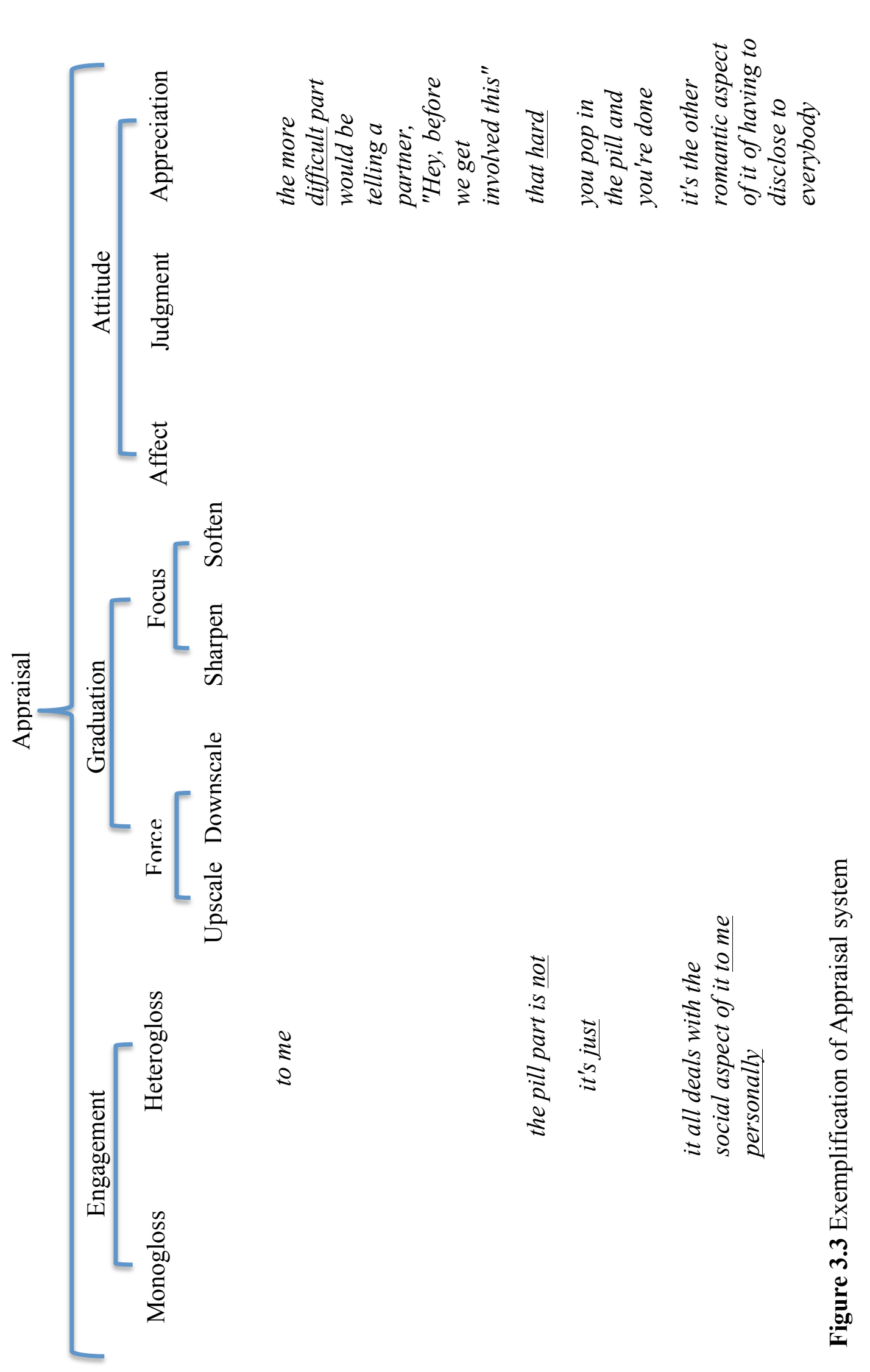


The analysis that I have done in Chapter 4 draws on existing typologies, makes functional interpretations of additional evaluative items, and exerts some effort in drawing connections among the three basic semantic domains as outlined in the basic Appraisal subsystems. I also use the evidence of such linguistic functions to argue through the lens of the tactics of intersubjectivity (Bucholtz and Hall, 2004; 2005) that the social identities of what I have deemed effective HIV manager and challenged HIV manager emerged, respectively, for the non-immigrant and immigrant men who I interviewed in relation to the heteroglossic notion that HIV is a manageable chronic illness. 


\section{Chapter 4: Analysis and Discussion}

This chapter reports on my analysis of the data and exemplifies my main finding. As discussed in Chapter 3, I selected discourse excerpts that best exemplify my main finding. The chapter is divided into three main sections. The first section describes the context of the HIV/AIDS organization through which I gained access to the men. The second section focuses on the three non-immigrant men's interviews. The third section focuses on the two immigrant men's interviews.

The rationale for dividing the chapter between non-immigrant and immigrant men is based on my main finding. The data reflect that each of the men I interviewed portrayed himself as an inexorable consumer of modern life-sustaining HIV medications. Unsurprisingly, the men simply evaluated their medications in terms of highly positive Appreciation. More interestingly, the discourse analysis elucidated a clear bifurcation between each group of men. The non-immigrant men typically used positive evaluative language when they talked about social practices associated with being a consumer of HIV medication. Thus, a social identity of effective HIV manager emerged in the nonimmigrants' interview discourse. In contrast, the immigrant men typically used highly graded negative evaluative language when they talked about these same social practices. In addition, the negative evaluative language that the immigrant men used often cooccurred with representations of income restrictions on obtaining assistance with expensive HIV medications. Specifically, the two immigrant men's evaluative language suggests that their social identities as independent and successful residents of the United States are threatened by the social structures and practices that constrain their access to 
life-sustaining HIV medications. Thus, a social identity of challenged HIV manager emerged in the immigrants' interview discourse.

In each of the immigrant men's interviews, where ideational meanings of medication and the health care system emerged, my analysis found negatively evaluative interpersonal meaning to be pervasive. In addition, such negative evaluation, particularly based on its frequency, was relatively highly graded in the immigrant men's interviews. Where such ideational meanings occurred in the non-immigrant men's interviews, evaluation was generally positive. In this chapter, I present the Appraisal analyses through the lens of the tactics of intersubjectivity. Using these two frameworks in conjunction affords a rich discussion of specific social structures, practices, and identities associated with the social construction of HIV/AIDS in relation to the health care system as it emerged in the context of this case study.

To be clear, each man reported having had social problems related to being HIVpositive. In addition, the five men's data evidenced intricate imbrications between the processes of negotiating their social identities as HIV illness managers. By structuring this chapter in terms of positive evaluations in the non-immigrant texts, on the one hand, and negative evaluations in the immigrant texts, on the other, there is no intention to trivialize any individual's experiences with HIV illness.

In fact, at approximately one hundred sixty pages, the data are copius, complex, and capable of corroborating findings from multiple extant studies on various social aspects of HIV/AIDS that have implications for men within the Latino community. More specifically, the data attest that local individual Latino men's experiences reflect findings 
in the literature on strategic disclosure of HIV status (Zea, Reisen, Poppen, \& Díaz, 2003; Zea, Reisen, Poppen, Echeverry, \& Bianchi, 2004; Zea, Reisen, Poppen, Bianchi, Echeverry, 2005), contradictions between knowledge and action with regard to HIV risk (Díaz, 1998), social constructions of hegemonic masculinity, machismo, and homophobia (Díaz, 1998; Organista, 2012), strategic safety sex practices (Körner, 2009), stigma (Díaz, 1998; Díaz, Sanchez, \& Schroeder, 2012), and alcohol and drug use as HIV risk factors (e.g. Díaz, 1998; Díaz, Sanchez, \& Schroeder, 2012). Such an abundance and complexity of data requires confining the basis of this chapter to a focused topic, and I have chosen to offer a comparison between the non-immigrant and immigrant men's respective positive and negative evaluations of the social practice of accessing financial assistance for accessing HIV medications. I should also note that the immigrant men's references to medications ubiquitously involved language that negative evaluated medication assistance, whereas the non-immigrant men's references to medications often lacked any mention of medical expense or assistance. My iterative analytical process, described in the previous chapter, led me to focus on this aspect of the data.

\subsection{Context: The HIV/AIDS advocacy organization}

The local HIV/AIDS advocacy organization through which I gained access to the men who participated in my study is a consortium that offers various services to their clients as well as their families. Their services are coordinated among 13 participating local organizations, including public and private medical organizations and social service agencies that also provide a range of services for HIV-positive persons. Social work and nurse case managers work with clients and their families based on need. All persons who 
are HIV-positive living in the four counties that make up our metropolitan area in Oregon are eligible for services.

Clients may access the organization on their own accord, through the organization's website or by way of a recommendation from a participating agency. Two of the men I interviewed reported that upon their HIV diagnosis, their medical institutions recommended they access services through the organization.

The organization provides a range of services. These include assessment, information, and referrals for assistance in accessing housing, nursing services, group and individual mental health counseling, substance abuse counseling, health insurance, and accessing health care and HIV medications. Of these services, the most relevant across my case study was accessing HIV medications.

The Federal Aids Drug Assistance Program (ADAP) provides funding to states to help HIV-positive persons access medications that are necessary to sustain their lives. States establish ADAP eligibility criteria, and criteria vary widely. Generally, basic eligibility is based on an income threshold calculated as a percentage of the Federal poverty level. At the time of my interviews, Oregon's threshold was approximately 300 percent of the Federal poverty level, which was approximately $\$ 35,000$. The two immigrant men I interviewed each reported that their medications cost approximately $\$ 2,000$ monthly. Fortunately, each currently had access to financial assistance.

Nevertheless, as illustrated in detail in Chapter 4, one man, Rofino, had quit his job as a result of his earnings placing him slightly above the established threshold. In addition, he had discontinued the use of his medications for five years while working that 
job. He reported that Oregon did not have a sliding scale for its ADAP assistance and that earning any amount more than the established threshold resulted in disqualification. Thus, those earning $\$ 35,500$ would have to pay, according to both immigrant men's medical expense reports, $\$ 24,000$ annually for their medications. The difference that results here, then, is $\$ 11,500$, which is equivalent to the relevant Federal poverty level. Rofino also told me during his interview that he had pled to no avail with appropriate authorities to help him gain access to assistance in such a way that allowed him to continue working. He also told me that he had plead to no avail with his employer to slightly reduce his hours in such a way that allowed him to access medications. Although the other immigrant man, "José," did not report having exactly the same problem, he conveyed a strong sense of fear that his circumstances could change and that he would face a similar situation as Rofino reported. The non-immigrant men did not address such a concern in their interviews.

I should note that I was unable to identify sources that adequately presented information about ADAP eligibility criteria in an understandable way. In their book on HIV/AIDS in the Deep South, Whetten and Pence (2013) made a similar observation: Some programs designed to provide assistance to low-income and/or disabled HIV-positive persons include Medicaid, Medicare, the Ryan White HIV/AIDS Program, AIDS Drugs Assistance Programs (ADAPs), Social Security programs, and food stamps. Each program has its own set of eligibility and reeligibility criteria, with eligibility lasting for differing amounts of time in each program. The programs have complex application forms and it often takes months and 
sometimes years to obtain approval for any single benefit. Often initial applications are denied, and if the person decides to reapply an appeal is required. Even case managers, the authors of this book, and research assistants have difficulty understanding the eligibility criteria and application processes for each of these systems. (p. 98)

As far as I was able to determine, each of the men I interviewed had accessed assistance through one of these programs. The organization's director told me that a major task for her social work case managers was to help clients access ADAP funds. Based on the numbers that the immigrant men reported, it is likely they had accessed funds through ADAP. It remains unclear exactly how the President's Affordable Care Act might affect this program.

\subsection{Non-immigrant men's discourse}

As set forth in the summary above, each man, regardless of immigrant status, represented as a common social identity being a consumer of modern life-sustaining HIV medications. According to Bucholtz and Hall (2005), social identities are discursive products that emerge in interaction and are partial accounts of the relations between structures and individual agency. These theorists also noted, in light of the work of Dubois, that "the display of evaluative, affective, and epistemic orientations in discourse" is one specific way that language can embody the tactics of intersubjectivity (p. 595). In this section, I use Appraisal to discuss discourse excerpts that exemplify the kinds of positive evaluations of the health care system that I found to typify the discourse of the three non-immigrant men, Oscar, "Mark," and "Charlie." I concurrently use the tactics of 
authorization/illegitimation and adequation/distinction to discuss how such evaluations in these men's interviews signal an ideology of HIV as a manageable chronic illness alongside the social identity of effective HIV manager.

\subsubsection{Oscar}

Oscar, a non-immigrant Latino man, was the first participant I interviewed. Oscar insisted on using his actual first name. He told me that he hoped his words would positively impact other HIV-positive Latino men. Thus, Oscar had imagined a specific, though unknown, intended audience outside the immediate interview context. In the following paragraphs, I analyze and discuss discourse excerpts that exemplify Oscar's positive evaluations, intersubjective alignment/disalignment in relation to discourses of HIV being a manageable chronic illness or not, and the fact that he referred to medications during the interview without referencing problems related to financial assistance.

At the outset of the interview, I asked Oscar to describe himself. His selfdescription, unsurprisingly, marks the initial emergence in this text of Oscar's social identity as an effective HIV manager. Example (1) illustrates the Appraisal analysis of Oscar's self-description.

1 Hopefully [ENTERTAIN], positive [+AFFECT]. I've had the mishaps [-AFFECT] of the things

2 that have happened and stuff,

3 but [COUNTER] I try to look positively [+JUDGMENT/+AFFECT] to everything as much as

4 possible [SOFTEN] and try to make the best [t:+JUDGMENT/t:+AFFECT] of every situation.

5 This is not [DENY] my worst [-AFFECT], by no means [FOCUS].

6 It doesn't [DENY] have to be the end of it [t:-JUDGMENT], either.

7 When you were describing [ENTERTAIN] the stuff with your dad [t:-JUDGMENT], 
8 I was just like [COUNTER] there's [MONOGLOSS] So much [UPSCALE]

9 advancement [+APPRECIATION] medically right now where people are living a lot

10 longer and probably [ENTERTAIN] normal [+APPRECIATION/t:+JUDGMENT]. I've had friends

11 that have died back in the nineties that didn't take care of themselves medically or

12 anything [t:+JUDGMENT], and [COUNTER] I'm trying to do my best to take care of myself

13 and live a normal life [+JUDGMENT/:+AFFECT] as much as possible [SOFTEN]

Consider first the ideational meanings in example (1). In each of the interviews, I

found the general idea of life with HIV, whether explicitly represented or not, to be

ubiquitous in the discourse. Given the context and purpose of the interviews, this finding was unsurprising. In example (1), this idea is the referent of the deictic this and the impersonal pronoun it. Oscar's language also represents himself, his own activities, others, and their activities. Specifically, $I$ represents Oscar, your dad represents my father, friends represents deceased HIV-positive persons who Oscar had known knew in the nineties, and advancement medically represents modern life-sustaining medications. Finally, there is the representation of historical change in terms of the availability of lifesustaining HIV medications. The time adverbial right now and comparative form longer in lines 9-10 function to represent the contemporary sociohistorical context in which lifesustaining HIV medications are available. In contrast, the past tense verbs and decade reference in the relative clauses that have died back in the nineties and that didn't take care of themselves or anything describing friends in lines 11-12 represent the sociohistorical context prior to the advent of these medications.

In terms of the relevant interpersonal meanings, it is necessary to describe the heteroglossic backdrop against which Oscar's identity as an effective HIV manager emerges. The intertextual fulcrum takes the form of Oscar's reporting verb describing, which he attributes to me in line 7. This Engagement resource expands the dialogic space 
to include my telling the story about my father to Oscar prior to the interview. Specifically, I had told Oscar that as far as I had known, my father had never sought lifesustaining HIV medications nor been diagnosed as HIV-positive until the final week of his life. What this means is that the heteroglossic backdrop includes a representation of a challenged HIV manager, one who did not take advantage of modern life-sustaining medications.

In relation to such a heteroglossic backdrop, I was just like in line 8 functions as a Counter that contracts the dialogic space between Oscar's opinion, the highly graded Appreciation evaluation so much advancement medically and the idea that an HIVpositive person would not take action to benefit from modern medical technology that can result in living longer and normal. It is noteworthy, too, that the existential phrase there's, which introduces so much advancement, is a monoglossic abeyance and does not engage with additional textual voices at all, thereby briefly closing the dialogic space altogether; there's is distinct from there's probably or there's usually, for example. This particular combination of Engagement and Attitude resources works, then, to make an assumption that HIV is a manageable chronic illness for all.

This same assumption emerges in lines 10-13. As mentioned above, the ideational representation here is of Oscar's friends who had died in the nineties, presumably before the advent of life-sustaining HIV medications. In relation to the heteroglossic backdrop I have hitherto described, this proposition sets up a parallel contrast between now and the nineties. Such a contrast has the effect of evoking tokens of negative Judgment, which connote anachronistic aberrance in lines 6-7. In other words, HIV being fatal in the 
nineties was normal but is now anomalous simply because life-sustaining medications are available. Note that the discourse does not include representations of medical expense, literacy, or other specific problematic issues that could potentially challenge one's access to or success with medications. Thus, there is an implication that the mere existence of modern medical technology entails access to and use of this innovation.

From the perspective of the tactics of intersubjectivity, the Appraisal analyses in the preceding paragraphs can show how Oscar's evaluations embody the relation authorization/illegitimation, which "considers the structural and institutional aspects of identity formation" (Bucholtz and Hall, 2005, p. 603). As the theorists have cogently expressed, "interactional dynamics may shore up ideological structures even in the absence of a locatable powerful authority" in the Gramscian process of hegemony. I would not argue that Oscar is a powerful authority figure, but his discourse in Example (1) appears to be sensitive to a hegemonic ideology that does not acknowledge issues that could impede one's access to HIV medications.

From a more individual perspective, the Appraisal analysis in Example (1) can show how Oscar's language embodies the tactic of adequation/distinction and functions to portray a social identity as an effective HIV manager. In line 1, for example, he describes himself as positive, a lexical item that works to position Oscar as someone who has been relatively successful in managing the illness. More saliently, however, Engagement resources of Counter and Deny distinguish Oscar's position from that of an ineffective HIV manager by challenging negative evaluative voicings. In lines 2-3, for example, Oscar acknowledges I've had mishaps then counters with but I try to look positively. 
Additional examples of distinction as Deny and Counter occur respectively in line 5, $\underline{\text { not }}$ my worst, by no means, and line 12, and I'm trying to do my best to take care of myself and live a normal life. These examples serves to distinguish Oscar's position from those of seriously challenged HIV managers while locating his relatively powerful individual agentive capacity to take care of himself within the authorized social structure of health care that I have described above.

As shown in Figure 4.1, both pairs of tactics, authorization/illegitimation and adequation/distinction, are inextricable. The figure summarizes how Oscar's evaluative language in Example (1) embodies each pair as the structural and individual agency components that constitute his emergent identity as an effective HIV manager.

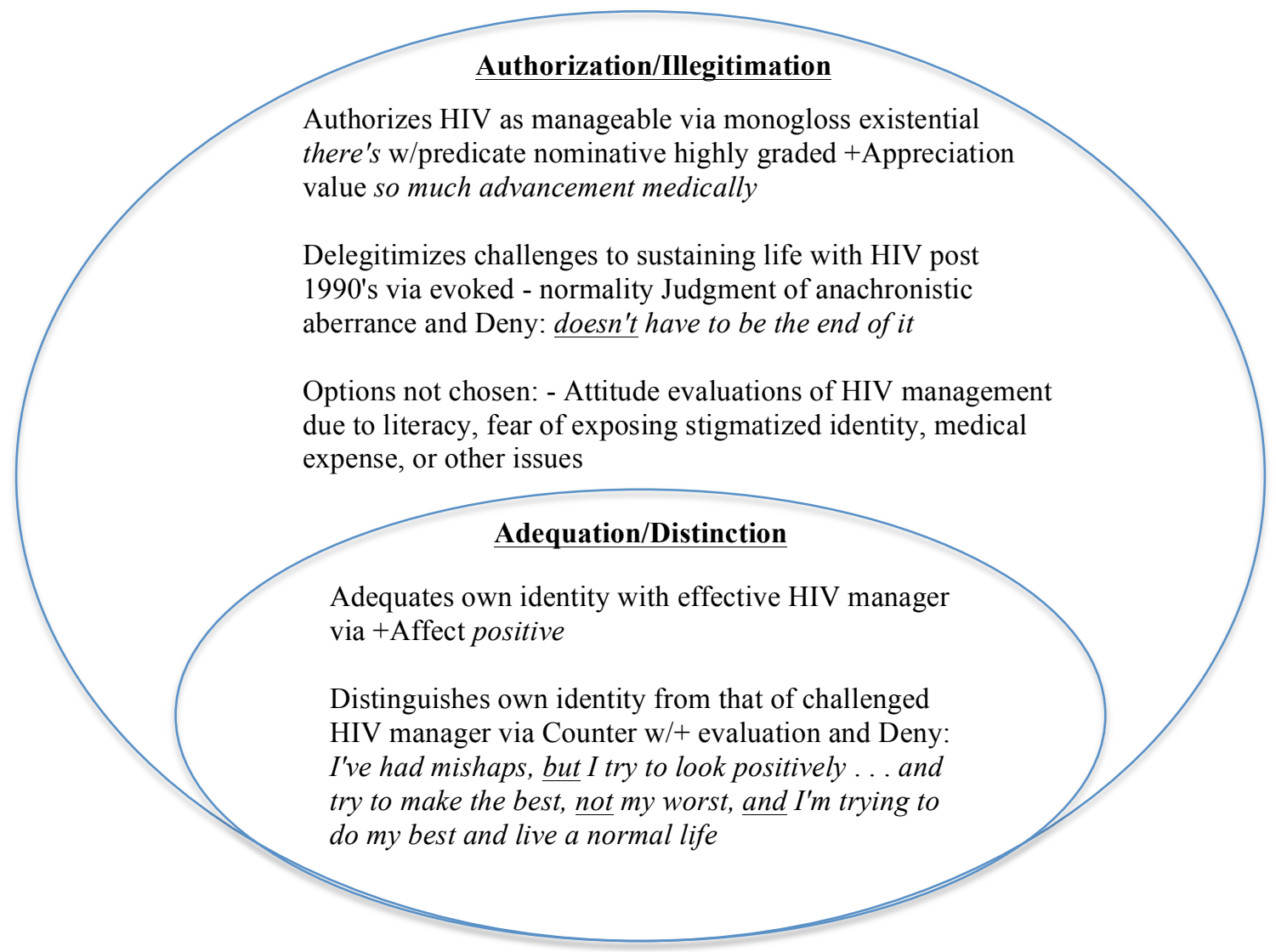

Figure 4.1 Intersubjective alignment/disalignment with regard to HIV management in Example (1). 
As Bucholtz and Hall have stressed, "because identity is inherently relational, it will always be partial, produced through contextually situated and ideologically informed configurations of self and other" (2005, p. 605). The analysis above strategically reentextualizes Oscar's words to emphasize subjective differences between the nonimmigrants' and immigrants' discourse in the specific context of this research project. In Example (1), Entertain values such as hopefully in line 1 and probably in line 12 reflect that Oscar's discourse leaves his effective HIV manager identity somewhat open to contestation. In other words, Oscar does not report being a fully capable individual agent with respect to managing HIV. Overall, however, in Example (1) Oscar's discourse represents the use of medications without referring to medical expense or other financial burdens. Such a representation sharply contrasts from the immigrant men's representations, which I discuss in the following section.

As in Example (1), the discourse in Example (2) is sensitive to a hegemonic ideology of HIV as perfectly manageable with modern medications.

1 O: When you run the risk [-JUDGMENT] of doing something, you do it and you just

2 hope for the best, and then when they told me I had it, then I mean it was

3 kind of [SOFTEN] like a shock [-AFFECT], but [COUNTER] I mean taking pills is

4 not $_{\text {[DENY] that hard [-APPRECIATION]. }}$

5 I mean it's not [DENY] like you're getting amputated [-APPRECIATION][FORCE].

6 O: So, taking a pill pills every day is not [DENY] that difficult [-APPRECIATION].

7 To me [ENTERTAIN], the more difficult [-APPRECIATION] part would be telling a partner

8 "Hey, before we get involved this ..."

9 W: sure, yeah

10 O: The pill part is not [DENY] that hard [-APPRECIATION]. It's just [COUNTER] you pop in

11 the pill and you're done [t:+APPRECIATION], but [COUNTER] the, I mean, it all deals with

12 the social aspect of it to me personally [ENTERTAIN]. I mean, although my friends

13 know and everything it's the other romantic aspect of it of having to disclose to 14 everybody [t:-APPRECIATION]. 
Before discussing the Appraisal analysis, I first need to describe the context and ideational meanings in Example (2). Immediately prior to the excerpt, Oscar had been talking about his seroconversion and had just told me about having been sexually involved with someone whom he had thought monogamous but later discovered had been "running around loose." Oscar's talk had implied his belief that this sexual activity had led to his seroconversion. Thus, run the risk in line 1 refers back to Oscar's sexual activity with this person. Prior to Example (2), Oscar had also told me that upon learning his serostatus he had initially been "totally shocked." The example shows Oscar elaborating on the description of his initial reaction. Finally, Oscar is comparing taking HIV medications to a perceived obligation to disclose his HIV status to future sexual partners.

As far as the interpersonal meaning in Example (2) is concerned, the most critical instance for purposes of my argument occurs with but in line 3. This Counter value disaligns Oscar's position in relation to a heteroglossic backdrop fraught with fearful expectations regarding managing HIV. The disaligment also manifests as the softening Graduation resource kind of. Crucially, the Counter value introduces in lines 3-4 a representation of HIV medications. This analysis offers insight into the pattern of disalignment from negative heteroglossic attitudes, beliefs, and expectations regarding HIV management through the use of medications that was typical throughout Oscar's interview discourse.

Also striking in Example (2) are the Deny and Counter values shown in lines 4-6 and 10. These Engagement resources disalign from heteroglossic voicings that view the 
physical consumption of HIV medications as problematic. Taking HIV medications is $\underline{\text { not }}$ that hard, not like you're getting amputated, not that difficult and just ... pop in the pill and you're done. I would later learn that Oscar has overcome some struggles with medication side effects, and the dialogistic contraction manifest in these Engagement resources works to challenge heteroglossic concerns about side effects resulting from the use of HIV medications. Here, Oscar seems to not only express his own opinion but also to invite his imagined audience to disalign from such concerns as well.

Lastly in Example (2), note the Entertain value to me personally in line 12. This Engagement resource works to expand the dialogic space and construe a heteroglossic backdrop that includes differing opinions. At the same time, this resource aligns Oscar's subjective position in such a way that prioritizes his worries about disclosing his HIV status to future sex partners over his concerns about using medications.

In sum, Oscar's language in Example (2) interacts with a heteroglossic backdrop that includes generally fearful expectations associated with managing HIV. Importantly, however, Oscar's disalignment from such expectations is associated with a representation of HIV medications. Subsequently, his Engagement resources challenge heteroglossic concerns about medication side effects. Although the Engagement with negative opinions regarding side effects is interesting and potentially serious, key to my argument is the fact that Oscar's discourse does not manifest a heteroglossic backdrop that includes concerns about accessing HIV medications. As will become evident, such concerns pervaded the immigrant men's interviews. 
In terms of the tactics of intersubjectivity, Example (2) exemplifies authorization and distinction. While Oscar's discourse disaligns from a heteroglossic backdrop laden with the negative emotion of fear via a representation of medications, there is no heteroglossic backdrop that includes problems associated with actually accessing medications. Thus, there is an implicit assumption that the existence of medications equals access. Such an assumption tacitly authorizes the discourse of HIV being a manageable chronic illness. The Deny and Counter resources as well as the Entertainment value to me personally also emphasize Oscar's differences from those who face serious challenges resulting from HIV medication side effects. Figure 4.2 summarizes how Example (2) embodies these related tactics. 


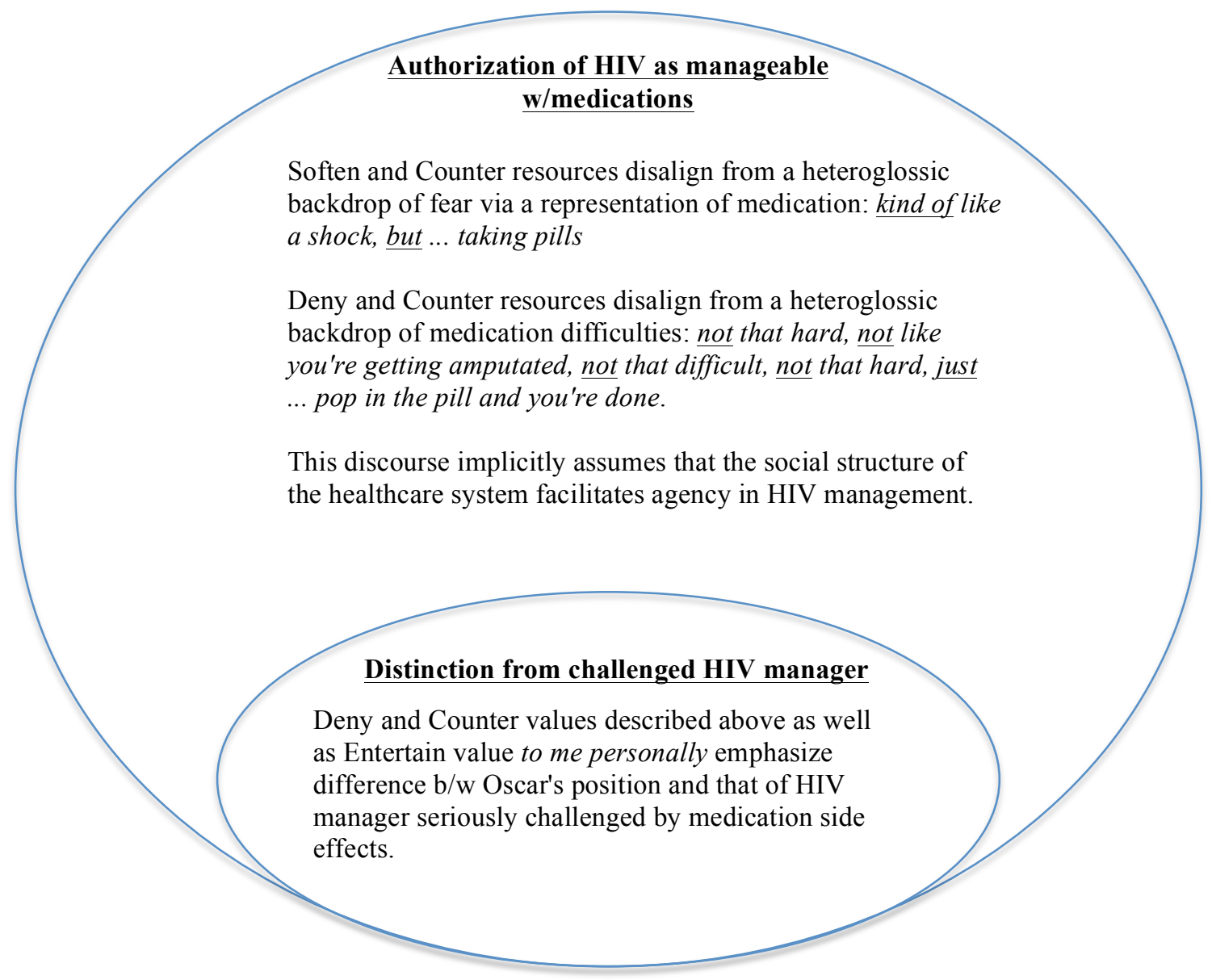

Figure 4.2 Intersubjective alignment/disalignment with regard to HIV management in Example (2)

Example (3) shows Oscar concluding a highly positive evaluative segment about the local HIV advocacy organization that connected me with him for the interview. The organization helps people living with HIV and their families in myriad ways, including facilitating access to health care and HIV medication prescription assistance through the Federal Ryan White CARE Act or Medicaid. Immediately prior to Example (3), Oscar had portrayed himself as a "great" procrastinator and had stressed that "you don't even have to procrastinate it" because "they're gonna call you and make every appointment." He had continued, "You can't get your meds? Guess what? They'll send 'em to you in the 
mail." By having portrayed himself as such a procrastinator for whom the system had worked so well, Oscar's discourse conveyed the sense that anyone else would be capable of successfully navigating the health care system and managing HIV as well as he has.

1 O: And, I don't know how it is far as medically how it would be dealt with with 2 somebody that's let's just say doesn't have that's an um, not legally here, 3 but [COUNTER] I know [PROCLAIM] that my case worker has dealt with people with 4 that and has managed to get them healthcare [t:+JUDGMENT $t:+$ APPRECIATION].

5 W: great

6 O: And, that's another aspect it's kind of an interesting thing it's like you know if 7 you don't have it I can, you know, there's some there's [MonogLoss] a way to get 8 it,

9 W: mm-hmm

10 O: healthcare, here even [COUNTER] if you're not a citizen.

11 W: mm-hmm

12 O: And, that's what I tell people, you don't have to they're not gonna turn you

13 down you're not [DENY] gonna get turned down

14 for something like this [t:-APPRECiATION]. There's [MONOGLOss]

15 a way to do it and a way to get healthcare [t:+APPRECIATION]

Example (3) opens with a proposition that denies knowledge of how the healthcare system that has worked so well for Oscar might work for undocumented or non-citizen Latino immigrants. Despite this initial claim of ignorance, the analysis shows several instances in lines 3,10, and 12-13 of Counter and Deny resources that contest negative expectations about the system among Oscar's imagined audience. For example, but I know that my caseworker . . has managed to get them health care. Moreover, such is the case even if you're not a citizen.

The analysis in Example (3) also shows two instances of briefly monoglossic utterances in lines 7 and 14. Existential there's, as in Example (1), again works to make an assumption. Here, the assumption is that accessing healthcare to manage HIV is 
relatively unproblematic because there are no Engagement resources nor other linguistic features that adjust the opinion about access to healthcare.

The analyses described in the preceding two paragraphs suggest that Example (3) functions in the overall interview discourse to diminish differences between and thus adequate, in terms of the tactics of intersubjectivity, the social identities of Oscar and his imagined audience with respect to being an effective HIV manager. In addition, what allows for the construction of this adequation is the hegemonic ideology or implicit authorization that managing HIV illness with medications is a relatively unproblematic process. Figure 4.3 illustrates how Oscar's evaluative language embodies these tactics of intersubjectivity. 


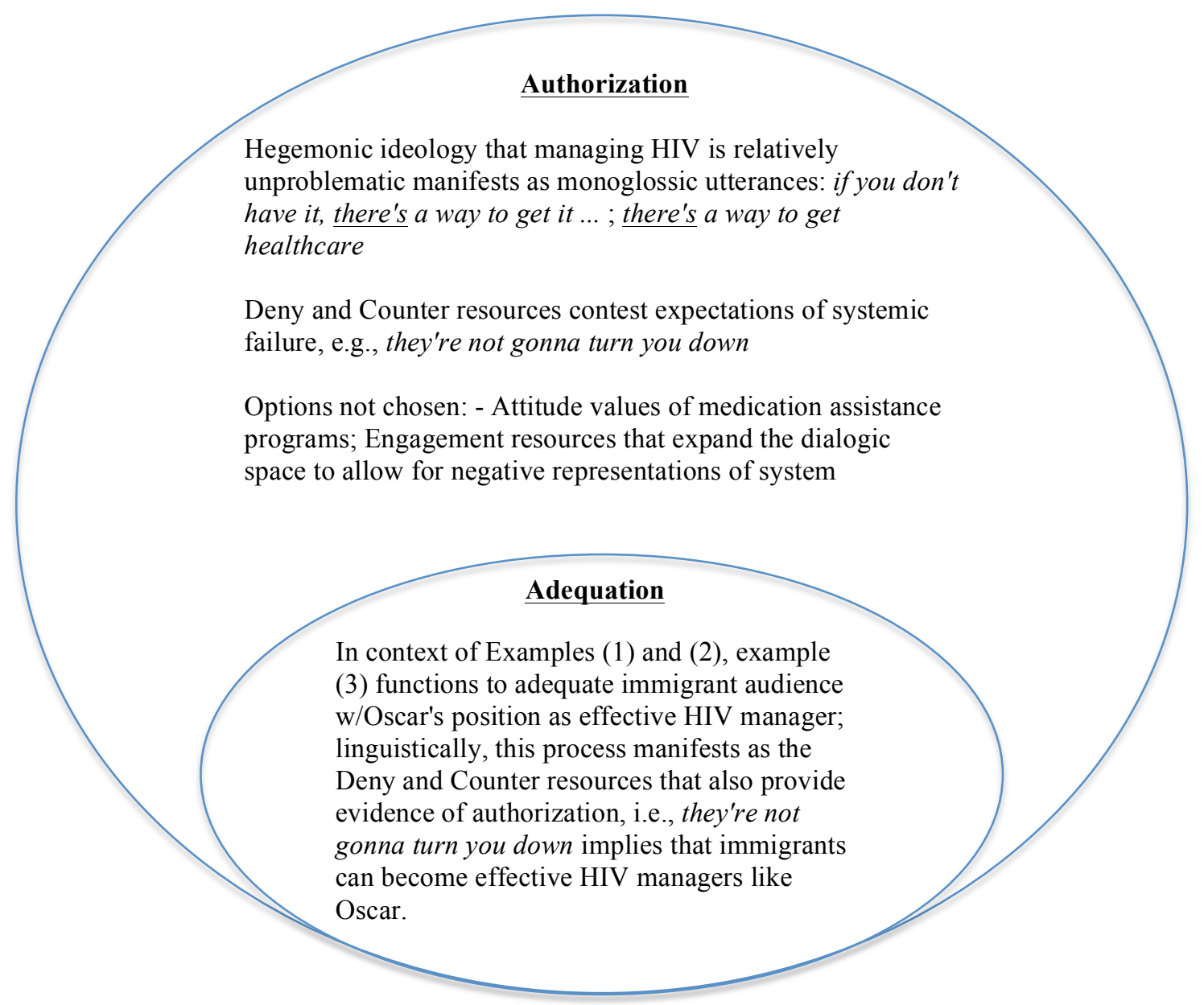

Figure 4.3 Intersubjective alignment/disalignment with regard to HIV management Example (3)

In summarizing Oscar's discourse, it is important to review the general functions of Engagement resources in each example. Counter and Deny values tend to contest negative heteroglossic evaluations of managing HIV. Such resources function to distinguish Oscar's subject position from that of the challenged HIV manager and to adequate the subject positions of an imagined audience of undocumented Latino immigrants with Oscar's social identity as an effective HIV manager. Each of these 
processes functions in relation to the assumption, which I have described as a hegemonic ideology, that accessing modern life-sustaining HIV medications is relatively unproblematic. This assumption manifests in Example (1) and Example (3) as the temporarily monoglossic utterances there's so much medical advancement and there's no way you're going to get turned down. Most importantly, Oscar's discourse only obtusely represents the need for systematic healthcare among HIV-positive Latino men, and where such acknowledgment occurs, Engagement resources function to contest any serious concerns.

\subsubsection{Mark}

"Mark" is the second non-immigrant man who participated in the project. Mark told me that his parents had "done everything that they were supposed to do . . like always looking for my education." Even though Mark described his family as having limited resources while he was growing up, he represented himself as relatively privileged, describing his education at an exclusive small university as "toney." Mark had earned a Masters degree with an emphasis on dramatic texts, which made him the most highly educated of all the men I interviewed. Mark possessed an artistic constitution and described himself as "rambunctious," "spirited," "iconoclastic," and "creative."

In the following paragraphs, I analyze and discuss discourse excerpts that provide evidence that Mark portrayed himself in the interview as an effective HIV manager who has had few problems with using HIV medications to control his illness. The excerpts also show that Mark did not report having problems with actually accessing assistance for purchasing his medications. Where representations of HIV medications emerged in 
Mark's discourse, he typically used positive evaluative language and downplayed problems. Overall, Mark's language had the effect of representing a discursive identity of a confidently capable HIV manager. Evidence of this claim is borne out in the analyses below.

Example (4) illustrates the first representation of HIV medications in Mark's interview. Here, he is answering my question about how he had responded upon learning about his HIV status. Immediately prior to this excerpt, Mark had mentioned the advent of life-sustaining HIV medications in 1996. Having taken up his comment, I had made the remark that the literature often refers to this historical event as having marked HIV as no longer being a death sentence.

1 M: When I received the news, I was like ok. I didn't [DENY] cry [-AFFECT]. I remember 2 thinking I'm not [DENY] gonna cry [-AFFECT]. I mean I knew about about the like

3 it's no longer like I knowing that it wasn't [DENY] a death sentence

4 W: mm-hmm

5 M: because in two thousand seven I'd had a sexual partner that was positive, um 6 W: ok

7 M: and he told [ATTRIBUTE] me that he was positive, and he told [ATTRIBUTE] me about

8 his drug regimen like that it was like just [COUNTER] pill and like he

9 explained [ATTRIBUTE] to me about being undetectable [t:+APPRECIATION] um he

10 explained [ATTRIBUTE], he educated me in such a patient and loving way

11 [+JUDGMENT/+AFFECT], and this is just someone that like I only met with two or three 12 times.

Example (4) resembles a passage that Körner (2009) used to illustrate "treatment optimism" (p. 119). There are two values of Deny associated with the negative Affect resources cry in lines 1-2. These Engagement resources dialogically contract the heteroglossic backdrop charged with notions of emotional devastation resulting from 
being HIV positive. An additional Deny value rejects the notion of HIV being a death sentence, evincing Mark's perception that HIV is a manageable illness, in line 3 . In line 5, Mark draws a causal connection, manifest as because, between his knowledge and the educational voice of a past HIV-positive lover, manifest as the Attribute values in lines 710.

Before further discussing the analysis in Example (4), it is necessary to briefly explain the term undetectable. According to AIDS.gov, viral load is the number of virus particles or copies in a milliliter of blood. The website also points out that the goal of HIV treatment is to reduce the levels of virus particles to an undetectable level, which is under 40-75 copies per milliliter. Moreover, the website explains that "having a low viral load greatly decreases the risk that you will pass HIV to someone else through sexual contact." As Körner (2009) has elucidated, monitoring one's viral load is sometimes a resource that HIV-positive gay men use when negotiating safe sex practices.

Mark's report of his past lover's words is paramount to the overall evaluation in Example (4). The description includes the Counter just connected to the word pill in line 8. This Engagement resource contracts the dialogic space in such a way that challenges heteroglossic opinions that using HIV medications would be more problematic than simply swallowing the material. In addition, the positive Appreciation value undetectable immediately follows in line 9 . Such a sequence suggests that Mark recalls having assumed upon learning his HIV status that he would be able to use medications effectively enough to achieve the best of all current possible outcomes, reducing his viral load to an undetectable status. 
Similar to Oscar's discourse, Example (4) is interesting for the fact that there is no interaction with a heteroglossic backdrop rife with concerns about paying for HIV medications. On the contrary, the excerpt shows a representation of HIV management as relatively unproblematic with modern medications. This is a remarkable observation given the pervasiveness of negative evaluation and disalignment from heteroglossic voicings of HIV manageability associated with representations of HIV medications and the concomitant negative evaluation of assistance with accessing the medications in the immigrant men's discourse that I will analyze in section 4.2 .

In terms of the tactics of intersubjectivity, Example (4) emphasizes authorization and distinction. The Deny values described above reject heteroglossic concerns that managing life with HIV is emotionally devastating, distinguishing Mark's social identity from that of an ineffective HIV manager. Of course, managing the illness hinges on the use of medications. The Counter just contests heteroglossic voicings that there is more to using the medications than simply swallowing the material. Mark has also recalled expecting the best possible outcome resulting from using medications. Importantly, there are no linguistic resources that interact with a heteroglossic backdrop fraught with concerns about actually accessing medications. The Engagement resources in Example (4), then, collectively work to draw an implicit ideology that discursively authorizes the social identity of an effective HIV manager. Figure 4.4 provides a visual summary of how the Appraisal resources embody Mark's intersubjectivity. 


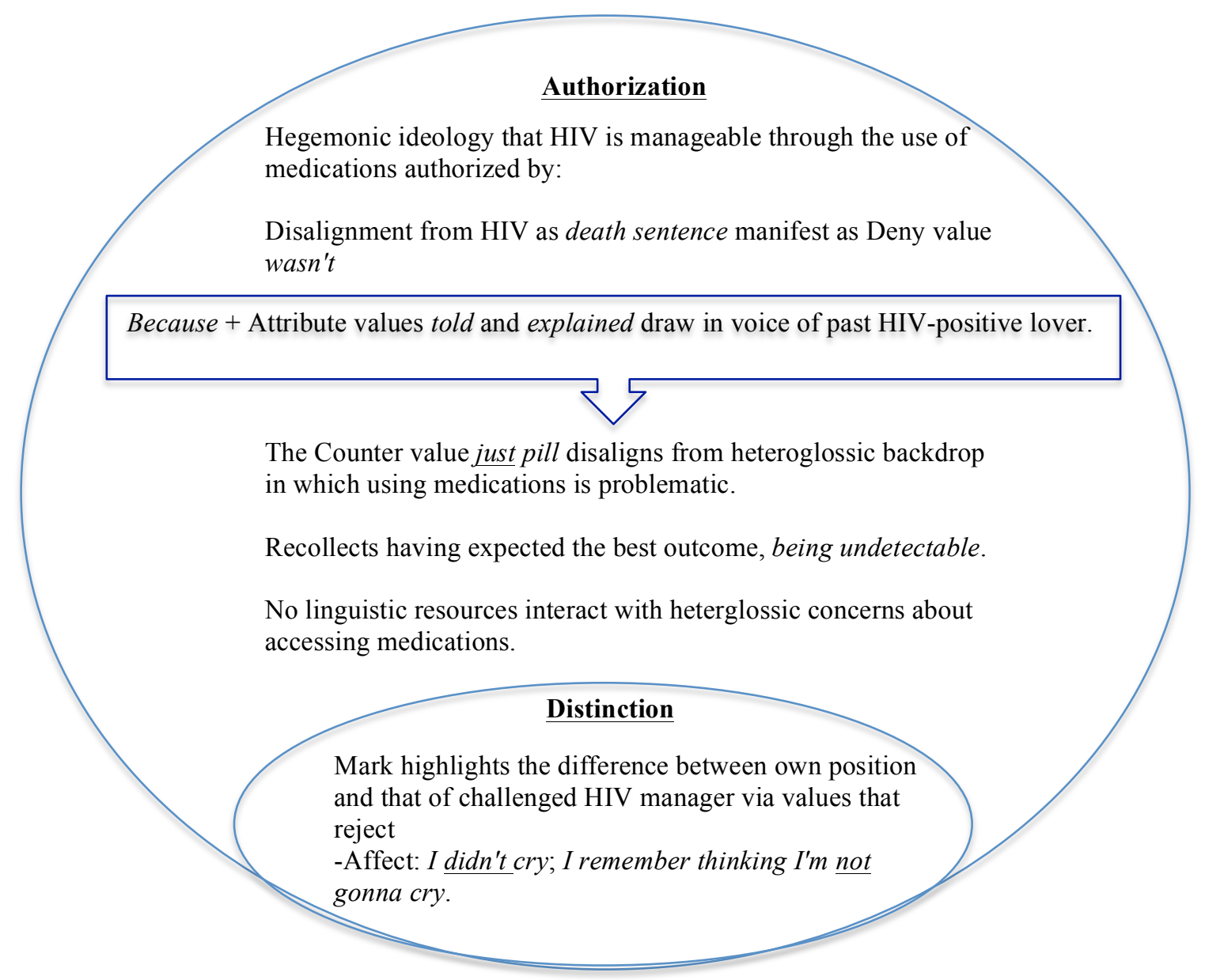

Figure 4.4 Intersubjective alignment/disalignment with regard to HIV management in Example (4)

Mark did represent certain social institutions as having encumbered the agency of HIV positive persons. Specifically, in response to a question about media and government efforts to educate people about HIV in comparison to the informal education described above in Example (4), Mark emphasized that these institutions had "done a terrible job." Particularly upsetting to him were his views that fear and punishment had been deployed in government and media campaigns that seek to prevent and reduce HIV risk and transmission. Nonetheless, the analysis in Example (5) suggests that Mark's 
positive evaluation of the healthcare system supplants such negative evaluation. This excerpt shows the discourse that emerged immediately following Mark's litany of harsh criticisms of media and government educational efforts.

1 So when I first got diagnosed, I like I had a meeting with a social worker and a 2 doctor on the same day and like they were like like I it was like crossing into like 3 oh, I'm positive now [t:-AFFECT], 4 but [COUNTER] I had no idea of this like

5 medical world that was like waiting for me $[\mathrm{t}:+$ APPRECIATION/t:+AFFECT] .

In Example (5), line 3 shows a token of negative Affect evoked by the interjection oh, I'm positive now. This token imparts the sense that Mark does indeed recall having had some fear upon learning about his status. Critically, the subsequent instance of but in line 4 signals a challenge to a heteroglossic backdrop involving attitudes that there is no health support for people living with HIV. This challenge issues forth as I had no idea of this ... medical world that was ... waiting for me and suffuses the discourse with a sense of pleasant surprise, coded as tokens of positive Appreciation and Affect. I should note that Mark's intonation influenced my interpretation here. Consequently, Example (5) conveys that media and government misrepresentations of HIV illness and HIV-positive persons as entities to fear and punish led Mark to think that the social structure of the healthcare system would probably also fail him; however, his positive evaluation has diffused such negative evaluation and left the impression that the healthcare system has functioned as a social structure that facilitates rather than constrains individual agency in managing HIV illness. 
From the perspective of the tactics of intersubjectivity, it should be clear that Example (5) represents the healthcare system's authorization of an effective HIV manager social identity. Of course, Mark's highly negative evaluations regarding government and media campaigns of fear and punishment embody the tactic of illegitimation; however, Mark's final positive evaluation seems to prioritize the functionality of the healthcare system over the other dysfunctional representations of the other social structures.

Example (6), the final excerpt I discuss from Mark's interview, involves Mark talking about what he has learned about himself since he learned that he is HIV-positive. Again, the discourse includes representations of medications and positive evaluative language.

1 M: I always [ENTERTAIN] take my medication. Um, and that's there there's

2 something, yes [CONCUR], ritualistic [t:+APPRECIATION] about it, um, you know, it's sort

3 of like a body of Christ like moment [t:+APPRECIATION].

4 W: uh-huh

5 M: like where everyday like this is what's keeping me alive [t:+APPRECIATION], and I

6 remember like having like that externalness externality to life like like this is

7 what's gonna let me live healthy [t:+APPRECIATION], um, as I don't know, it really

8 maybe [ENTERTAin] like deepened my relationship to myself [t:+APPRECIATION] like by

9 externalizing

10 W: mm-hmm

11 M: that relation

In Example (6), Mark appears to have drawn on his identities as a creative writer and, perhaps, Catholic to metaphorically compare his use of medications to the Eucharist in lines 2-3. As shown in the subsequent positive tokens of Appreciation coded in lines 58, Mark has clearly experienced a vibrant sense of renewal as a result of his using HIV medications. 
The Engagement resource of Entertain in line 1 conveys the sense that Mark's representation of always taking medications is his subjective option chosen from other possible constructions such as usually or never. Additional Engagement resources of Concur and Entertain in lines 2 and 8, I suspect, reflect the interaction between Mark's social position as writer/artist and my social position as researcher. These linguistic resources perhaps reflect a hesitancy on Mark's part to fully align with such constructions in relation to a "researcher" who may have been viewed as a seeker of objectively verifiable causal explanations.

In terms of the tactics of intersubjectivity, Example (6) most directly reflects adequation/distinction via Mark's use of always. This Engagement resource positions Mark's subjectivity on a cline of always/usually/sometimes/rarely/never that might reflect one's effectiveness in managing HIV illness. This works to both adequate Mark with the social identity of an effective HIV manager and distinguish him from the position of a challenged HIV manager.

In summarizing the analysis and discussion of Mark's discourse, I have provided evidence that Mark has used evaluative language that has represented a social identity as an effective HIV manager, the construction of which has been contingent upon positive representations of using medications. Crucially, Mark's discourse did not involve negative language about financial burdens as a result of accessing medications. I have identified instances in which Mark's evaluative language embodies the tactics of adequation/distinction and authorization/illegitimation. Importantly, too, the Engagement resources in Mark's discourse, along with representations of HIV medications, generally 
function to reject and challenge heteroglossic backdrops that are fecund with notions that HIV is burdensomely challenging to manage. Such constructions, as I will show in section 4.2, contrast sharply with those of the immigrant men.

\subsubsection{Charlie}

The third and final non-immigrant man I interviewed called himself "Charlie." Charlie had been living with HIV since the early 1990's, before the advent of lifesustaining medications, a fact that puts him in the fairly unique social position of being a "long-term survivor" of HIV/AIDS. Tez Anderson, a self-described long-term survivor, has written about some of the issues facing this group, and there is now a National HIV/AIDS Long-Term Survivors Awareness Day in recognition of their and their loved ones' struggles. (see Anderson, 2014, for more information.) Because of a misunderstanding regarding scheduling, I was unable to effectively manage Charlie's interview in such a way that allowed me to ask him all of the questions I would have liked.

Charlie told me stories of absolute brutality and abuse that he had suffered at the hands of his father and a male sibling over the years. Unfortunately, I am unable to address those issues here, but I want to make clear that Charlie, like all the men I interviewed, has faced numerous problems in various social domains related to his identity as a gay man as well as his HIV status.

Overall, I did learn that Charlie felt very fortunate to be alive. He attributed his survival in large part to his decades-long partner, a fairly asexual man whom Charlie described as being "kinda like a saving grace". Of course, medications and the health care 
system also played a crucial role in Charlie's survival. His descriptions of HIV medications and the health care system were very positive, and he did not report any problems when he was talking about these topics.

In the paragraphs below, I analyze and discuss the single discourse excerpt in which Charlie referenced medications during his interview. My analysis argues that Charlie made an assumption that HIV medications are generally accessible.

Like Oscar, Charlie's response to the story about my father early in his interview marked the emergence of his position as a capable HIV manager. Example (7) shows Charlie asking for clarification as to when my father had died.

1 C: So how long was this? Was it before the uh the medications came out?

2 W: No, this just happened about three years ago.

3 C: Oh my goodnesS [-AFFECT/T:-JUDGMENT][UPSCALE].

From an Appraisal perspective, line 3 encodes a highly graded negative Affect response as an interjection. The most appropriate lexical item that could replace this interjection is perhaps shock. Apparently provoking Charlie's strong response is his assumption, instantiated as the second question in line 1, that my father had died before the advent of life-sustaining medications. Thus, Charlie's negative emotional reaction also imbues his emotional response in line 3 with a negative token of Judgment. Similar to Oscar's evoked Judgment Appraisals in Example (1), Charlie's interjection evaluates the behavior of not using modern HIV medications as archaically aberrant.

Even though Example (7) is very short, the interaction draws on the ideology that HIV is a perfectly manageable illness. My claim is based specifically on the assumption I 
have described above. Given Charlie's experience of having lived with the illness through some of its darkest historical moments, it would indeed be difficult to imagine him constructing the illness in any other way. My purpose in identifying this ideology is to emphatically distinguish Charlie's experience from those of the immigrant men whose discourse I discuss in section 4.2. Like the other non-immigrant men, Charlie did not refer to financial burdens with regard to accessing medications.

\subsection{Immigrant men's discourse}

In this section, I provide analyses of selected discourse excerpts from the two immigrant men's interviews. As mentioned, the immigrant men evaluated their ideational representations of HIV medications very differently than did the non-immigrant men. When the immigrant men talked about these topics, their discourse was always fraught with fear, worry, anger, and criticism, particularly with regard to the impact accessing medications has had on their sense of financial independence.

Much of this negativity occurred as the immigrant men complained about their perceptions that the medication assistance system had constrained their capacity to enact their identities as independent persons. There is a relatively low income threshold, approximately $\$ 35000$ annually at the time of the interviews, established for gaining

access to assistance in accessing exceedingly expensive HIV medications, and each of the immigrant men told me that, without assistance, the medications that keep them alive would cost about $\$ 2000$ per month. Although each of them had such assistance, they also used negative evaluative language to represent the system as constraining their agency in earning more than the assistance program allowed. This issue pervaded both of their 
interviews, whereas none of the non-immigrant men explicitly mentioned medical expense.

The issue of expense may be associated specifically with immigrant status because each of the immigrant men differed on a number of other demographic variables. "José" had little formal education, whereas Rofino had completed a higher education program after immigrating. José worked as a manual laborer and in restaurants, whereas Rofino had secured a job in his field of study. José identified as heterosexual, whereas Rofino identified as gay. Considering these differences, the similarity between these two men's discourse is very striking.

The issue of expense is more complex than the high cost of medications alone. For each of these men, maintaining a sense of financial independence appeared to be a core value. As the analyses below will show, each man represented a highly valued social identity of a financially independent worker as being under threat as a result of the relatively low income requirements for obtaining assistance with accessing HIV medications. Indeed, this issue so pervaded each of these men's discourse that it would have been irresponsible to have not centered the thesis on this topic.

In the following two sections, I analyze and discuss selections of discourse from each of the immigrant men's interviews in turn. From the perspective of Appraisal, I attempt to show how this issue has prevented or frustrated these men's enacting of capable HIV manager subject positions in their respective discourse data. Where helpful in elucidating the dissonance between the structure of the health care system and the 
agency of these individual men in managing their illness, I also draw on Bucholtz and Hall's tactics of intersubjectivity.

\subsubsection{José}

José's interview was challenging for each of us. He was visibly upset, and his negative affect manifest in both his linguistic and paralinguistic behavior, swearing and crying for example. At times, I felt very uncomfortable as the interviewer and even suggested we stop the interview at one point because José appeared extremely distraught; however, he adamantly insisted that we continue. Perhaps, José felt like he had something to gain from continuing even though talking about his experience with HIV appeared to be so unsettling.

Obviously, José did not want to elaborate on certain topics. The most interesting of these topics emerged when José answered my request asking him to describe himself. He had responded,

I consider myself heterosexual. Have I been with men? Yes, I have. Uh, how can I consider myself heterosexual? When I was younger I run away from home. Uh, so I run away from home at one time, you know, another, more than once. Obviously, didn't have no place to stay, no food, no nothing, kind of had to sell myself, you know. Life is tough. You gotta do whatever you need to do. You gotta survive. This is life.

This response provides crucial background context for the analyses and discussion that ensues because it situates José's trajectory as an immigrant from a starting point of economic circumstances so difficult that he had had to sell his body to other men to earn money. 
As illustrated in the quote above, José often took control during the interview, presenting questions then providing answers himself. This kind of rhetorical pattern may have been characteristic of his conversation style, but I interpreted it as a strategy to preempt my questioning and probing for information that he preferred not to address or elaborate. Regardless of the reason, much of the discourse that transpired in José's interview involved such rhetorical patterns. These types of questions functioned as Engagement resources in José's interview, manifesting interesting heteroglossic backdrops in relation to José's subjective positioning.

In the following paragraphs, I analyze and discuss discourse excerpts that illustrate the pervasiveness of José's negative evaluation and intersubjective disalignment from the discourse of HIV being a manageable chronic illness. More specifically, I show that José evaluated in highly positive terms his sense of financial independence and reported as one of his major problems a fear that he would become financially dependent as a result of the process of accessing HIV medications.

The discourse shown in Example (9) occurred early in the interview after José took up my remark that the stigmatization of HIV illness is pervasive in the U.S. South. Relevantly, I had not asked José a question here; he had simply begun talking. Here, José had concurred that HIV illness is generally stigmatized and described a process of selfstigmatization that he himself had experienced. In Example (9), he was elaborating further.

1 And then you know I don't [DENY] even [COUNTER] know what happens with the 2 disease itself. Do I wanna know? I don't [DENY] know. What's there in the future? 
3 Am I going to have a whole bunch of wounds in my mouth? I don't [DENY] know. Is 4 there gonna be a time where life is not worth living [t:-APPRECIATION]? Will I be

5 strong [+JUDGMENT] enough to understand it? What happens when the quality of life

6 when one has been self-sufficient [+JUDGMENT] all of his life

7 how do you become dependent [t:-JUDGMENT]?[ENTERTAIN][t:-AFFECT][UPSCALE].

The Engagement resources in Example (9) disalign José's subjective position from a heteroglossic backdrop of attitudes that view HIV as a manageable illness. One specific presumption in this backdrop is that there is a relatively secure and healthy future for HIV-positive persons who are using medications. Values of Deny and Counter coded in lines 1-3 reject such heteroglossic voicings. Additionally, the subsequent rhetorical questions instantiate the Entertain function, insinuating the answer I don't know, which heteroglossically manifest the possibilities that there may come a time when life is not worth living and that José will not be strong enough to understand it in lines 4-5. These resources also collectively evoke an amplified token of negative Affect evaluation in that they convey a strong sense of fearing an uncertain and potentially unhealthy future.

Crucially, the last question, shown in lines 5-7 introduces representations of selfsufficiency and dependence within such a fearful context. Within the context of José's interview, then, the notion of self-sufficiency, particularly financial independence, is positive whereas the notion of dependence and related ideas are negative. I have, thus, accordingly coded these representations in terms of Judgment.

After the talk shown in Example (9) had occurred in the interview, I asked José if he felt that he had been able to maintain his self-sufficiency at all. Excerpt (10) displays how he responded. 
1 J: I done all right [CONCUR][DOWNSCALE].

2 W: uh-huh

3 J: There, has there been trouble [-AFFECT]? Has there been issues? Is there

4 questions? Yeah [Concur], many of them. Uh, obviously [Concur], I get

5 helped with medicine [t:-JUDGMENT]. Who's gonna buy two thousand dollar

6 medicine every month [CONCuR]? I mean,

7 W: right

8 J: unless [ENTERTAIN] you make ten, twenty thousand dollars a month. I mean,

9 unless [ENTERTAIN] you're a doctor, a lawyer, an architect, somebody not only,

10 even [COUNTER] with a degree, it's not [DENY] enough [UPSCALE].

Example (10) again involves a heterglossic backdrop in which José's financial independence is under threat. Here, his discourse specifies the negative possibilities Entertained in Example 9. In addition, values of Concur and Entertain disalign José's position from notions of effective HIV management while constructing his subjective position as a less effective HIV manager than others. Line 1 shows a code of Concur assigned to done alright. While this resource disaligns José's position from a heteroglossic backdrop of challenged HIV management, the lexical item all right downgrades this disalignment, conveying the sense that José is not thoroughly convinced about his answer. Critically, the subsequent Concur value in line 4 functions in an almost directly opposite way in that it disaligns José's position from a heteroglossic backdrop comprising interpretations that he has had no trouble, issues, or questions. Most importantly, José has represented as a specific problem his inability to pay for his own expensive HIV medications. The Concur value shown in line 6 identifies an instance in which one of José's rhetorical questions has disaligned his position from a heterglossic 
notions of effective HIV management, having the effect of conveying his opinion that the cost of HIV medication is ludicrously and problematically expensive.

Example (10) also represents a socioeconomic system that, in José's opinion, functions to allow only a select few to become truly effective HIV managers, who are persons requiring no financial assistance with accessing HIV medications. The values of Entertain in lines 8 and 9 expand the dialogic space and reflect that José views his position as one among others. These others are also much more economically privileged and include doctors, lawyers, and architects. Furthermore, the Counter and Deny values in even with a degree it's not enough, coded in line 10 function to represent educated persons as not being capable of effectively managing HIV, which of course also works to amplify José's represented incapacity. The overall result is a highly graduated indictment of a system that has positioned José in such a way that threatens his highly valued sense of financial independence.

In terms of the tactics of intersubjectivity, Example (10) exemplifies distinction and illegitimation. The Concur values work to disalign or distinguish his position from heteroglossic manifestations of notions of manageability in terms of paying for his medications independently. In addition, the Entertain resources of unless in conjunction with the Counter and Deny values in even with a degree it's not enough highlight the difference José has constructed between his subject position and those of more privileged others who have greater capacity to effectively manage HIV. José's language has also worked to indict a social structure that constrains the individual agency of people in positions such as his in relation to the process of effectively managing HIV. The overall 
effect is a discursive construction of a challenged HIV manager social identity for José.

Figure 4.5 summarizes José's intersubjective alignment/disalignment in Example (10).

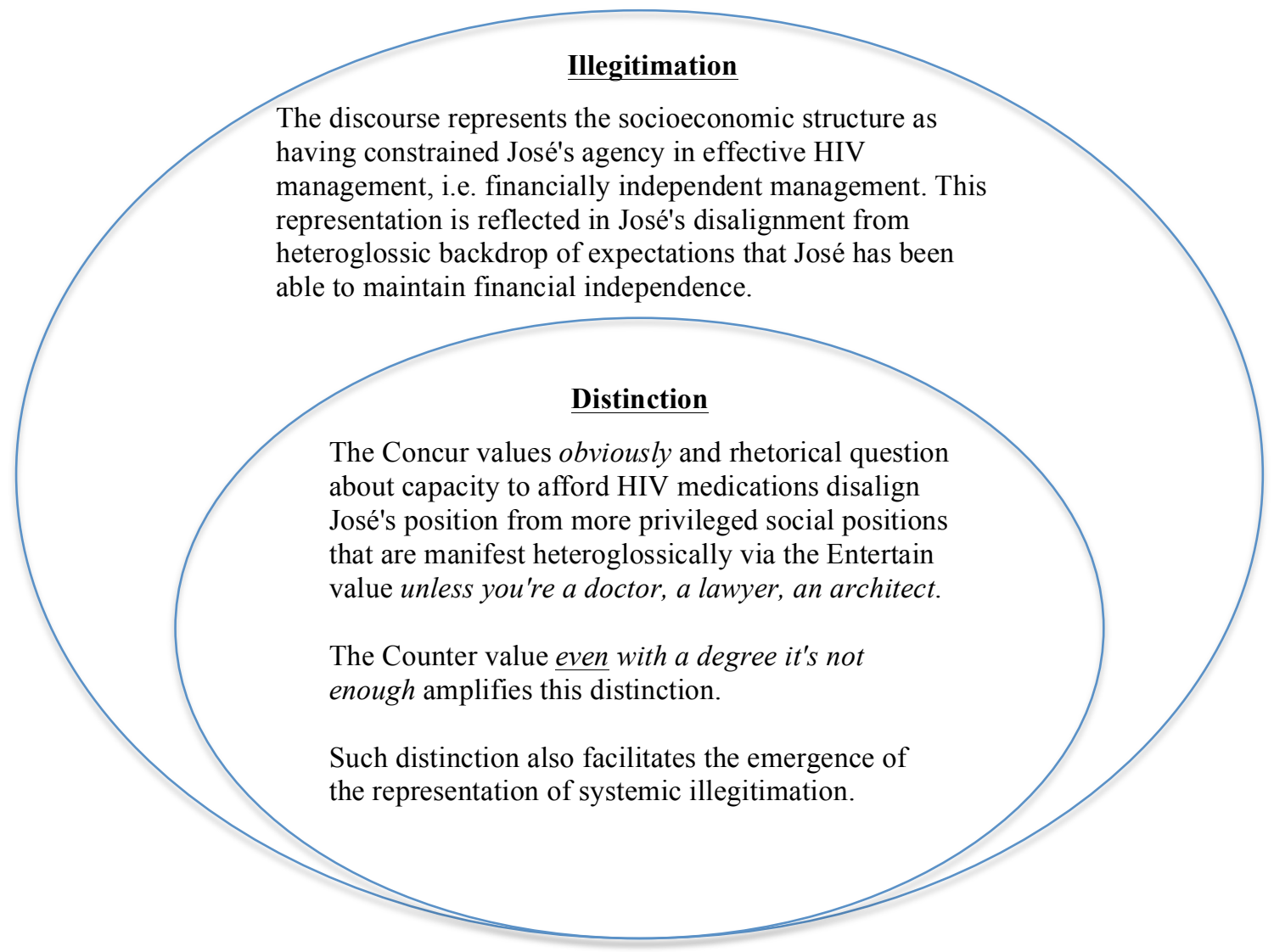

Figure 4.5 Intersubjective alignment/disalignment with regard to HIV management in Example (10)

José not only feared the loss of his financial independence, but he also represented the bureaucratic negotiations involved in obtaining assistance in accessing his medications frustratingly problematic. During another segment of the interview, José told me that he was required to complete paperwork every six months to renew his eligibility for assistance and indicated that this process was very burdensome. The discourse in Example (11) displays one of many instances in which José damningly evaluated these 
negotiations as "jumping through hoops." Elsewhere in the interview, too, José had briefly described growing up in México and told me, "There was never a question when we had to go to the doctor, no issue, no nothing." Example (11) occurred in the interview immediately following the discourse from Example (10).

1 but [COUNTER] then, you know, you still [COUNTER] gotta

2 jump through hoops [t:-APPRECiation]. You still [COUNTER] gotta do things. Uh, there's

3 a, there will always be, it will be impossible to think [PRONOUNCE] that having a

4 deadly [-APPRECiaTION] disease is not gonna affect [t:-AFFECT] you. It will be impossible

5 to think [PRONOUNCE] that having a, uh having your life on the line [t:-AFFECT] will not

6 depress [-AFFECTI you. And, what happens when if you're depressed

7 [-AFFECT] and you still [COUNTER] gotta jump through hoops [t:-APPRECIATION] and you

8 will to do everything else disappears [t:-JUDGMENT]?

9 Then where, where you get left out? [t:-AFFECT]

In Example (11), the Engagement resources construct a heteroglossic backdrop of expectations that, with the medical assistance José had previously mentioned, HIV is a manageable illness. Values of Counter, coded in lines 1 and 2, along with the negative descriptor jump through hoops construct a disalignment from a heteroglossic backdrop involving systemic expectations of autonomy on the part of the HIV manager in the United States. Values of Pronounce, coded in lines 3 and 5, resist heteroglossic opinions that having a deadly disease will not affect you or that having your life on the line will not depress you. The discursive proximity of the values of negative Affect therein, moreover, implies a perception on José's part that there is a causal connection between his represented frustrations in managing the process of obtaining medical assistance and his negative Affect evaluations. 
José's final evaluation in Example (11) is shown in the token of evoked negative Affect tagged in lines 7-9. Here, José ultimately appears to fear losing access to his medications as a result of his depression's impeding his capacity to successfully negotiate the bureaucracy associated with applying for Aids Drug Assistance Program funds.

Thus far, I have argued that José constructed a representation of the United States' socioeconomic system as having constrained his agency as a capable HIV manager. Despite these representations, José also represented this same system, at least implicitly, as having enabled his agency as a relatively successful immigrant. José had told me during his interview "I'm just a regular guy like everybody else . . . like the billions and billions of people with a $401 \mathrm{~K}$ with an IRA. I'm just a regular person." This utterance functions, in the terms of tactics of intersubjectivity, to adequate José's position with subjects within mainstream U.S. culture. José's position here thus emerges as a fairly successful "middle-class" immigrant within the mainstream socioeconomic and cultural systems of the U.S. Much of José's negative representations of his capacity to effectively manage HIV, then, likely result from the tension in trying to reconcile his social identity as a successful immigrant with that of a challenged HIV manager.

Example (12) provides additional evidence for the tension described in the previous paragraph. This discourse occurred immediately after José had severely criticized what he described as the hypocrisy of celebrity activists. His tirade had prompted me to ask whether he thought money was a "corrupting influence." 
1 J: I'm not I'm not [DENY] an anarchist. I think [ENTERTAIN] I'm a capitalist.

2 But [COUNTER], I think [ENTERTAIN] money is just a, it's just [COUNTER] a means, and I

3 think [ENTERTAIN], you know, sometimes [ENTERTAIN] it

4 gets in the way [t:-APPRECIATION], and sometimes you know, I mean, what happens

5 if I make more money? If I can even [COuNTER] get the freaking medicine then? I

6 mean what happens if something happens? I mean when is when? [t:-AFFECT]

7 What if [ENTERTAIN] it's better to be a welfare mom [t:-JUDGMENT] than it is to go to

8 work [t:JUDGMENT]? What if [ENTERTAIN] it's better to collect unemployment [t:-

9 JUDGMENT] than, what if [ENTERTAIN] it's better to collect food and stamps and

10 everything else [t:-JUDGMENT and, you know, you get a bigger paycheck than

11 actually going to work for McDonald's [t:+JUDGMENT]?

12 W:Well, yeah, I guess everyone has to make those decisions and

13 J: Yeah, kind of, kind of [SOFTEN], but [COUNTER], you know, everybody has to kinda

14 [SOFTEN] make their own decisions, but [COUNTER] the reality of things is the reality

15 of things, and the reality is not [DENY] gonna change. A hundred dollars is a

16 hundred dollars and if this pays a hundred dollars and this pays fifty, the choice

17 is obvious [PRocLaIM]. So there's no [DENY] rule everybody has to make their own

18 choice. Sometimes [ENTERTAIN] the choice is already made.

Example (12) constructs a contentious heteroglossic backdrop of a socioeconomic struggle between the middle-class faith in capitalism and the more radical social and economic idea of anarchism. José initially rejects heteroglossic voicings interpreting his being an anarchist in line 1. Nevertheless, three instances of the Entertain value I think, coded in lines 1-3, expand the dialogic space and allow for additional interpretations of José's stance in relation to the economic system that he had represented as functioning well for him until he learned about his HIV status. José had told me elsewhere in the interview that working hard and saving money had always been very important to him, but these Entertain values seem to disalign his position from the representation of capitalist and the synecdochically related lexical item money. 
What José's negative evaluation of money, it gets in the way, means is that he could potentially lose the assistance he receives for accessing his medications if he earns too much money. Too much money here is roughly 300 percent of the Federal poverty level, which at the time of the interview was slightly less than $\$ 36,000$ annually. In other words, if José earns more than that amount, he will likely be paying nearly $\$ 24,000$ annually for his life-sustaining medications. José fears this possible scenario, and I have tagged his expressions of fear as negative Affect and Appreciation in lines 6 and 7.

José also makes highly negative, even potentially offensive, evaluations of those who do not or cannot work throughout lines 7-12. Note that in line 7 , he asks what if these values are better? These lines represent his fear that me may become a welfare mom rather than a self-reliant person who would actually ... work for McDonald's.

In lines 14-19, José explicitly constructs a discourse in which individual agency is constrained by the economic system. He Counters my comment about individual agency then elaborates using two proclamations and finally concludes that sometimes the choice is already made. Here, the lack of grammatical agent represents challenged HIV managers whose independent agency is constrained by criteria for accessing medication assistance that position them as unable to simultaneously pay for medications and earn more money than the prescription benefits program allows.

In terms of the tactics of intersubjectivity, the discourse I have described in this section from José's interview embodies adequation/distinction and authorization/illegitimation in a rather complex fashion. On the one hand, José has adequated himself with the average financially independent middle-class American 
subject and distinguished himself from those less fortunate people who must rely on assistance. In so doing, his discourse seems to construct a system that has authorized a social identity that José evaluates positively. However, José has also made clear that he fears that the American system that has worked so well for him in certain ways is now potentially disempowering him by stripping him of his individual agency. José's fear of losing his agency works to represent the American socioeconomic and the Aids Drug Assistance Program (ADAP) income criteria as operating to make illegitimate José's construction of a capable HIV manager persona in his interview discourse. Thus, there is not only a tension between José's more familiar identity of financially independent immigrant and his newer identity of HIV manager, but also a tension between José's representations of the socioeconomic and the ADAP system.

\subsubsection{Rofino}

Rofino was the second and last of the two immigrant men I interviewed. As I have mentioned above, even though José and Rofino differ on a number of demographic variables, the analysis resulted in a similar pattern of Appraisal in their discourse about managing HIV. In the following paragraphs, I analyze and discuss discourse segments that exemplify Rofino's subject position with respect to the management of HIV illness through the use of life-sustaining medications.

In Example (13), Rofino is concluding a longer segment in which he had been describing his initial reaction to learning about his HIV status.

1 And, that's what I I came out was thinking and say to others not use a condom it

2 doesn't [DENY] matter sometimes a publicity has a, the 
3 mistake [-APPRECIATION] to say [ATTRIBUTE] oh we we find a cure for HIV or things like

4 that, you know, and what what they're doing is like or we have already medication

5 no one [DENY] is gonna die now from HIV because now we have medication.

6 W: mm-hmm

7 R: And and that that's great [+APPRECIATION] for them [ENTERTAIN] because they

8 still need more customers for, with HIV, so they can sell those drugs,

9 but [COUNTER] the bottom line is why don't they say [ATTRIBuTE], you know, uh, we

10 have more medications for for uh people with HIV but still [COUNTER] take care of

11 yourself because we haven't [DENY] find a cure?

12 R: You know what I mean, but [COUNTER] they don't [DENY] do that. They just

13 W: So do you, it sounds it sounds like you see you kind of see a

14 conflict [-APPRECIATION] between the interests of the drug companies and prevention 15 messages.

16 R: Absolutely [CONCUR].

It is first necessary to provide an ideational description of Example (13). Here, Rofino is talking about people who choose not to use condoms because he perceives them to have been influenced by certain advertisements that, in his opinion, have portrayed HIV as actually curable through the use of modern medications. The interpersonal meanings are interesting in this context.

The Engagement resources in Example (13) disalign Rofino's subjective position from a heteroglossic backdrop of HIV being a curable illness through the use of medications. Importantly, the lexical item say, coded as Attribute in line 3, holds pharmaceutical companies accountable for constructing such a heteroglossic backdrop in society through advertising. Rofino has evaluated this heteroglossic representation as a mistake in line 3.

The analysis most clearly elucidates Rofino's disalignment in lines 9-12. Here, two Counter values of but collectively work to position Rofino's subjectivity against the backdrop of pharmaceutical companies' failure to adequately convey the message that 
HIV is indeed something that men should try to avoid. Recall from section 4.1 that Mark had criticized fear-based HIV risk prevention and reduction campaigns. In contrast to Mark, Rofino appears here to be calling for campaigns that, not necessarily through fear tactics, do represent HIV as something more difficult to deal with than his interpretation of the pharmaceutical companies' representations in Example (13).

More interestingly, Rofino suggests that the drug companies are benefitting from more seroconversions, and he connects pharmaceutical profits to what he views as the misrepresentation that one can cure HIV. Rofino describes this situation as great, but he grounds this positive Appreciation in the subjectivity of the drug companies, which the analysis identifies as the Entertainment value for them in line 7 . In addition, line 16 shows a value of Concur where Rofino has affirmatively taken up my clarification request as to whether he sees a conflict between the interests of drug companies and prevention messages.

I would later discover that Rofino, like José, highly values his financial independence and capacity to work. In fact, Rofino had actually been earning more income than the qualifying threshold for prescription assistance. Because Rofino had so highly valued his financial independence and specific job, he had decided to forego his medications for five years rather than quit his job in order to put himself below the threshold for receiving assistance. It is relevant, too, that in order to satisfactorily perform his job, Rofino had been unable to reduce the number of hours he had worked. In Example (14), Rofino is concluding a longer stretch of discourse that had begun with his 
talk of having discontinued the use of medications, which led to his health deteriorating and forced him to quit his job.

1 R: Right, but what I see with that is so now ok or I stop

2 working [t:-APPRECIATION] in order for me to get the to

3 qualify for the medication [t:+APPRECIATION] because out of pocket with the

4 insurance that I had I had to pay close to it was like eighteen hundred a month,

5 out of pocket, [t:-APPRECIATION] and that

6 W: wow

7 R: just for prescrip-, just for prescription

8 W: wow

9 R: You know, and so ok so I did that, I paid eighteen hundred a month so how

10 much I had left for my rent, for my food, for my, you know, so there is my

11 poverty level that they want [t:-APPRECIATION/t:-JUDGMENT]

Rofino had already told me earlier in the interview that he loved to work and highly valued being financially independent. Example (14), then, constructs a conflict of values similar to the one that emerged in José's discourse. Like José, Rofino's discourse has represented two conflicting social identities in relation to the general socioeconomic system and income criteria in programs such as the Aids Drug Assistance Program (ADAP). On the one hand, Rofino has represented himself as a relatively successful, financially independent immigrant; on the other hand, he has represented his social identity of a financially independent immigrant and capacity to work as under threat by the low-income threshold for utilizing HIV medication assistance programs.

Later in the interview, I asked Rofino about his experience receiving help through local HIV/AIDS organizations. Example (15) shows part of his response. 
1 R: In general, I can say that they have I have been I have to be

2 thankful [+AFFECT] for the agencies cause they have been at least

3 helpful [+APPRECIATION/t:+AFFECT] On my part, but [COUNTER] again, I haven't really

4 need anything

5 W: mm-hmm

6 R: Uh, cause I had work all these years [t:+APPRECIATION], but [COUNTER] I know people

7 that they receive services [t:+APPRECIATION] and they have been very maybe not

8 working for years [t:-APPRECIATION]

9 W: mm-hmm

10 R: and receive the services [t:+APPRECIATION], you know, and these people looks

11 healthy [+APPRECIATION]

12 W: mm-hmm

13 R: to me, but [COUNTER], uh, again they're probably doing the same thing, you

14 know, [ATTRIBUTE] I'm not I don't qualify for for my medications so I have to be

15 poor [t:-APPRECIATION/t:-JUDGMENT/t:-AFFECT].

In Example (15), Rofino initially evaluates his experience with local service organizations and the organizations themselves in positive terms, i.e., thankful and helpful in lines 2 and 3. The resource of Counter, coded in line 3, however, challenges a heteroglossic backdrop of opinions that these organizations have significantly helped Rofino. He had told me during another section of the interview that he expected to soon need help paying his rent and other expenses due to the fact that he had had to quit his job. Here, he seems to be disaligning from heteroglossic voicings that HIV is very manageable specifically because he can no longer maintain financial independence while effectively managing his illness.

The Counter value coded in line 6 subsequently challenges heteroglossic voicings that the organizations might not be able to significantly help Rofino from his current position by introducing representations of people who have maintained the appearance of health. Nonetheless, an additional Counter value, coded in line 13, again disaligns 
Rofino's position from his perception of a truly effective HIV manager, i.e., one who is capable of concurrently maintaining his social identity of successful immigrant.

In concluding Rofino's section, I present a general review then describe how the Appraisal resources I have identified embody the tactics of intersubjectivity by identifying exemplary instantiations from the examples presented above.

Rofino represented two different but related social structures, the socioeconomic system of the United States and HIV medical assistance programs. The former had facilitated Rofino's agency, thus authorizing the social identity of a financially independent immigrant. The latter, however, had constrained Rofino's agency in reconciling this identity with the identity of an effective HIV manager. He represented these two social identities in either/or terms. This conveyed the sense that what he had achieved was not the construction of a truly effective HIV manager social identity but a challenged HIV manager. In excerpts not discussed here, I also identified numerous Engagement resources that functioned to disalign Rofino's subjective position from heteroglossic voicings that construct HIV as a manageable illness because he represented himself as having been forced to live in poverty.

Example (13) also represented the pharmaceutical industry as having authorized the idea that HIV is actually curable. Rofino challenged such a representation via the negative evaluation mistake as well as additional Engagement resources that functioned to disalign his position from this idea. This resistance embodies Rofino's distinction from representations of the effective HIV manager. 
Also, the Appraisal resources in Example (14) manifest distinction on Rofino's part from his view of the effective HIV manager. Primarily, this distinction manifest as the negative Attitude Appraisal of so there's my poverty level they want. At the same time, such an evaluation instantiates the tactic of illegitimation because it illustrates systemic constraints on Rofino's agency in constructing an effective HIV manager social identity.

Finally, Example (15) exemplifies adequation. There, Rofino's discourse constructs similarities between his position and those of other HIV-positive persons who are also in poverty due to the income constraints on obtaining medical assistance. The adequation manifest via the taking on of others' voices and saying I don't qualify for my medications so I have to be poor. Of course, the adequation here also represents the system's constraints on agency once again in Rofino's representations of an effective HIV manager.

Figure 4.6 represents a visual summary of Rofino's intersubjectivity constructed throughout the discourse I have presented here. Overall, the effect is a discursive construction of what I have chosen to call a challenged HIV manager on the part of Rofino. 


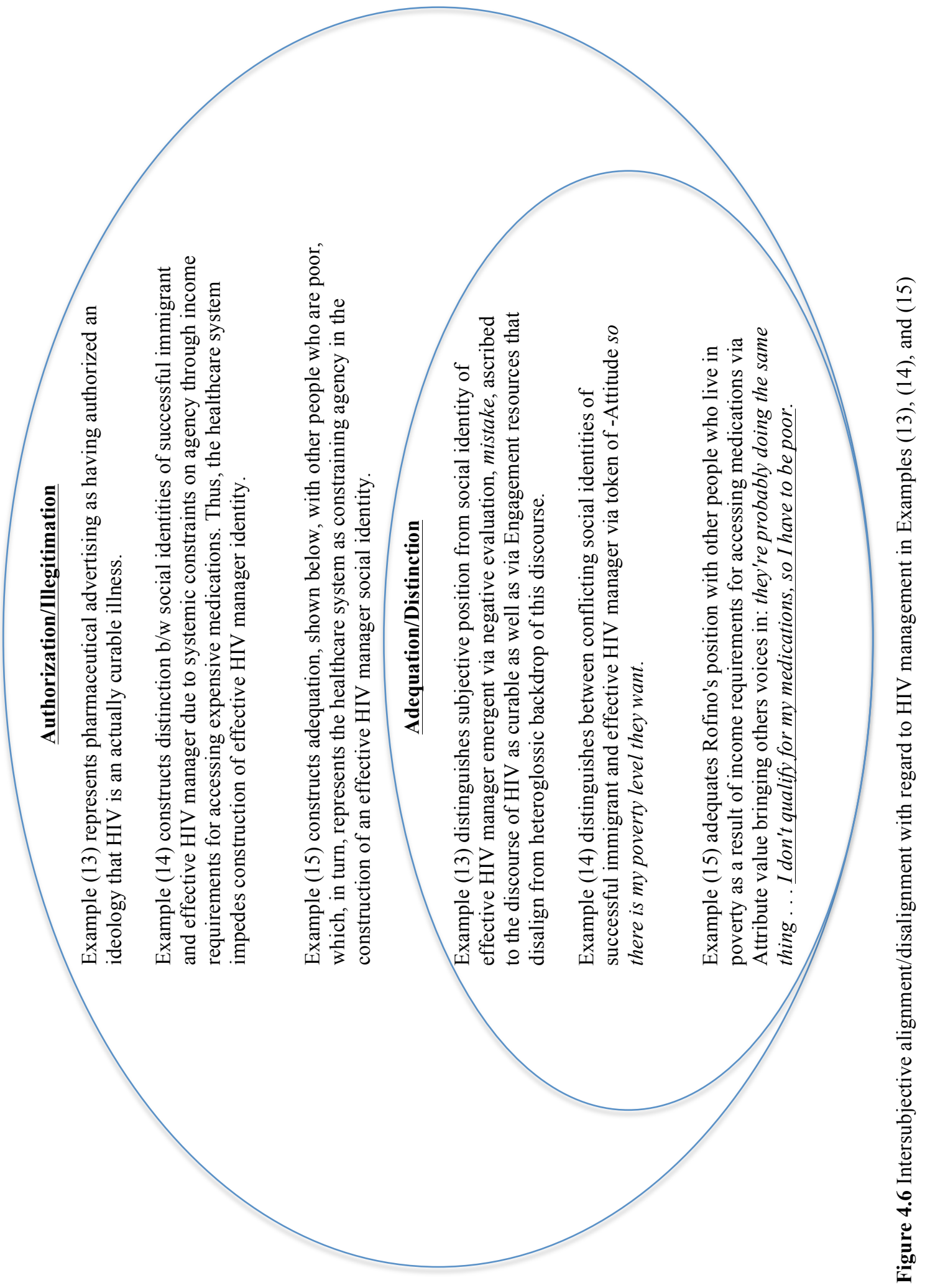




\subsection{Conclusion}

In this chapter, I have analyzed and discussed selected discourse segments showing the evaluative and rhetorical linguistic resources that non-immigrant and immigrant men used in the interviews to construct respective social identities of effective and challenged HIV managers. I have argued that non-immigrant men constructed discursive personas of capable HIV managers because they tended to disalign themselves from heteroglossic representations of managing HIV as problematic and because they tended to avoid referring to or used positive evaluations of their experiences with accessing assistance to purchase medications. In contrast, I have argued that the immigrant men constructed discursive personas as incapable HIV managers because they tended to disalign themselves from heteroglossic representations of managing HIV as unproblematic and because they tended to use negative evaluations to describe their experiences with accessing assistance to purchase medications. What specifically inhibited the immigrant men from constructing positions as capable HIV managers was their inability to reconcile the importance they place on financial independence with the income criteria established for accessing medication assistance. 


\section{Chapter 5: Conclusion}

This chapter concludes the thesis. Here, I seek to answer my research question, offer possible explanations for my findings, position my study within existing literature, make recommendations for HIV/AIDS organizations, address limitations of the study, suggest directions for future research, review in some depth my efforts to apply the Appraisal framework, and personally reflect on the work I have undertaken toward completing this thesis.

\subsection{Answering the research question}

The broad question that guided my investigation was: What are the relationships between social structure and individual agency with respect to managing HIV as reflected in the discursive representations of research interviews? My subsequent thematic analysis led me to formulate the more specific question: How does the notion that HIV is a manageable chronic illness reflect the social construction of HIV in terms of relationships between social structures and individual agency as discursively constructed by the men I interviewed? In this section, I first summarize my answer to this question then articulate a more detailed response that offers potential explanations for my finding.

There are two basic answers to my research question. First, the data that speak most directly to the question, particularly those presented in my thesis, suggest that a strong sense of financial independence could be a uniquely salient factor contributing to the social construction of HIV for HIV-positive immigrant men of Mexican origin. Second, the data I have collected also offer insight into how the political landscape shapes socially constructed reality of HIV/AIDS in the lives of these individual men. 
These two factors are very much interrelated in the social construction of HIV for these men. In the following paragraphs, I elaborate these answers in more detail.

My main finding was that there was a clearly delineated bifurcation in this study between the non-immigrant and immigrant men's alignment/disalignment with the heteroglossic backdrop of HIV as a manageable chronic illness and their respective positive and negative evaluations of managing HIV. This finding was rather surprising. I had approached the interviews having assumed, perhaps naively, that each man would exemplify agentive power. Because these men had accessed health care services, I had thought they would have had triumphant stories of having overcome obstacles that might have otherwise impeded their access. Triumphant is likely a too highly graduated positive evaluation for describing the non-immigrant Latino men's experiences in HIV management; however, the analysis in Chapter 4 has shown that these men reported very different experiences in managing HIV. Relying on the Appraisal analysis and the tactics of intersubjectivity, I have argued that the income threshold criterion for accessing medication assistance impinges upon the immigrant men's highly valued social identities of financially independent persons. In the data that I collected, this particular constraint on individual agency appeared to be unique to the immigrant men and could be a salient cultural factor shaping the social construction of HIV such that managing the illness is more challenging for the immigrant men than for the non-immigrant men. 


\subsection{Possible Explanations}

My detailed Appraisal analysis has shown that the non-immigrant men tended to view HIV management through an optimistic lens whereas the immigrant men tended to take a more pessimistic view, particularly because they indicated that their identities as economically successful and financially independent immigrants were under threat because they had to rely on assistance in obtaining expensive medications, an issue that did not arise in the non-immigrant men's discourse.

One possible explanation for this finding is that the immigrant men may have invested higher hopes in achieving the "American Dream" than the non-immigrant men; thus, the immigrant men may feel that much more is at stake in light of a situation in which options to work and earn money for themselves become limited.

In addition, each of the immigrant men expressed unpleasant surprise that the country that had provided opportunities for them to improve their economic standing could become so harsh in the context of managing their HIV illness. José had commented that when he was growing up in México he had never found accessing needed health care to be problematic, and Rofino had commented that he did not think managing HIV in other countries was as difficult because he thought that much more affordable generic medications were available. These comments suggest a painful awareness on the part of both of these men that they may have left behind valuable cultural assets and social networks that could facilitate better management of HIV in their home countries.

It is well documented that gay men from Latin American countries often leave their home countries to escape sociocultural factors such as homophobia and machismo 
(Díaz, 1998). For Rofino, the one immigrant man who identified as gay, such factors may have influenced his decision to emigrate. Although I was unable to talk with him explicitly about his decision, I got the sense that he had come for primarily economic reasons. Nonetheless, Rofino also told me that when he had come to the United States, he feared his family would disown him had they learned that he was gay. After witnessing a friend's death as a result of AIDS while visiting México, Rofino had seen how his friend's family had been hurt that their brother and son had been unable to share his gay identity, which he revealed near the end of his life, with them sooner. Shortly thereafter, Rofino told me, he had decided to share his gay identity with some members of his family, who responded in a loving and accepting way. I have made this point because it could also be the case that the fear of negative judgment and stigmatization may have factored into Rofino's decision to come to the U.S. West Coast, an area that is typically seen as more gay-friendly than Latin America. Now that he is having trouble managing HIV illness and has learned that he has support among his family, if this was indeed a factor in his decision to emigrate, he may be experiencing some painful regret about his decision.

\subsection{Positioning the study within existing research}

As I have mentioned in Chapter 2, much of the knowledge that has been constructed about HIV/AIDS among Latino men addresses social factors that have worked to heighten risk for contracting HIV. (See Organista, 2012, for the most comprehensive collection of such literature.) With the exception of studies that have examined patterns of HIV disclosure, research that focuses on HIV/AIDS among Latino men does not appear to have examined social and cultural factors related to HIV 
management. In addressing issues of health inequality between Latinos born in the U.S. and those from México and Central America, Hirsch and Vasquez (2012) have admonished that "enhancing access to care is of signal importance for the broader dynamics of the epidemic" (p. 108). Rofino reported having quit his medication due to expense, and José at one point alluded to enacting a strategy of reducing the dosage of his medications so that he could hoard doses in case he ever lost his benefits. The reported experiences of these two immigrant men suggest that medication expense may have negative implications for HIV management. Although my sample size was small and did not include a diverse range of Latino men, my study adds to this research by including the voices of a few immigrant and non-immigrant Latino men, with each group having reported very different respective experiences with regard to HIV medications.

In their meta-analysis of qualitative studies on HIV/AIDS among minority men who have sex with men, Dillon and Basu (2014) recommended that communication scholars take a structure-based approach when analyzing how structural and cultural factors shape these men's meaning making processes in discussions about HIV/AIDS. Moreover, this meta-analysis implied that including HIV-positive men of color in studies taking such an approach is important. Dillon and Basu recommended using Giddens's structuration theory (1984), which allows for a relational analysis between structure and agency. For these scholars, structure simply refers to social, cultural, and contextual factors that are salient to men of color with regard to HIV/AIDS. While I did not use Giddens's theory, my approach, informed by Applied Linguistics, did use a theory that allowed for an analysis of relationships between structure and agency as manifest in 
discourse. Thus, my study offers a novel approach to the analysis of identity while adding additional Latino voices to this literature.

In addition, studies that have focused on identity work among HIV-positive persons have included a few Latino voices, but from what I have found, none have exclusively examined Latino men's experiences in constructing identities as HIV-positive persons. Moreover, these studies have not approached such identity work from a discourse perspective, particularly one that allows for analyzing identity as a relational construct comprising both social structure and individual agency. Thus, my study offers a new approach to the analysis of identity as well as adds additional Latino voices within this literature.

Finally, excepting the early work of Leap (1990) and Savage's autobiographical account (2009), most of the small body of Applied Linguistics HIV/AIDS literature has focused on social constructions of the illness outside the boundaries of the United States. My study has focused on the population of Latino men within the United States and thus enriches the small body of Applied Linguistics literature by including the voices of a local marginalized population. More specifically, my study has shown that the Appraisal framework is a useful discourse analysis method for investigating social constructions of HIV/AIDS in a context different from that of Australia, which Körner (2009) investigated. 


\subsection{Recommendations for HIV/AIDS Organizations}

Based on this study, there are important implications for HIV/AIDS organizations. In this section, I offer such organizations suggestions that grow out of what I have learned.

First, organizations should remember that Latinos are not a monolithic group. Only among the five men I interviewed, there were numerous differences based on immigrant status, first language, education, sexual orientation, access to social support networks, level of disclosure of HIV status, age, and relationship status. Although I was unable to explore most of these issues in my study, the data I collected do allow for reasonable speculation and even demonstrate more explicitly that each of these characteristics was likely related to these men's experiences in managing HIV. José felt very stigmatized, for example, and had told no one other than healthcare personnel and me about his HIV status, whereas Mark, for example, had also experienced stigma but appeared to feel no shame regarding his serostatus, which he was willing to share with various people in his social networks.

Second, HIV/AIDS advocacy organization personnel might want to be aware of the possibility that Mexican immigrants may have a more difficult time relying on assistance than native-born Latinos. At least in my data, the desire to maintain financial independence was important enough to warrant discontinued adherence to HIV medications for about five years in Rofino's case. José also seemed to fear the loss of financial independence as he thought about the future, and he reported having considered a plan to hoard medication in anticipation of losing access to assistance as a result of 
making too much money. Of course, failing to adhere to HIV medications has potentially dire consequences for individuals and for public health. In my opinion, the potential importance of financial independence among other Mexican immigrants should not be disregarded. The literature does not often discuss these values among Mexican immigrants, but in my data they emerged as salient and interacted with low income criteria set forth in HIV medication assistance programs in such a way that was related to negative outcomes in my analysis..

\subsection{Limitations of the study}

My study relied on a convenience sample of Latino men recruited through an HIV/AIDS organization that works to provide a number of necessary services. Such a context has the major implication that the voices of the most vulnerable Latino men do not appear in this thesis. Even though each of the men, particularly the immigrants, I spoke with reported problems in managing his HIV illness, they had indeed been able to access assistance in obtaining medications through the HIV/AIDS organization's service network. In contrast to these men, who had secured relatively stable lives over time in the U.S., migrant Latino men often face a host of social and cultural factors that both exacerbate their risk for contracting HIV and lead to "health inequalities among those diagnosed with HIV" (Hirsch and Vasquez, 2012, p. 107). As Hirsch and Vasquez further specify, "questions of access to care and clinical outcomes are relevant because they emphasize the acute nature of this health inequality" (p. 107). I emphasize this point to make clear that many HIV-positive immigrant Latino men are in much more precarious circumstances than those I interviewed. 
Another implication of my small convenient sample is that my study did not include non-immigrant Latino men who were living in conditions of dire poverty. Poverty has long been documented as one of the most salient structural factors that heightens risk and leads to adverse health outcomes in the context of HIV among Latino men (Díaz, 1999; Carrillo, 2012). Such literature tends to emphasize conditions of poverty among immigrants because this group is so large and is indeed at greater social disadvantage in the context of HIV risk than native-born Latinos (see, Carrillo, 2012). Nonetheless, a recent report compared the poverty rates between immigrant and nonimmigrant persons of Mexican origin living in the United States and indicated that the rate for immigrants was only three percent higher. While immigrants in general are certainly at a disadvantage, in terms of poverty, there are certainly native-born Latino men who suffer heightened HIV risk and face great challenges in HIV management due to poverty. Unfortunately, accessing such men was beyond the scope of this study.

Another limitation of my study is the fact that I was unable to include monolingual Spanish speakers. Although I speak Spanish, my lack of confidence in understanding fine pragmatic aspects of the Spanish language precluded my doing so. That each of these men had sufficient mastery of English to participate in an English-only interview indicates that they were likely at a large advantage in utilizing HIV medication assistance programs in comparison to monolingual Spanish speakers.

Geography is another limiting factor in my study. Many states have had to create long waiting lists or even cut access to government assistance programs for HIV medications (Sack, 2013). In comparison to states where HIV rates are particularly high, 
our state has suffered relatively little in this area, which works to the advantage of all the men I interviewed. My finding, then, cannot be applied to the larger general population of HIV-positive Latino men in the United States.

The final limitation is a general one having to do with other demographic factors. Each of the men I interviewed has a unique history and personality that cannot be adequately reduced in any report. My re-entextualization of their stories in the discourse analysis might suggest otherwise, but I was unable to address more unique aspects of their stories in a cohesive way that included each of their voices. There were certainly other demographic factors besides immigrant status that shaped each of these men's experience. Mark, for example, was much younger than the other men and had had access to a high level of education at a prestigious university. Charlie, whose voice is least represented in the thesis, had a long-term boyfriend who obviously had eased Charlie's burden in managing HIV through his trajectory of becoming a long-term HIV survivor. Oscar, based on aspects of his story, had started life with a greater economic advantage than the other men, both non-immigrant and immigrant. In addition, Oscar's dress suggested that he was still probably better off economically than the other men. José had a more detailed story to tell about his reasons for emigrating and his subsequent sex work in difficult economic times. Teasing out and discussing factors that were more unique to each man I interviewed proved to be beyond the scope of my study.

\subsection{Suggestions for Future Research}

A study focusing on the issues treated here would greatly benefit by including monolingual Spanish speakers. A Spanish version of a basic overview of Appraisal is 
indeed available. (See http://www.grammatics.com/appraisal/SpanishTranslationAppraisalOutline.pdf) Researchers undertaking such a project should probably have native-like fluency in Spanish and even the varieties of Spanish spoken by interviewees because interpretive analytical work that depends on often subtle pragmatic understanding will likely be involved. It should also be noted that there are also likely HIV-positive immigrants from Latin America who speak various indigenous languages and for whom Spanish may be a second language if spoken at all.

At the broader political level, applied linguists interested in Critical Discourse Analysis (CDA) have abundant territory to investigate. Those interested in elucidating relations of power at this level could productively draw on the CDA work of Fairclough (2001, 2003). Fairclough's work centers on a criticism of late modernity in which specific neoliberal visions for society too often hold hegemonic sway over the autonomy of individuals and other social entities. In this domain, I would recommend investigating the power relations involved in pharmaceutical companies' acquisition of patents that allow them to keep prices for HIV medications high in the United States. It is likely that there are dubious practices involving trade agreements, patents, and relationships between corporations and governments waiting to be explored and documented from a CDA perspective.

For those interested in using CDA in such a way, I also offer a caveat. Disentangling social relations at a very broad level is vastly complex, and adequate investigations will likely require expertise in sociology and/or critical theory. Linguists 
without such additional expertise would do well to enter such a research pursuit, if possible, collaboratively as part of an interdisciplinary team.

In addition to investigating HIV-positive persons' illness management, my research and data have led me to conclude that applied linguistics research on several other topics would contribute to social understandings of HIV/AIDS. First, examining the language that Latino men use to talk about disclosing or not disclosing their HIV status could yield much useful information about community values and the social construction of HIV. Second, asking men to talk about experiences with stigma would likely produce language that provides evidence for how and in which contexts stigma is produced. Stigma emerges in social interaction as a relational phenomenon (Goffman, 1963), and analyzing descriptions of the social interactions in which men have felt stigmatized due to their HIV status could inform efforts to redress HIV stigma in the Latino or other communities. Finally, health literacy is increasingly important. HIV illness and disease are incredibly complicated. Being able to effectively engage with HIV health information could reduce stress for HIV-positive persons. Discourse analysts and corpus linguists could analyze on a large scale the language used in disseminating information, particularly in digital environments, about HIV. Such studies could inform efforts to simplify language in ways that scaffold interaction with complex information for those HIV-positive persons with low levels of education.

Both Appraisal analysis and ethnomethodological conversation analysis are useful tools for investigating each of the topics I have identified above. Eggins and Slade (1997) 
have even used a combination of these two methods, and other applied linguistics researchers should refer to their work to learn more about a unique analytical approach.

\subsection{Review of Methodology}

The synthesis of the Appraisal framework with Bucholtz and Hall's theory of identity $(2004,2005)$ used here was a fairly novel methodology. Although this method of analysis drew inspiration from Morrish and Sauntson (2007), those researchers did not employ the Engagement subsystem. I agree with Bucholtz and Hall's (2005) observation that "theoretical assumptions about identity" are "often left implicit" in sociocultural linguistics research (p. 586). The Appraisal notion of a speaker's relative subjective position to the heteroglossic backdrop is very similar to Bucholtz and Hall's theory in that both are fundamentally relational; yet, I noticed during my research that the Appraisal literature often used the term intersubjectivity without unpacking its meaning. Both my adviser and I found such nebulousness problematic. Drawing on the tactics of intersubjectivity as articulated by Bucholtz and Hall facilitated a theoretically grounded discussion of the intersubjective relations between representations of social structures and individual agency that emerged in the interview discourse. At the same time, the Appraisal framework allowed for a robust analysis of specific instantiations of the relations that Bucholtz and Hall have theorized at a broader level of abstraction. In the end, my synthesis of these two frameworks created a challenge in writing succinct methodology and analysis chapters, but I hope the additional theoretical robustness has been worth the additional work involved. 
Using the Appraisal framework to guide my fine discourse analysis both facilitated and challenged my work as an analyst. In the following paragraphs, I will review salient aspects of the system by detailing how each aspect helped and challenged me.

The existing taxonomies of linguistic resources developed within the Engagement subsystem's categories of Deny and Counter helped me identify specific lexical items as instantiations of subjective disalignment. Particularly useful from these existing taxonomies were simple instantiations of Deny and Counter values such as not, don't and but. Such kinds of items emerged fairly frequently in the discourse, and even though these are fairly simple, chapter 4 shows that these kinds of resources constructed important relational representations. Körner (2009) drew heavily on the Deny and Counter categories, but I was sometimes tempted to disregard the semantic power of such resources for their apparent simplicity as compared to some of the more complex instantiations of the Engagement function discussed in the Appraisal literature. As a result, my analysis at times became unwieldy. I often had to remind myself that the purpose of the Appraisal analysis was to elucidate the differences between the intersubjective relations in terms of the men's representations of their individual agency and the healthcare system as HIV managers. Before finalizing my analysis, I had to eliminate sections that involved more complex Engagement analyses because they did not help elucidate my argument. Future Appraisal analysts would likely do well to consider my experience and not disregard the semantic power manifest in superficially simple items. 
The Appraisal system's notion of modality as theorized within the Entertainment subsystem proved useful in elucidating specific identifications of partial subjective identifications, which at times the speakers further adjusted via additional Engagement resources. Martin and White (2005) made an effort to distinguish dialogic views of modality from perspectives of a "truth-functional semantics" (p. 105). In addition, these scholars pointed out that Halliday had made convincing claims that certain mental verbs, I think for example, function in modal like ways (p. 105). I found examples in my data that support these arguments. "José," for example uttered I think I'm a capitalist after having uttered I'm not anarchist. If we take into additional consideration the fact that Martin and Rose (2007) have argued that negation can also be productively viewed as the low end along a cline of subjective positionality, with an unmodalized copula at the high end, the instantiation of I think in the context above indeed seems to function to position José's subjectivity somewhere between that of capitalist and anarchist.

Appraisal theorists are careful to make clear that existing taxonomies of resources that perform certain functions are not complete and depend on context (Körner, 2009; Martin and Rose, 2007; Martin and White, 2005). This fact created a challenge in that my analysis often relied on meticulous consideration of surrounding discourse to identify certain functions. I identified unless as a potentially previously unrecognized resource of the Entertain function. "José" had uttered the phrase unless you're a doctor, a lawyer, an architect when expressing his opinion that not many people can afford to pay for HIV medications without assistance. I found that such an utterance functioned in such a way as other Entertain resources, i.e., by explicitly constructing a subjective position that is 
only one of a number of other subjective positions. Identifying a potentially new resource was exciting from my perspective as an analyst.

At the same time, because the Appraisal system is grounded in a functional linguistic approach, having to read carefully, as opposed to simply identifying lexical items as instantiations of certain functions was challenging. This became particularly problematic with respect to the Attitude analysis. I had initially hoped that identifying resources that instantiated various aspects of the Attitude subsystem would prove fruitful for my discussion. This strategy proved to be unproductive, which resulted, in my opinion, from the fact that the topic of the interviews was inherently emotional and at a broad level evaluative in terms of the Appreciation subsystem, i.e., the men were always generally evaluating their management of HIV.

The most documented strategy of determining what type of Attitudinal evaluation is being made is to determine what is actually being evaluated. (See Martin, 2000; Martin \& Rose, 2007.). In my study, however, I found this strategy to often be unproductively complicated. In other words, it was difficult to distinguish whether the most salient targets of evaluation had to do with the Affect, Judgment, or Appreciation subsystems. This problem supports the tentative claims of Appraisal theorists that the Affect subsystem might "be taken as the basic system, which is then institutionalized in two major realms of uncommon sense discourse," those two realms being the Judgment and Appreciation systems (Martin, 2000, p. 147). In the final analysis, I found that distinguishing the types of Attitudinal evaluation at fine levels to be unproductive; yet, 
identifying positive and negative Attitudinal evaluation, when used in conjunction with the Engagement analysis was necessary to my overall argument.

A related limitation to that I have described directly above is the difficulty in systematically identifying instances of implied, as opposed to direct evaluation, tokens of evaluation, which I described in Chapter 3. Martin (2003) has acknowledged this limitation and described it as a "crisis point" in Appraisal work (p. 172). Furthermore, he offers his own highly graded negative positive Appreciation evaluation of coding for implied evaluation in the following statement: "The problem here is that evaluation is implied even where it is not directly realized and this creates something of a coding nightmare, especially for qualitative analysts" (p. 173). Nonetheless, I agree with Martin and White's (2005) opinion that "avoiding invoked evaluation of this kind amounts to a suggestion that ideational meaning is selected without regard to the attitudes it engenders" is an untenable position (p. 62). My strategy in dealing with this issue was to describe my reasons for interpreting implied instances of evaluation in detail to justify my claims. Here, the Appraisal framework was particularly unhelpful analytically.

My analytical work has led me to conclude that using the Appraisal framework with a large data set of spoken language can be very challenging. Although Körner (2009) as well as Eggins and Slade (1997) have used the Appraisal system with spoken language, their data sets were much smaller than the one my work generated. In addition, the theoretical literature on Appraisal by and large uses written language to exemplify the system's functional semantic domains. I would recommend that future researchers who wish to employ the Appraisal system in analyses of spoken language not expect to use 
this type of analysis in a bottom-up way in order to elucidate findings in an exploratory study; rather, analysts should probably conduct a general thematic analysis, which will likely identify salient heteroglossic backdrops. Such backdrops having been identified, additional analyses from the perspective of the Attitude and/or Graduation systems can help facilitate the ways in which subjective (dis)alignment has emerged in the discourse.

The final challenge regarding Appraisal that I will address has to do with presenting the data. Because each of the Appraisal subsystems is imbricated with others, presenting the data can be very problematic. Despite the fact that Appraisal theorists emphasize the collective operation of these subsystems, I was unable to locate any studies or theoretical examples that attempted presenting analyses that effectively presented analyses that simultaneously included each subsystem. Instead, the analyses I have seen tend to focus on just one or two subsystems, and even among these, data presentation sometimes appears awkward. Contributing to such awkwardness in an exploratory study such as mine is the fact that Appraisal theorists view meaning as unfolding throughout stretches of discourse; thus, meanings constructed early in the discourse setting might be adjusted at any later point. Identifying such shifts in meaning throughout long stretches of discourse proved sufficiently difficult, but my attempts to present such meanings in tables and charts were very frustrating. My strategy for addressing this issue was to offer contextual backgrounds for each discourse segment that I analyzed, but I still often had to write up detailed descriptions explaining why I coded for certain functions based on the discourse context. Again, I recommend that future Appraisal analysts use the system with smaller data sets and take a top-down approach. 


\subsection{Personal Reflection}

In addition to a document that has sought to position new findings within the literature on HIV/AIDS from the perspective of risk and prevention among Latinos, social identity, and applied linguistics, my thesis project has served as the culminating experience of my time in graduate school. Here, I reflect on the value of my project in terms of professional and personal growth.

My motivation for pursuing the MA TESOL degree has always been strongly grounded in a social justice perspective. I believe that all humans are valuable and have potential regardless of cultural and linguistic backgrounds. Unfortunately, in the United States, a person's cultural and linguistic backgrounds are far too often factors that can limit one's social capital. Upon entering graduate school, I admittedly did not know much about Applied Linguistics; I simply wanted to become a more professional ESL instructor so that I could better help students such as the Latino immigrants who I had worked with in the past develop English skills as resources that they could use to empower themselves. Even though I still plan to teach ESL upon graduation, I have now come to understand that in addition to issues directly related to the ESL classroom the field of Applied Linguistics is a seemingly infinite wellspring of theories and methodologies that scholars can draw on to address numerous social problems. Below, I reflectively outline the development of my own social identity as an applied linguist while framing my experience within the work I have undertaken herein.

In the first quarter of the program, I gained a cursory knowledge of myriad theoretical perspectives, methodologies, and topics that form our interdisciplinary field. 
While this initiation was overwhelming, I soon recognized that certain strands of the seemingly disparate field of Applied Linguistics resonated with me much more strongly than did others. Particularly interesting were functional linguistic approaches, the notion of social identity, and critical applied linguistics. Throughout the remainder of the program, I made a concerted effort to take classes that touched on and to independently explore these areas.

I came to discover that there is significant overlap between these areas. The critical discourse analysis of Fairclough (2001, 2003), for example, draws on Hallidayan Systemic Functional Linguistics (SFL) as its primary linguistic paradigm. Conversely, SFL scholars often discuss language as a social semiotic system that people use to represent themselves as and through which they are understood to be certain kinds of people, i.e., social identity. (See, for example, Martin and White, 2005; Martin and Rose, 2003.) Likewise, as I have discussed in this thesis, the work of Bucholtz and Hall (2004, 2005, 2008), grounded in both queer linguistics and feminist theory among other perspectives, broadly theorizes the discursive construction of social identity while specifically identifying one way that such construction is achieved as the use of evaluative language, the fundamental focus of SFL's Appraisal theory. Over the past four years, it has been an exciting process for me to come to a greater understanding of these individual areas and their interconnectedness. This has been a challenging process, and I look forward to learning more about these areas of applied linguistics.

I should note that even though I have not explicitly framed my study as CDA, I have drawn inspiration from the approach's unapologetically political stance. Had I 
known before the interviews that the immigrant men would talk about medical expense as much as they had, I might have framed my study as a critical discourse analysis that specifically sought to examine the macro-level discourse that constructs the political economy shaping HIV medication prices. It is an absolutely ignominious state of affairs that HIV-positive Latino immigrants, and likely members of other vulnerable classes, are positioned as less than worthy of full participation in society in order to be able to access the medications that sustain their lives. Particularly appalling is that this is the case in such a resource-rich country as the United States. In keeping with the CDA spirit, I do hope that the work I have reported on will incite other researchers to take up this issue, as I have suggested above, and conduct investigations that seek to redress the problem of medical expense that emerged in the discourse I analyzed.

Overall, while I do not think this thesis is perfect or offers revolutionary insight, I do feel proud about having persevered in pursuing personally interesting strands of Applied Linguistics throughout the program and applying what I have learned from those areas in this very personal culminating project. My accomplishment partially fulfills the promise to work with the HIV/AIDS community I had made to my father more than four years ago as he lay so helplessly in his hospice bed. At that time, I would never have thought that my graduate school experience would help me make good on that promise.

In addition to the knowledge and skills I have used, my personal reflection would be far from complete without again acknowledging the encouragement of my adviser, Keith Walters, as well as my professor, Susan Conrad. As part of the broad Applied Linguistics discourse community, which I am now a proud initiate, these two people 
inspired me to pursue the greatly challenging work that has culminated in my thesis. I will forever be grateful to them as well as the broader discourse community of scholars, particularly the ones cited in this thesis, for participating in the co-construction of the knowledge that has made this work possible. 


\section{References}

Anderson, T. (2014). A day to call our own. Retrieved from http://nhaltsad.org

Bache, C. (2010). Hjelmslev's glossematics: A source of inspiration to Systemic Functional Linguistics? Journal of Pragmatics, 23(2), 2562-2578. doi: 10.1016/jpragma.2010.03.005

Bucholtz, M. \& Hall, K. (2004). Theorizing identity in language and sexuality research. Language in Society, 33, 469-515. doi: 10.1017/S004740450044021

Bucholtz, M. \& Hall, K. (2005). Identity and interaction: A sociocultural linguistic approach. Discourse Studies, 7(4-5), 585-614.

Bucholtz, M. \& Hall, K. (2008). All of the above: New coalitions in sociocultural linguistics. Journal of Sociolinguistics, 12(4), 401-431.

Carrillo, H. (2012). Sexual culture, structure, and change: A transnational framework for studies of Latino/a migration and HIV. In K. Organista (Ed.) HIV prevention with Latinos: Theory, research, and practice (pp. 41-61). Oxford: Oxford University Press.

Clemente, A. \& Higgins, M. J. (2009). Is it safer to talk about sex in English or Spanish? Performing young adulthood in Oaxaca, Mexico. In C. Higgins \& B. Norton (Eds.) Language and HIV/AIDS [Adobe Digital Editions] (pp. 82-101). Retrieved from http://www.powells.com

Corbin, J. \& Strauss, A. (2008). Basics of qualitative research (3rd ed.): Techniques and procedures for developing grounded theory. Available from http://www.srmo.sagepub.com doi:10.4135/9781452230153 
Díaz, R. (1998). Latino gay men and HIV: Culture, sexuality, and risk behavior. New York, NY: Routledge.

Díaz, R. M. , Sánchez, J. \& Schroeder, K. (2012). Inequality, discrimination, and HIV risk: A review of research on Latino gay men. In K. Organista (Ed.) $H I V$ prevention with Latinos: Theory, research, and practice (pp. 121-137). Oxford: Oxford University Press.

Dillon, P. J. \& Basu, A. (2014). HIV/AIDS and minority men who have sex with men: A meta-ethnographic synthesis of qualitative research. Health Communication, 29, 182-192. doi:10.1080/10410236.2012.732911

Eggins, S. \& Slade, D. (1997). Analysing casual conversation. London: Cassell.

Fairclough, N. (2001). Language and power. London: Longman.

Fairclough, N. (2003). Analysing discourse: Textual analysis for social research. Abingdon: Routledge.

Halliday, M. A. K. (1978). Language as a social semiotic: The social interpretation of language and meaning. London: Edward Arnold.

Halliday, M. A. K. (1985). An introduction to functional grammar. London: Edward Arnold.

Han, C., Lauby, J., Bond, L., LaPollo, A. B., \& Rutledge, S. E. (2010). Magic Johnson doesn't worry about how to pay for medicine: Experiences of black men who have sex with men living with HIV. Culture, Health, and Sexuality 12(4), 387-399.

Higgins, C. \& Norton, B. (2009). Language and HIV/AIDS. [Adobe Digital Editions] Retrieved from http://www.powells.com 
Hirsch, J. S. \& Vasquez, E. (2012). Mexico-U.S. migration, social exclusion, and HIV risk: Multisectoral approaches to understanding and preventing infection. In K. Organista (Ed.) HIV prevention with Latinos: Theory, research, and practice (pp. 103-120). Oxford: Oxford University Press.

Jones, R. (2009). Learning about AIDS online: Identity and expertise on a gay internet forum. In C. Higgins \& B. Norton (Eds.), Language and HIV/AIDS [Adobe Digital Editions] (pp. 190-215). Retrieved from http://www.powells.com

Körner, H. (2009). Safe sex—not so straight forward: Intersubjective positioning in gay men's accounts of sexual exposure to HIV. In C. Higgins \& B. Norton (Eds.), Language and HIV/AIDS [Adobe Digital Editions] (pp. 83-112). Retrieved from http://www.powells.com

Leap, W. (1990). Language and AIDS. In D. A. Feldman (Ed.), Culture and AIDS (pp. 137-158). New York, NY: Praeger Publishers.

Leap, W. (1995). Linguistic perspectives on non-neutral discourse. In H.T. Brummelhuis \& G. Herdt (Eds.), Culture and sexual risk: Anthropological perspectives on AIDS (pp. 227-238). Amsterdam: Overseas Publishers Association.

Leap, W. \& Colón, S. (2010). Gay men, language, and AIDS. In D. A. Feldman (Ed.), AIDS, culture, and gay men (pp. 60-79). Gainesville: University Press of Florida. Lewis, J. (1999). Status passages: The experience of HIV-positive gay men. Journal of Homosexuality 37(3), 87-115. 
Martin, J. R. (2000). Beyond exchange: Appraisal systems in English. In S. Hunston \& G. Thompson (Eds.), Evaluation in text (pp. 142-175).

Martin, J. R. (2003). Introduction. Text 23(2), pp. 171-181. Retrieved from http://www.grammatics.com/appraisal/textSpecial/martin-intro.pdf

Martin, J. R. \& Rose, D. (2007). Working with discourse: Meaning beyond the clause. London: Continuum International Publishing Group.

Martin, J. R., \& White, P. R. R. (2005). The language of evaluation. Basingstoke: Palgrave Macmillan.

Moisse, K. (2013). Hydeia Broadbent, born with HIV, reacts to 'cure.' ABC News. Retrieved from http://www.abcnews.go.com/Health/born-hiv-longer-deathsentence-life-sentence/story?id=18658471

Morley, G. D. (1985). An introduction to systemic grammar. London: Macmillan. Morrish, E. , \& Sauntson, H. (2007). Analysing evaluation in coming out narratives. In E. Morrish \& H. Sauntson (Eds.), New perspectives on language and sexual identity (pp. 53-86). Houndmills: Palgrave Macmillan.

Murray, S. O., \& Payne, K. W. (1989). The social classification of AIDS in American epidemiology. Medical Anthropology, 10, 115-128.

Mutonyi, H. \& Kendrick, M. E. (2009). Ugandan students' visual representations of health literacies: A focus on HIV/AIDS knowledge. In C. Higgins \& B. Norton (Eds.) Language and HIV/AIDS [Adobe Digital Editions] (pp. 57-81). Retrieved from http://www.powells.com 
Organista, K. C. (2012). HIV prevention with Latinos: Theory, research, and practice. Oxford: Oxford University Press.

Rhodes, S. D. (2012). Demonstrated effectiveness and potential of community-based participatory research for preventing HIV in Latino populations. In K. Organista (Ed.) HIV prevention with Latinos: Theory, research, and practice (pp. 121-137). Oxford: Oxford University Press.

Richards, K. (2009). Interviews. In J. Heigham \& R. Croker (Eds.) Qualitative research in applied linguistics: A practical introduction (pp. 182-199). Basingstoke: Palgrave Macmillan.

Sack, K. (2010, June 30). Economy hurts government aid for H.I.V. drugs. New York Times. Retrieved from http://www.nytimes.com/2010/07/01/us/ 01aidsdrugs.html

Sandstrom, K. L. (1990). Confronting deadly disease: The drama of identity construction among gay men with AIDS. Journal of Contemporary Ethnography 19(3), 271294.

Sandstrom, K. L. (1994). Confronting deadly disease: Challenges to selffaced by gay men living with advance HIV disease. (Unpublished doctoral dissertation). University of Minnesota, Minneapolis.

Savage, W. (2009). Lengths of life: Stories of being with HIV. In C. Higgins \& B. Norton (Eds.) Language and HIV/AIDS [Adobe Digital Editions] (pp. 39-56). Retrieved from http://www.powells.com

Sontag, S. (1989). AIDS and its metaphors. Retrieved June 30, 2014, from monoskop.org/images/d/d3/Susan_Sontag_AIDS_and_Its_Metaphors_1989.pdf 
Teague, A. (2007). HIV: Now a manageable chronic illness. Pharmacy Times. Retrieved September 11, 2014, from www.pharmacytimes.com/publications/issue/2007/ 2007-03/2007-03-6317

Treichler, P. (1987). AIDS, Homophobia, and Biomedical Discourse: An Epidemic of Signification. AIDS: Cultural Analysis/Cultural Activism, 43, 31-70.

Viral load. (2009, August 6). Retrieved July 27, 2014, from http://www.aids.gov/ hiv-aids-basics/just-diagnosed-with-hiv-aids/understand-your-test-results/ viral-load/

Wells, K. (2011). Narrative inquiry. New York: Oxford University Press.

Whetten, K. \& Pence, B. W. (2013). You're the first one I've told: The faces of HIV in the Deep South. New Brunswick: Rutgers University Press.

Young, L. \& Harrison, C. (2004). Systemic functional linguistics and critical discourse analysis: Studies in social change. London: Continuum.

Young, S. (2013). HIV no longer considered death sentence. CNN Health. Retrieved from www.cnn.com/2013/12/01/health/hiv-today

Zea, M. C. , Reisen, C. A. , Poppen, P. J., Bianchi, F. T. \& Echeverry, J. J. (2005). Disclosure of HIV status and psychological well-being among Latino gay and bisexual men. AIDS and Behavior 9(1), 15-26.

Zea, M. C. , Reisen, C. A. , Poppen, P. J. , Echeverry, J. J. \& Bianchi, F. T. (2004). Disclosure of HIV positive status to Latino gay men's social networks. American Journal of Community Psychology 33(1-2), 107-116. 
Zea, M. C. , Reisen, C. A. , Poppen, P. J. \& Díaz, R. M. (2003). Asking and telling: Communication about HIV status among Latino HIV-positive gay men. AIDS and Behavior 7(2), 143-152. 


\section{Appendix A \\ Interview Protocol}

\section{Welcome}

Thank you so much for agreeing to participate in this research project. I know that much of the information I am going to ask you about is sensitive. This interview may lead you to feel troubling emotions or psychological discomfort. I have arranged for a counselor to be here in case you need his help today. Remember, too, that you may withdraw from this process at any time for any reason without affecting your relationship with Partnership Project, OHSU, or PSU.

My project is based on the personal stories that you and the other men I am interviewing tell me. I am not looking for particular answers to the questions that I have planned to ask you. It is OK if you decide to talk about anything you feel is important after I ask the questions. Feel free to ask me questions as we go, too.

Because there is a minimal risk that someone might read this study and identify you, you should choose a fake name for yourself. You will be referred to only by this name in the written study. I realize you might not have participated in a research project before. Do you have any questions before we begin?

Before I ask you to tell me your story about living with HIV, I would first like to tell you my own HIV/AIDS story. [Here, I will recount the story of my father.]

\section{Initial identity questions}

- How would you describe yourself? Probe:

- Do you use any labels to describe yourself?

- Could you describe the people you spend time with? Probe for:

○ Family

○ Friends

- Romantic partners

○ Work relationships

○ Community/civic/religious acquaintances

- Latino and non-Latino

- How would these people describe you?

- Do you feel like these people know you like you know yourself?

- Would you describe your social relationships prior to learning about your HIV status? Probe for:

o Family

- Friends

- Romantic partners

○ Work relationships

- Community/civic/religious acquaintances 
- Specific social activities with these people

- Latino and non-Latino

- Did you feel the same or different from these people you've been talking about before you learned about your HIV status?

- What did you think about HIV before you learned about your HIV status? Probe for:

- How participant viewed HIV positive people

- How participant viewed gay men

\section{Negotiating HIV identity}

- When did you first learn that you were HIV positive?

- What led you to get an HIV test?

- How did you react to the news that the test was positive? Probe for:

$\circ$ Changes in ways participant viewed self

- Changes in ways participant viewed others with HIV

- Changes in ways participant viewed members of Latino community

- Would you describe your social relationships after you learned you were HIV positive? Probe for changes in these relationships:

○ Family

- Friends

- Romantic partners

- Work relationships

- Community/civic/religious acquaintances

- Specific social activities with these people

- Latino and non-Latino

- Did you feel the same or different from other people in your social circle after learning about your status?

- Did you tell anyone when you learned about your HIV status? Probe for:

○ Family

○ Friends

- Romantic Partners

- Work relationships

- Community/civic/religious acquaintances

○ How participant felt about telling these people or not. 
- How did the people you told about your HIV status react when you told them? Probe for:

- Whether participant expected these reactions

- Whether participant was surprised by reactions

- How participant felt about reactions

- Whether participant saw himself or those he told differently after disclosure

- How would you compare your relationships with the people you told to your relationships with the people you didn't?

- Have you since told anyone else about your HIV status? Probe for:

○ How these people reacted

- Whether participant expected reactions

- Whether participant was surprised by reactions

- How participant felt about reactions

- Whether participant saw himself or those he told differently after these disclosures

- Are you involved with any social or community groups? Probe for:

- Descriptions of groups

- HIV/AIDS support groups

- How well participant feels he fits in with these groups

- How participant sees himself as member of these groups

- How group members see the participant

o How participant may have changed after participating in groups

- Have you noticed many changes in yourself since you became HIV-positive? Probe for:

$\circ$ What has changed the most

$\circ$ What has changed the least

- Have you learned much about yourself and the other people in your life since you became HIV-positive?

- It is possible that people who work with HIV/AIDS organizations read about the work we are doing today. Is there anything you would like them to know about you?

- Is there anything you would like to say to other Latino men who are living with HIV? 


\section{Closing questions and comments}

- How have you felt about this interview today?

○ Whether participant learned anything about himself

○ How interview questions could work better for other men

- Is there anything else you would like to say?

Thank you so much for sharing your story with me. I imagine that it must have been difficult talking about this information to a relative stranger. I really appreciate your willingness to open yourself to these questions in a setting that I'm sure was uncomfortable at times. I have learned a lot about your experience living with HIV, and I'm going to do the best I can to write up what I have learned in a way that presents what you have said accurately. I assure you that I will remove the names of any people or places that might identify you in this write up. I sincerely hope that HIV/AIDS organizations can learn more about supporting men like you as a result of the work we have done here today. As a token of my appreciation, I want to offer you ten dollars. I wish I were able to offer you more. I hope this interview has helped you in some way as well. Thank you so much. 


\section{Appendix B \\ Initial Contact Telephone Script}

Hello [name of potential participant] this is [your name] from Partnership Project. We've been working with Will Caston. He's a student in the Department of Applied Linguistics at Portland State University who is doing a research study to learn more about the social and cultural experiences of local Latino men who are living with HIV. The research study is also one of the requirements for Will to complete his Master's degree. You're being invited to take part in this study because you identify as Latino, you are male, you are HIV-positive, and you speak English.

Your decision to take part in the study is completely voluntary. Whether you choose to participate or not will not affect the services you get from us or OHSU in any way. You can say yes or no. It won't change anything.

If you choose to participate, Will, rather than one of our staff, will do the interview. The interview will take place in our office. At the interview, you will be able to talk with one of our staff members at any time if you need to, though. You will not have to answer any questions you don't want to, and you can also stop the interview at any point if you don't want to go on.

In the interview, you will be asked questions about the social interactions with people covering the time just before you learned about your HIV-status to the present. You may benefit from participating in this study. Telling your story may help you learn something new about yourself. Your story may also help increase the knowledge about local HIV-positive Latino men. This new knowledge might help organizations like us serve people like you better. You will also be compensated ten dollars as a way of saying thanks for taking part in this study.

As you know, some people find it difficult to talk about their own lives. You may feel some emotional or psychological discomfort as you tell your story. As I mentioned before, you will be able to speak with one of our staff immediately if you need help any time during the interview.

Your experiences will be documented in detail and written up in the study. There is a minimal chance that you will be recognized by someone who might read this study. You will be asked to create a name to be used in the written part of the study to protect you from being recognized.

Would you be interested in participating in this study?

If they answer no, thank them for their time.

If they answer yes, please schedule an appointment to meet with Will. 


\section{Appendix C \\ Informed Consent Form}

Will Caston is doing a research study to learn more about how local Latino men living with HIV talk about their social and cultural experiences. Will is a student in the Department of Applied Linguistics at Portland State University. He is doing this study to help finish his graduate program at Portland State. Will is working with Partnership Project. He is also being helped by Dr. Keith Walters with this research. Dr. Walters has a lot of experience working with people with HIV/AIDS.

\section{What Will I Have To Do?}

If you decide to take part in this study, I will ask you to talk with me for about an hour. The interview will be on these topics:

- How you see yourself as a person

- How other people see you as a person; these people will include family, friends, partners, co-workers, or other people you know

\section{Are There Any Risks?}

I know that I am asking you to talk about very personal issues. While telling me your personal story, you may feel uncomfortable, sad, angry, guilty, embarrassed, or scared. You do not have to answer any questions you don't want to. If do not want to go on, you can stop at any time. If you become upset and want to talk to someone here at Partnership Project, you can walk out the door and talk to them right away at any time.

\section{What Will I Get In Return?}

1. $\$ 10$ for taking part in the study

You will receive ten dollars as my way of saying thank you for taking part in the study.

2. Learning something about yourself

People often learn new things about themselves when they talk about their lives. You may learn something about yourself today.

3. Knowing you are helping other Latino men with HIV

Your story can teach us a lot about what it is like as a Latino man with HIV. What you tell me might help HIV/AIDS organizations serve other HIV-positive Latino men better in the future.

\section{What Are You Doing To Protect Me?}

Your privacy is very important to me. I have taken many steps to protect you:

- You will choose a different name to be used for yourself in the study.

- When I write or talk about what you say in the study, I will leave things out or change names so that it will be difficult for someone to identify you. 
- Your name and other personal information, which I need to keep track of who I talked to, will be kept in a locked file cabinet or a locked computer file at Portland State.

- The audio recording of the interview will also be kept in a locked computer file at Portland State. I will permanently delete this recording as soon as I have completed the study.

- You might want to talk about your immigration status. I know that may be an important part of your experience. But, I recommend that you do not talk about this. I would have no power to stop Federal authorities if they wanted to take the documents and recordings connected to this project. This is a minimal risk, but it is safer for you to just not talk about this today.

- It is the investigator's legal obligation to report abuse or harm to a minor or elder, and in those circumstances, your confidentiality will not be maintained.

\section{Any Questions?}

If you have any questions about this study, this form, or the interview, you can talk to Will Caston at (503) 725-8593. You can also contact the Chair of the Human Subjects Committee of Portland State University about your rights as a research participant (someone who takes part in a study). Hours are 9:00 a.m. to 5:00 p.m. The office is located at 1600 SW 4th Street, Market Center Building, Ste. 620, Portland, OR 97201. The telephone number is (503)725-2227.

\section{If I Sign, What Does It Mean?}

This is a consent form. Your signature below means that:

- You have read and understand what this form says.

- You are willing to take part in the study by talking with me in an interview.

- You know that you do not have to take part in this study. And even if you agree, you can change your mind and stop at any time. No problem

- You know that taking part in this study has nothing to do with the services you get from Partnership Project or OHSU. If you agree to take part or if you say no, they won't know and it won't matter. They will treat you the same.

- You will get a copy of this form to keep for yourself. 